\title{
Type studies and fourteen new North American species of Cortinarius section Anomali reveal high continental species diversity
}

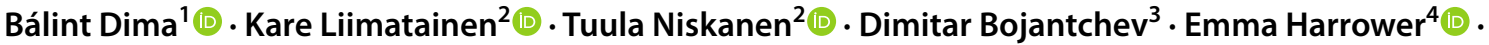

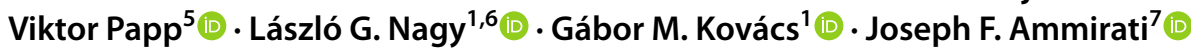

Received: 14 June 2021 / Revised: 19 August 2021 / Accepted: 20 August 2021 / Published online: 8 November 2021

(c) The Author(s) 2021, corrected publication 2022

\begin{abstract}
Section Anomali is a species-rich group in North America belonging to Cortinarius, the most diverse genus in the Agaricales. This study is based on extensive morphological investigations and molecular methods using 191 nrDNA ITS sequence data and recovered 43 phylogenetic species from which 14 are described here as new to science. We sequenced ten type materials which belonged to eight species. The synonymy of $C$. caesiellus with $C$. albidipes and $C$. copakensis with $C$. albocyaneus is proposed here. The North American occurrence of four species (C. albocyaneus, C. anomalus, C. caninus, and C. tabularis), so far known only from Europe, was confirmed. Thirteen species were not formally described here due to lack of relevant information. An identification key to the known Anomali species in North America is provided.
\end{abstract}

Keywords DNA barcoding $\cdot$ Ecology $\cdot$ ITS phylogeny $\cdot$ Morphology $\cdot$ Taxonomy $\cdot$ Type specimens

\section{Introduction}

Cortinarius is an important ectomycorrhizal genus in the Agaricales and is known to be the largest agaric genus worldwide (e.g., Garnica et al. 2016; Liimatainen et al. 2017, 2020; Varga et al. 2019). Species recognition based

Section editor: Zhu-Liang Yang

Bálint Dima

cortinarius1@gmail.com

1 Department of Plant Anatomy, Institute of Biology, Eötvös Loránd University, Pázmány Péter sétány 1/c, 1117 Budapest, Hungary

2 Jodrell Laboratory, Royal Botanic Gardens, Kew TW9 3AB, Surrey, UK

3 Hercules, USA

4 Vancouver, Canada

5 Department of Botany, Hungarian University of Agriculture and Life Sciences, Ménesi út 44, 1118 Budapest, Hungary

6 Synthetic and Systems Biology Unit, Institute of Biochemistry, Biological Research Centre, Hungarian Academy of Sciences, Temesvári krt. 62, 6726 Szeged, Hungary

7 Department of Biology, University of Washington, P. Box 351800, Seattle, WA 98195-1800, USA on morphology is difficult in Cortinarius lineages due to overlapping species characteristics and variation within species (e.g., Frøslev et al. 2007; Niskanen et al. 2009, 2013, 2016; Liimatainen et al. 2014, 2015).

Section Anomali represents a monophyletic, globally distributed group of Cortinarius (e.g., Soop et al. 2019) characterized by a telamonioid/sericeocyboid appearance, often with yellowish to brownish universal veil remnants on the stipe, typically bluish young lamellae, and subgloboid to broadly ellipsoid or rarely ellipsoid, verrucose spores. In section Anomali, more than 50 binomials were introduced in the last century, mainly from Europe with fewer from North America and elsewhere, but only ca. $20 \%$ of these names have been in general use (Dima et al. 2017). Classical European species were examined and typified in Dima et al. (2016) prior to studying species from other parts of the world, such as North America, where knowledge of sect. Anomali has been limited. Some earlier workers (e.g., Peck 1873, 1874, 1878, 1888, 1912; Murrill 1946; Kauffman 1905, 1932; Kauffman and Smith 1933; Smith 1939, 1944), and a few recent ones (Ammirati 2014; Ammirati et al. 2017; Liimatainen and Niskanen 2021) described a dozen species from the North and Central America. However, to date, the classical European names such as $C$. anomalus, $C$. albocyaneus, $C$. tabularis, and others have been applied to most of the taxa in North 
America (Harrower et al. 2011). This is a general problem based on recent phylogenetic revisions in Cortinarius (e.g., Liimatainen et al. 2014, 2020; Garnica et al. 2016; Soop et al. 2019) and similar to what has occurred in other groups of fungi (e.g., Kropp et al. 2010).

To extend the knowledge of the taxonomy and distribution of species in section Anomali in North America, we present here an extensive nuc rDNA ITS1-5.8S-ITS2 (ITS barcode) dataset as a phylogenetic and taxonomic framework, based on sequences from basidiomata, including type materials and environmental samples belonging to this group of Cortinarius. Our taxonomic revision is based on both phylogenetic data and detailed macro- and microscopical observations.

\section{Materials and methods}

\section{Taxon sampling}

Own material and published data were analyzed. The following type materials described from North America were investigated from the FLAS-F, MICH, and NYS herbaria: C. albidipes, C. albidoavellaneus, C. brevissimus, C. caesiellus, C. caesiifolius, C. copakensis, C. clintonianus, $C$. deceptivus, $C$. modestus, and $C$. perviolaceus. BLASTn comparisons (Altschul et al. 1997) against GenBank (http://www.ncbi.nlm.nih.gov/) and UNITE (http:// unite.ut.ee/) databases were used to download sequences of sect. Anomali and related lineages focusing on North America as well as sequences from Europe, Asia, Central and South America, and Australasia (Table 1).

\section{Molecular analysis}

The universal fungal DNA barcode region (Schoch et al. 2012), the ribosomal internal transcribed spacer (ITS1-5.8S-ITS2) was amplified, sequenced and analyzed. A total of 81 ITS sequences belonging in sect. Anomali were generated in this study, of which 77 originated from specimens collected in North America (Table 1). For DNA extraction, PCR, and sequencing, we followed the protocols described in Liimatainen et al. (2014) and Dima et al. (2016). Primer pairs of ITS1F-ITS4 or ITS1F-ITS4B, and alternatively in case of old type materials ITS1F/ITS2 and ITS3/4 (Gardes and Bruns 1993; White et al. 1990), were used to amplify the whole or partial ITS region. Sequencing was performed at the University of Helsinki (Finland) or at LGC Genomics (Berlin, Germany). GenBank accession numbers of the novel sequences are listed in Table 1.

\section{Phylogenetic analyses}

Sequences were aligned in MAFFT v7 (http://mafft.cbrc. jp/alignment/server) choosing the E-INS-I method (Katoh and Standley 2013) under default settings. SeaView 4 (Gouy et al. 2010) was used to inspect the alignment. Based on the work of Nagy et al. (2012), phylogenetically informative indels were coded as presence/absence data with FastGap 1.2 (Borchsenius 2009) following the simple indel coding algorithm (Simmons et al. 2001). The final alignment including nucleotide and binary data was analyzed in RAxML (Stamatakis 2014) and MrBayes 3.1.2 (Ronquist and Huelsenbeck 2003). Maximum Likelihood (ML) phylogenetic reconstruction was performed in raxmIGUI (Silvestro and Michalak 2012) using rapid bootstrap analysis with 2000 replicates. Three nucleotide partitions (ITS1, 5.8S, ITS2) were set to the GTRGAMMA substitution model in addition to one binary partition (indel characters) that was set to default. In the Bayesian Inference (BI) phylogeny, the alignment was divided into four partitions (ITS1, 5.8S, ITS2, and indels) as well. The GTR $+\Gamma$ substitution model was applied to the nucleotide characters, while the two-parameter Markov model was set for the indels. Two independent runs of four Markov Chain Monte Carlo (MCMC) were performed each for 5,000,000 generations, sampling every 1000th generation. The first $30 \%$ of the trees was discarded as burn-in. For the remaining trees, a 50\% majority rule consensus phylogram with posterior probabilities as nodal supports was computed. Intra- and interspecific genetic differences were calculated by dividing the number of differences (substitutions and/or indels) found in the whole ITS region by the length of the region (ca. 610-618 bases long). The best scoring ML tree from Maximum Likelihood analysis was further edited in MEGA 7 (Kumar et al. 2016) and Adobe Illustrator CS4 and shown in Figs. 1 and 2.

\section{Morphological study}

The morphological descriptions of the species are based on notes taken from fresh collections and associated photographs, fungarium specimens, and previously published descriptions of the holotype specimens and other sequenced materials or collections that are not sequenced. Microscopic characteristics are taken from air-dried specimens. Dextrinoid basidiospore reactions were recorded from pieces of lamellae placed in Melzer's reagent for $5 \mathrm{~min}$. Lamella trama hyphae were examined for encrusting pigment in Melzer's reagent and 3\% $\mathrm{KOH}$. The pileipellis and basidia were examined in $3 \% \mathrm{KOH}$. Basidiospore measurements were made in $3 \% \mathrm{KOH}$ from 
Table 1 The nrDNA ITS sequences of Cortinarius species used in the phylogenetic analysis. Newly generated sequences are in boldface.

\begin{tabular}{|c|c|c|c|c|}
\hline Species & Voucher & Country & Section & ITS acc. no \\
\hline C. albidipes & JFA12420 (WTU) & USA, Colorado & Anomali & MZ580486 \\
\hline C. albidipes & NYS-F-000129 (holotype) & USA, New York & Anomali & MZ580485 \\
\hline C. albidipes (as C. caesiellus) & MICH10325 (holotype) & USA, Michigan & Anomali & MZ580484 \\
\hline C. albidipes & YL1826 / MQ18-CMMF001826 & Canada, Québec & Anomali & MN750945 \\
\hline C. albidipes (as C. tabularis) & HRL0614 (DAOM) & Canada, Québec & Anomali & KJ705108 \\
\hline C. albidipes (as C. cf. xanthocephalus) & CNV98 & USA, New Hampshire & Anomali & MT345274 \\
\hline C. albidoavellaneus & MICH10313 (holotype) & USA, Michigan & Anomali & MZ580483 \\
\hline C. albocyaneus (as C. copakensis) & NYS-F-000864 (holotype) & USA, New York & Anomali & MZ580482 \\
\hline C. albocyaneus & CFP1482 & Italy & Anomali & KX302202 \\
\hline C. albocyaneus & CFP1177 (epitype) & Sweden & Anomali & KX302206 \\
\hline C. albomalus & H7000816 (holotype) & Canada, Ontario & Anomali & MZ568645 \\
\hline C. albomalus & iNAT59505932 & USA, New Jersey & Anomali & MW305253 \\
\hline C. albomalus & HRL2777 & Canada, Québec & Anomali & MN751632 \\
\hline C. anocorium & H7068022 (holotype) & USA, Florida & Anomali & MZ568646 \\
\hline C. anomalellus & TU105328 & Estonia & Anomali & UDB018358 \\
\hline C. anomalodelicatus & TN11-241 & USA, Alaska & Anomali & MZ580481 \\
\hline C. anomalodelicatus & JFA8146 (holotype) & USA, Colorado & Anomali & MZ580480 \\
\hline C. anomalomontanus & JFA9919 (holotype) & USA, Wyoming & Anomali & MZ580478 \\
\hline C. anomalomontanus & JFA9973 & USA, Wyoming & Anomali & MZ580479 \\
\hline C. anomalopacificus & DBB11745 (holotype) & USA, California & Anomali & MZ663774 \\
\hline C. anomalopacificus & DBB27748 & USA, California & Anomali & MZ663775 \\
\hline C. anomalopacificus & JFA11887 & USA, California & Anomali & MZ580471 \\
\hline C. anomalopacificus & TN12-301 & USA, California & Anomali & MZ580477 \\
\hline C. anomalopacificus & TN12-154 & USA, California & Anomali & MZ580470 \\
\hline C. anomalopacificus & TN12-091 & USA, California & Anomali & MZ580472 \\
\hline C. anomalopacificus & TN12-161 & USA, California & Anomali & MZ580474 \\
\hline C. anomalopacificus & TN12-074 & USA, California & Anomali & MZ580469 \\
\hline C. anomalopacificus & TN12-253 & USA, California & Anomali & MZ580468 \\
\hline C. anomalopacificus & TN12-164 & USA, California & Anomali & MZ580475 \\
\hline C. anomalopacificus & TN12-271 & USA, California & Anomali & MZ580476 \\
\hline C. anomalopacificus & TN12-093 & USA, California & Anomali & MZ580473 \\
\hline C. anomalovelatus & DBB23800 & USA, Oregon & Anomali & MZ663776 \\
\hline C. anomalovelatus & PK4741 & Canada, British Columbia & Anomali & FJ039655 \\
\hline C. anomalovelatus & TN12-236 & USA, California & Anomali & KJ019014 \\
\hline C. anomalovelatus & JFA13109 (holotype) & USA, Washington & Anomali & FJ717605 \\
\hline C. anomalus & NL-5414 & USA, Massachusetts & Anomali & MZ663777 \\
\hline C. anomalus & TENN067720 & USA, North Carolina & Anomali & MZ663778 \\
\hline C. anomalus & TENN067730 & USA, North Carolina & Anomali & MZ663779 \\
\hline C. anomalus & MQ18-HL1492-QFB30079 & Canada, Québec & Anomali & MN750971 \\
\hline C. anomalus & CFP1154 (neotype) & Sweden & Anomali & KX302224 \\
\hline C. anomalus & CNV9 & USA, New Hampshire & Anomali & МT345186 \\
\hline C. barlowensis & TN07-366 & USA, Washington & Anomali & KJ019015 \\
\hline C. barlowensis & $\mathrm{MN}$ & Canada, British Columbia & Anomali & FJ157009 \\
\hline C. barlowensis & JFA13140 (holotype) & USA, Washington & Anomali & FJ717554 \\
\hline C. bolaris & CFP1008 (neotype) & Sweden & Bolares & KX302233 \\
\hline C. bolaris & 3861 & Canada, Québec & Bolares & KJ705110 \\
\hline C. bolaris (as $C$. aff. bolaris) & TENN61650 & USA, Tennessee & Bolares & FJ596851 \\
\hline C. brevissimus & NYS-F-000541 (holotype) & USA, New York & Anomali & MZ580467 \\
\hline C. brevissimus (as Cortinarius sp. 1) & SGT2012/Cort H2QY2 & USA, New York & Anomali & JX030219 \\
\hline C. caeruleoanomalus & JFA13084 (holotype) & USA, Tennessee & Anomali & MZ663780 \\
\hline
\end{tabular}


Table 1 (continued)

\begin{tabular}{|c|c|c|c|c|}
\hline Species & Voucher & Country & Section & ITS acc. no \\
\hline C. caeruleoanomalus & PBM3902/TENN068383 & USA, North Carolina & Anomali & KY744156 \\
\hline C. caesiifolius & TN12-136 & USA, California & Anomali & MZ580465 \\
\hline C. caesiifolius & TN12-066 & USA, California & Anomali & MZ580463 \\
\hline C. caesiifolius & TN12-118 & USA, California & Anomali & MZ580464 \\
\hline C. caesiifolius & TN07-489 & USA, Washington & Anomali & MZ580466 \\
\hline C. caesiifolius & DBB37600 & USA, Minnesota & Anomali & MZ663781 \\
\hline C. caesiifolius & MICH10326 (holotype) & USA, Washington & Anomali & MZ580462 \\
\hline C. caesiifolius & SAT13-298-15 & USA, Oregon & Anomali & MZ048733 \\
\hline C. caesiifolius & JMB10-20-2007-15 & USA, Washington & Anomali & FJ717517 \\
\hline C. caesiifolius (as C. cf. ochrophyllus) & UBC-F28442 & Canada, British Columbia & Anomali & KP406565 \\
\hline C. caesiifolius (as Cortinarius sp.) & UBC-F31305 & Canada, British Columbia & Anomali & UDB024899 \\
\hline C. camphoratus & $\mathrm{EH} 23$ & Canada, British Columbia & Camphorati & FJ717505 \\
\hline C. caninus & JFA7985 & Canada, Ontario & Anomali & MZ580454 \\
\hline C. caninus & NS18 & USA, California & Anomali & MZ663782 \\
\hline C. caninus & JFA10347 & USA, Wyoming & Anomali & MZ580459 \\
\hline C. caninus & JFA9425 & USA, Wyoming & Anomali & MZ580461 \\
\hline C. caninus & JFA12434 & USA, Wyoming & Anomali & MZ580456 \\
\hline C. caninus & JFA9470 & USA, Wyoming & Anomali & MZ580457 \\
\hline C. caninus & JFA10348 & USA, Wyoming & Anomali & MZ580460 \\
\hline C. caninus & JFA8009 & USA, Minnesota & Anomali & MZ580455 \\
\hline C. caninus & JFA9920 & USA, Wyoming & Anomali & MZ580458 \\
\hline C. caninus (as Unc. EcM) & TH4Cc & Canada, British Columbia & Anomali & KF753582 \\
\hline C. caninus & CFP627 (epitype) & Sweden & Anomali & KX302250 \\
\hline C. clackamasensis & JFA11616 (holotype) & USA, Oregon & Anomali & MZ580452 \\
\hline C. clackamasensis & TN11-451 & USA, Washington & Anomali & MZ580453 \\
\hline C. clackamasensis (as C. barlowensis) & OSC109672 & USA, Oregon & Anomali & EU652360 \\
\hline C. clackamasensis (as C. barlowensis) & OSC114858 & USA, Oregon & Anomali & EU669315 \\
\hline C. clintonianus & DBB21645 & Canada, British Columbia & Anomali & MZ663783 \\
\hline C. clintonianus & JFA8329 & Canada, Ontario & Anomali & MZ580451 \\
\hline C. clintonianus & MIN896348 & USA, Minnesota & Anomali & MZ663784 \\
\hline C. clintonianus & NYS-F-000786 (holotype) & USA, New York & Anomali & MZ580450 \\
\hline C. clintonianus & YL2618 / MQ18-CMMF002618 & Canada, Québec & Anomali & MN751121 \\
\hline C. clintonianus (as Cortinarius sp.) & UBC-F31352 & Canada, British Columbia & Anomali & UDB024961 \\
\hline C. clintonianus (as Unc. clone) & $136 \mathrm{C}$ & Canada, British Columbia & Anomali & KM403009 \\
\hline C. clintonianus (as Unc. clone) & SDL13 & USA, Michigan & Anomali & FJ769528 \\
\hline C. deceptivus & NL-5180 & USA, New York & Anomali & MZ663785 \\
\hline C. deceptivus & WTU-F-69333 & USA, New Hampshire & Anomali & MZ663786 \\
\hline C. deceptivus & WTU-F-69313 & USA, Massachusetts & Anomali & MZ663787 \\
\hline C. deceptivus & MICH10343 (syntype) & USA, New York & Anomali & MZ663788 \\
\hline C. deceptivus & iNAT56430786 & USA, New York & Anomali & MT939445 \\
\hline C. durifoliorum & PDD101829 (holotype) & New Zealand & Anomali & KJ635210 \\
\hline C. dysodes & PDD70499 (holotype) & New Zealand & Camphorati & GU233340 \\
\hline C. epsomiensis & K(M)74,963 (holotype) & UK & Anomali & MK010952 \\
\hline $\begin{array}{l}\text { C. epsomiensis (as C. pastoralis, holo- } \\
\text { type) }\end{array}$ & TN06-165 & Finland & Anomali & KX302258 \\
\hline C. eunomalus & PDD94040 (holotype) & New Zealand & incertae sedis & JQ287690 \\
\hline C. ferrusinus & JB8106 13 (holotype) & Spain & Spilomei & KY657254 \\
\hline C. harvardensis & NL-5415 (holotype) & USA, Massachusetts & Anomali & MZ663789 \\
\hline C. harvardensis & MQ18-HL1449-QFB30070 & Canada, Québec & Anomali & MN751560 \\
\hline C. harvardensis & MQ17058-QFB29566 & Canada, Québec & Anomali & MN751559 \\
\hline
\end{tabular}


Table 1 (continued)

\begin{tabular}{|c|c|c|c|c|}
\hline Species & Voucher & Country & Section & ITS acc. no \\
\hline C. harvardensis (as Cortinarius sp. 6) & clone ads9.e & Canada, Nova Scotia & Anomali & MK131480 \\
\hline C. huddartensis & DBB12118 (holotype) & USA, California & Anomali & MZ663790 \\
\hline C. huddartensis (as Cortinarius sp.) & $\operatorname{src} 174$ & USA, California & Anomali & DQ974719 \\
\hline C. ionomataius & PDD89089 (holotype) & New Zealand & incertae sedis & GU222303 \\
\hline C. jonimitchelliae & HL03-339 (holotype) & Sweden & Anomali & KX302253 \\
\hline C. kranabetteri & TN11-287 (holotype) & Canada, Alberta & Anomali & MZ580449 \\
\hline C. kranabetteri (as Cortinarius sp.) & UBC-F16436 & Canada, British Columbia & Anomali & FJ039657 \\
\hline C. kranabetteri (as Cortinarius sp.) & UBC-F16435 & Canada, British Columbia & Anomali & FJ039656 \\
\hline C. latiodistributus & TN02-490 & Finland & Anomali & MZ580448 \\
\hline C. latiodistributus & DB6139 (holotype) & Sweden & Anomali & MZ663791 \\
\hline C. latiodistributus & DB6359 & Norway & Anomali & MZ663792 \\
\hline C. latiodistributus & JFA13487 & USA, Washington & Anomali & MZ663793 \\
\hline C. latiodistributus (as C. barlowensis) & OSC115143 & USA, Washington & Anomali & EU652359 \\
\hline C. latiodistributus (as C. barlowensis) & OSC114595 & USA, Washington & Anomali & EU837213 \\
\hline C. latiodistributus (as C. cf. anomalus) & UBC-F16437/SMIA46 & Canada, British Columbia & Anomali & FJ039658 \\
\hline C. latiodistributus (as C. cf. barlowensis) & UBC-F17514/SMI16 & Canada, British Columbia & Anomali & FJ157134 \\
\hline C. latiodistributus (as Cortinarius sp.) & YM187 & Japan & Anomali & AB848436 \\
\hline C. lepidopus & DB6253 & Hungary & Anomali & MZ663794 \\
\hline C. lepidopus & TAAM128884 & Estonia & Anomali & UDB016290 \\
\hline C. lepidopus & TU105192 & Estonia & Anomali & UDB016140 \\
\hline C. lepidopus & TU105182 & Estonia & Anomali & UDB016132 \\
\hline C. lividomalvaceus & JMT-15102001 (holotype) & France & Anomali & KY315416 \\
\hline C. modestus & TN10-035 & Canada, Québec & Anomali & MZ580447 \\
\hline C. modestus & NYS-F-001966 (holotype) & USA, New York & Anomali & MZ580446 \\
\hline C. modestus & MQ17140-QFB29648 & Canada, Québec & Anomali & MN751561 \\
\hline C. modestus & MQ17272-QFB29780 & Canada, Québec & Anomali & MN751565 \\
\hline C. modestus & MQ18-HL0629-QFB30005 & Canada, Québec & Anomali & MN751564 \\
\hline C. modestus (as C. anomalus) & Q-2313/QFB25737 & Canada, Québec & Anomali & KJ705109 \\
\hline C. nettieae & TN09-167 & USA, Oregon & Anomali & MZ580444 \\
\hline C. nettieae & JFA8747 & USA, Oregon & Anomali & MZ580443 \\
\hline C. nettieae & TN09-176 & USA, Oregon & Anomali & MZ580445 \\
\hline C. nettieae & JFA9613 (holotype) & USA, Washington & Anomali & MZ580442 \\
\hline C. nettieae (as C. alboviolaceus) & DAVFP27503 & Canada, British Columbia & Anomali & EU821675 \\
\hline C. ochraceodiscus & DJM2195 (holotype) & USA, Minnesota & Anomali & MZ663795 \\
\hline C. ochraceodiscus & DJM2194 & USA, Minnesota & Anomali & MZ663796 \\
\hline C. pelerinii & XC2012-21 (holotype) & France & Anomali & MH784627 \\
\hline C. perrotensis (as Cortinarius sp.) & TENN071126 (holotype) & Canada, Québec & Anomali & KX897405 \\
\hline C. perviolaceus & JFA9132 & USA, Florida & Anomali & MZ580441 \\
\hline C. perviolaceus & JFA9128 & USA, Florida & Anomali & MZ580440 \\
\hline C. perviolaceus & JFA9124 & USA, Florida & Anomali & MZ580439 \\
\hline C. perviolaceus & WU-Myc 44,566 & USA, Georgia & Anomali & MZ663797 \\
\hline C. perviolaceus & NL-5173 & USA, Massachusetts & Anomali & MZ663798 \\
\hline C. perviolaceus & JFA13070 & USA, Tennessee & Anomali & MZ663799 \\
\hline C. perviolaceus (as Cortinarius sp.) & FLAS-F61753 & USA, Florida & Anomali & MH281882 \\
\hline C. perviolaceus (as Cortinarius sp.) & FLAS-F61648 & USA, Florida & Anomali & MH212024 \\
\hline C. perviolaceus (as Unc. clone) & 3Bart56R & USA, New Hampshire & Anomali & HQ022110 \\
\hline C. perviolaceus (as Cortinarius sp. 1) & FN05_2 & USA, New York & Anomali & KU878589 \\
\hline C. perviolaceus (as Cortinarius sp.) & HBK-M11-2 & USA, Tennessee & Anomali & MG982536 \\
\hline C. perviolaceus & FLAS-F32992 (holotype) & USA, Florida & Anomali & MZ580438 \\
\hline C. perviolaceus (as Cortinarius sp.) & FLAS MES-2177 & USA, Florida & Anomali & MT415970 \\
\hline
\end{tabular}


Table 1 (continued)

\begin{tabular}{|c|c|c|c|c|}
\hline Species & Voucher & Country & Section & ITS acc. no \\
\hline C. putorius & TN12-230 & USA, California & Camphorati & KR011123 \\
\hline C. rarus & DBB04712 (holotype) & USA, California & Anomali & MZ663800 \\
\hline C. rarus & ADP-140531-1 & USA, Washington & Anomali & MZ663801 \\
\hline C. rarus (as C. cf. alboviolaceus) & JLF3304 & USA, California & Anomali & MF135162 \\
\hline C. rarus (as Cortinarius sp.) & JLF8771 & USA, Oregon & Anomali & MW341331 \\
\hline C. rarus (as Cortinarius sp.) & JLF8707 & USA, Oregon & Anomali & MW341328 \\
\hline C. rattinoides & PDD88283 (holotype) & New Zealand & Anomali & JX000375 \\
\hline C. sclerophyllarum & HO-A20430A6 (paratype) & Australia & Anomali & AY669637 \\
\hline C. sericeolazulinus & JFA12053 (holotype) & Costa Rica & Anomali & EF420146 \\
\hline C. spilomeus & CFP1137 (neotype) & Sweden & Spilomei & KX302267 \\
\hline C. spilomeus (as C. cf. spilomeus) & SMI297 & Canada, British Columbia & Spilomei & FJ039659 \\
\hline C. suecicolor & PDD74698 (holotype) & New Zealand & Anomali & JX000360 \\
\hline C. tabularis & TN11-219 & USA, Alaska & Anomali & MZ580437 \\
\hline C. tabularis & TRTC156544 & Canada, Québec & Anomali & BOLD: JULY102-08 \\
\hline C. tabularis & TRTC156541 & Canada, Québec & Anomali & BOLD: JULY100-08 \\
\hline C. tabularis & IK98-1190 & Finland & Anomali & KX302269 \\
\hline C. tabularis & CFP949 (epitype) & Sweden & Anomali & KX302275 \\
\hline C. tasmacamphoratus & HO A20606A0 & Australia, Tasmania & Camphorati & AY669633 \\
\hline C. tetonensis & JFA10350 (holotype) & USA, Wyoming & Anomali & MZ580436 \\
\hline C. tetonensis (as C. caninus) & JFA10349 & USA, Wyoming & Anomali & U56024 \\
\hline C. tetonensis (as $C$. cf. alpinus) & 36_N343 & Norway, Svalbard & Anomali & HQ445618 \\
\hline C. tetonensis (as Cortinarius sp.) & ME12-B10 & USA, Alaska & Anomali & JX436875 \\
\hline C. tetonensis (as Cortinarius sp.) & ME12-B4 & USA, Alaska & Anomali & JX436874 \\
\hline C. tetonensis (as Cortinarius sp.) & ME12-D3 & USA, Alaska & Anomali & JX436876 \\
\hline C. tristis s. Garnica & TUB011917 & Chile & Anomali & AY669648 \\
\hline Cortinarius sp1 (as Cortinarius sp.) & ME12-D2 & USA, Alaska & Anomali & JX436862 \\
\hline Cortinarius sp1 (as Unc. clone) & HV_D8 & USA, Alaska & Anomali & JX630733 \\
\hline Cortinarius sp1 (as Unc. clone) & MEN-JG-096 & Norway, Svalbard & Anomali & JF304376 \\
\hline Cortinarius sp2 (as Unc. Cortinariaceae) & JLP2431 & USA, Oregon & Anomali & DQ377379 \\
\hline Cortinarius sp3 (as C. spilomeus) & OUC97199 & Canada, British Columbia & Anomali & DQ093855 \\
\hline Cortinarius sp4 (as C. alboviolaceus) & OUC97234 & Canada, British Columbia & Anomali & DQ097877 \\
\hline Cortinarius sp4 (as Unc. Cortinarius) & YM1162 & Japan & Anomali & LC175062 \\
\hline Cortinarius sp4 & HRL1598-QFB32934 & Canada, Québec & Anomali & MW845268 \\
\hline Cortinarius sp5 (as Unc. clone) & 7 70M6 & USA, California & Anomali & JQ393041 \\
\hline Cortinarius sp6 (C. aff. nettiae) & MQ17280-QFB29788 & Canada, Québec & Anomali & MN750926 \\
\hline Cortinarius sp6 (C. aff. nettiae) & MQ17300-QFB29808 & Canada, Québec & Anomali & MN750925 \\
\hline Cortinarius sp7 (as $C$. aff. caninus) & F18506 & Canada, British Columbia & Anomali & FJ157104 \\
\hline Cortinarius sp8 (as C. holophaeus) & UBC-F17161 & Canada, British Columbia & Anomali & GQ159904 \\
\hline Cortinarius sp8 (as C. rigens) & UBC-F17157 & Canada, British Columbia & Anomali & GQ159900 \\
\hline Cortinarius sp9 (as Cortinarius sp. 2) & RG2012/GO2010171 & Mexico & Anomali & KC152091 \\
\hline Cortinarius sp10 & TN10-141 & Canada, Québec & Anomali & MZ821030 \\
\hline Cortinarius sp11 & MQ21-HRL2477-QFB32937 & Canada, Québec & Anomali & MW845269 \\
\hline Cortinarius sp12 & Russell iNaturalist 8602253 & USA, Indiana & Anomali & MZ710565 \\
\hline Cortinarius sp13 (as Cortinarius sp.) & QFB28611 & Canada, Québec & Anomali & MN992356 \\
\hline Cortinarius sp. (as C. iodes) & NVE433 & Colombia & Anomali & KF937326 \\
\hline Cortinarius sp. (as C. iodes) & NVE219 & Colombia & Anomali & KF937328 \\
\hline Cortinarius sp. & PERTH06659462 & Australia & Anomali & MG553083 \\
\hline Cortinarius sp. & PERTH06437109 & Australia & Anomali & MG553013 \\
\hline Cortinarius sp. & PDD10596 & New Zealand & Anomali & MH101576 \\
\hline Cortinarius sp. & PDD107512 & New Zealand & Anomali & MG019346 \\
\hline
\end{tabular}


Table 1 (continued)

\begin{tabular}{|c|c|c|c|c|}
\hline Species & Voucher & Country & Section & ITS acc. no \\
\hline Cortinarius sp. (as Unc. EcM) & Pdmt24 & Japan & Anomali & AB251830 \\
\hline Cortinarius sp. (as $C$. aff. caesiifolius) & MHHNU 8228 & China & Anomali & KU518318 \\
\hline Cortinarius sp. (as Unc. Cortinarius) & YM73 & Japan & Anomali & LC175532 \\
\hline Cortinarius sp. & YM873 & Japan & Anomali & AB848465 \\
\hline Cortinarius sp. (as Unc. Cortinarius) & Pj3-mOTU024 & Japan & Anomali & LC260432 \\
\hline Cortinarius sp. (as Unc. clone) & SWUBC741 & Canada, British Columbia & Spilomei & DQ481671 \\
\hline Cortinarius sp. (as Unc. clone) & SWUBC747 & Canada, British Columbia & Spilomei & DQ481752 \\
\hline Cortinarius sp. (as C. spilomeus) & TU105220 & Sweden & Spilomei & UDB015906 \\
\hline Cortinarius sp. (as Unc. Cortinarius) & BH3573F & Australia, Tasmania & Camphorati & JF960738 \\
\hline Cortinarius sp. (as Unc. Cortinarius) & $\mathrm{BH} 2055 \mathrm{~F}$ & Australia, Tasmania & Camphorati & JF960672 \\
\hline
\end{tabular}

Fig. 1 Maximum Likelihood phylogenetic tree showing the main structure within sect. Anomali based on nrDNA ITS sequence analyses in RAxML and MrBayes. ML bootstrap values $>70 \%$ as well as Bayesian posterior probabilities $>0.90$ are indicated above branches (ML/BI). Delimitation of sect. Anomali is marked with blue. Scale bar indicates 0.03 expected change per site per branch

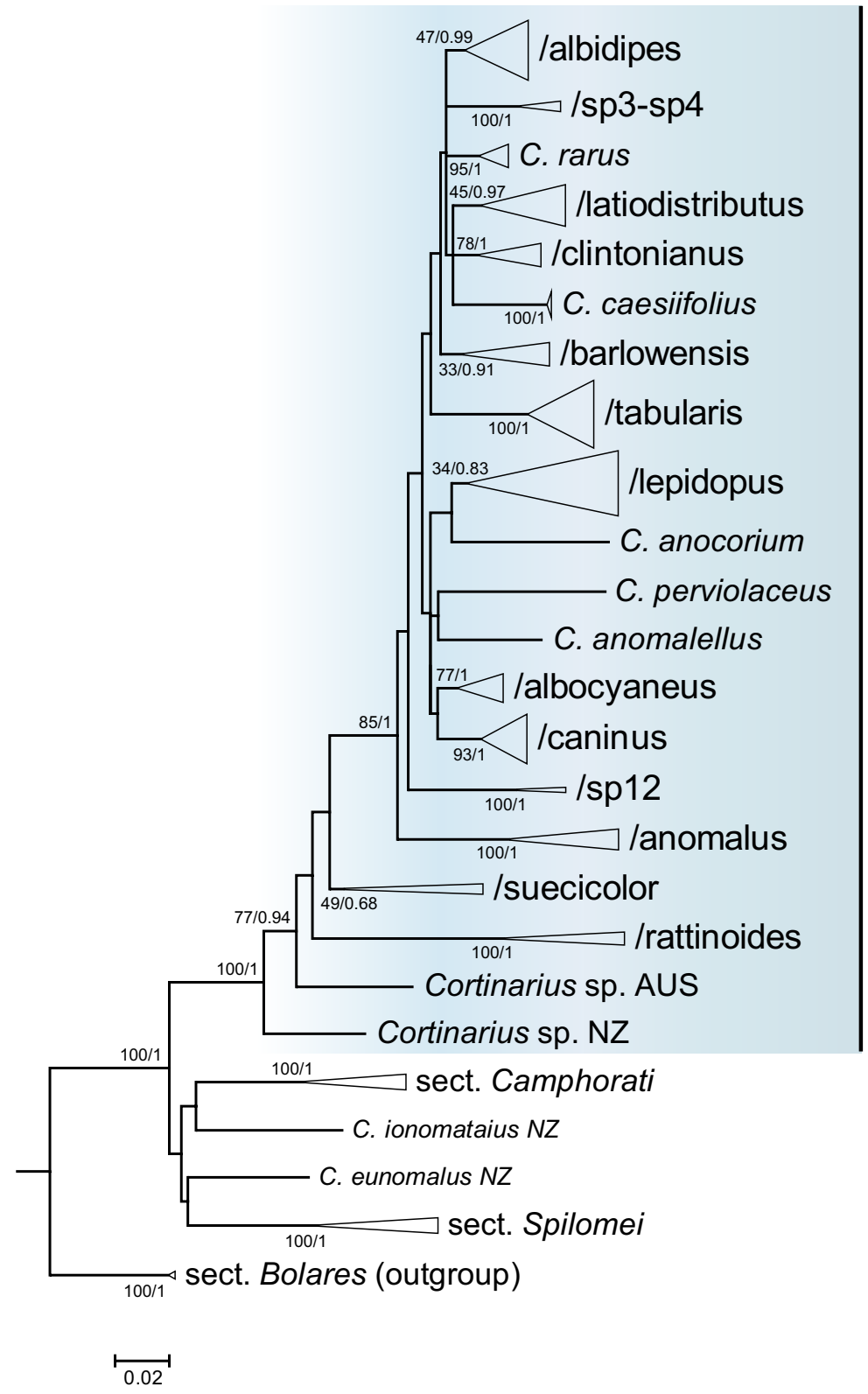

sect. Anomali 
Fig. 2 Maximum Likelihood phylogenetic tree showing the species-level relationship in sect. Anomali based on nrDNA ITS sequence analyses in RAxML and MrBayes. Clades containing the newly described North American species are highlighted in pale blue squares. Further undescribed species are compressed and written in blue. Sequences generated for this study are in boldface and their voucher numbers are also given. ML bootstrap values $>70 \%$ as well as Bayesian posterior probabilities $>0.90$ are indicated above branches (ML/BI). Scale bar indicates 0.02 expected change per site per branch

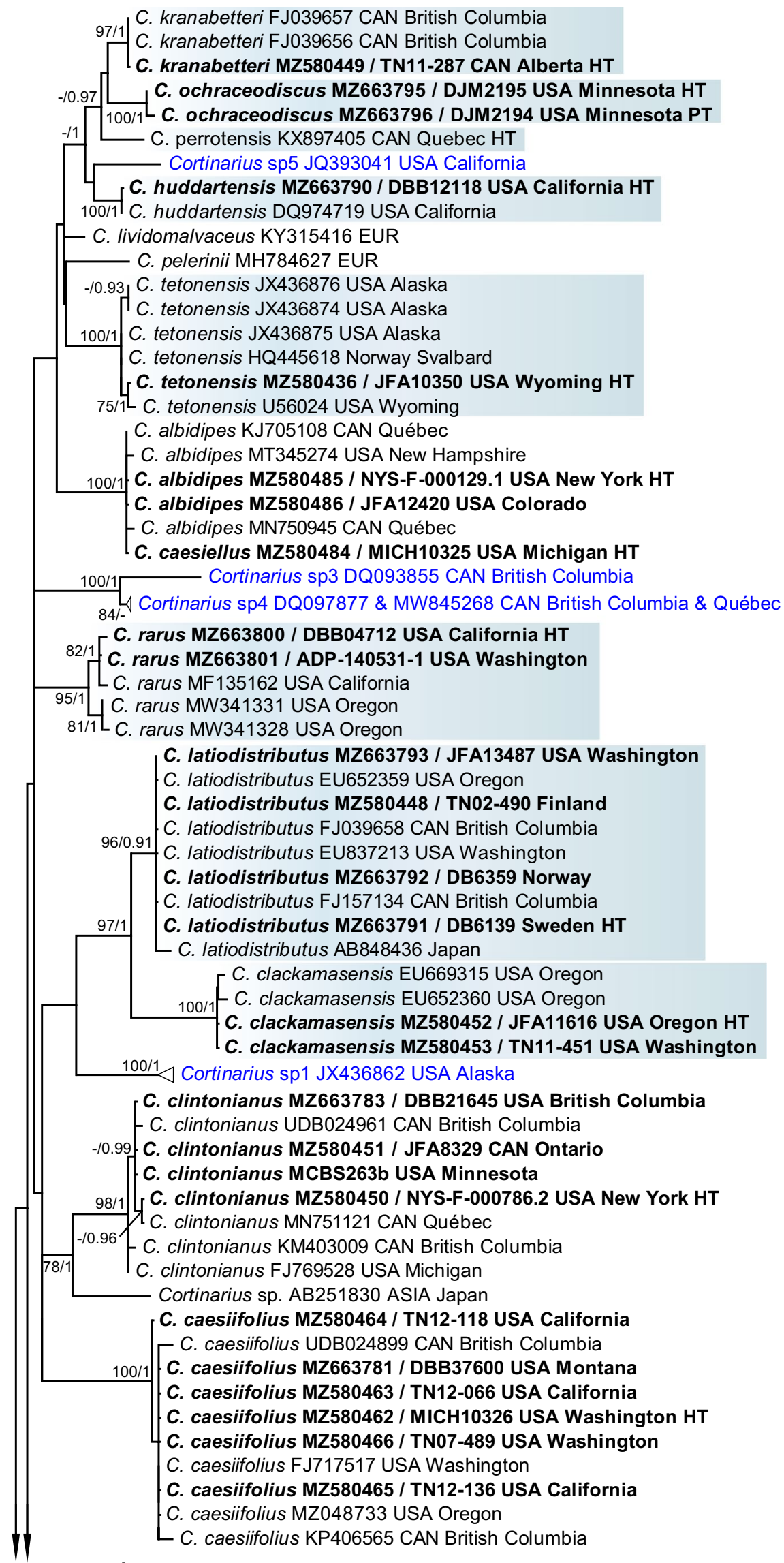


Fig. 2 (continued)

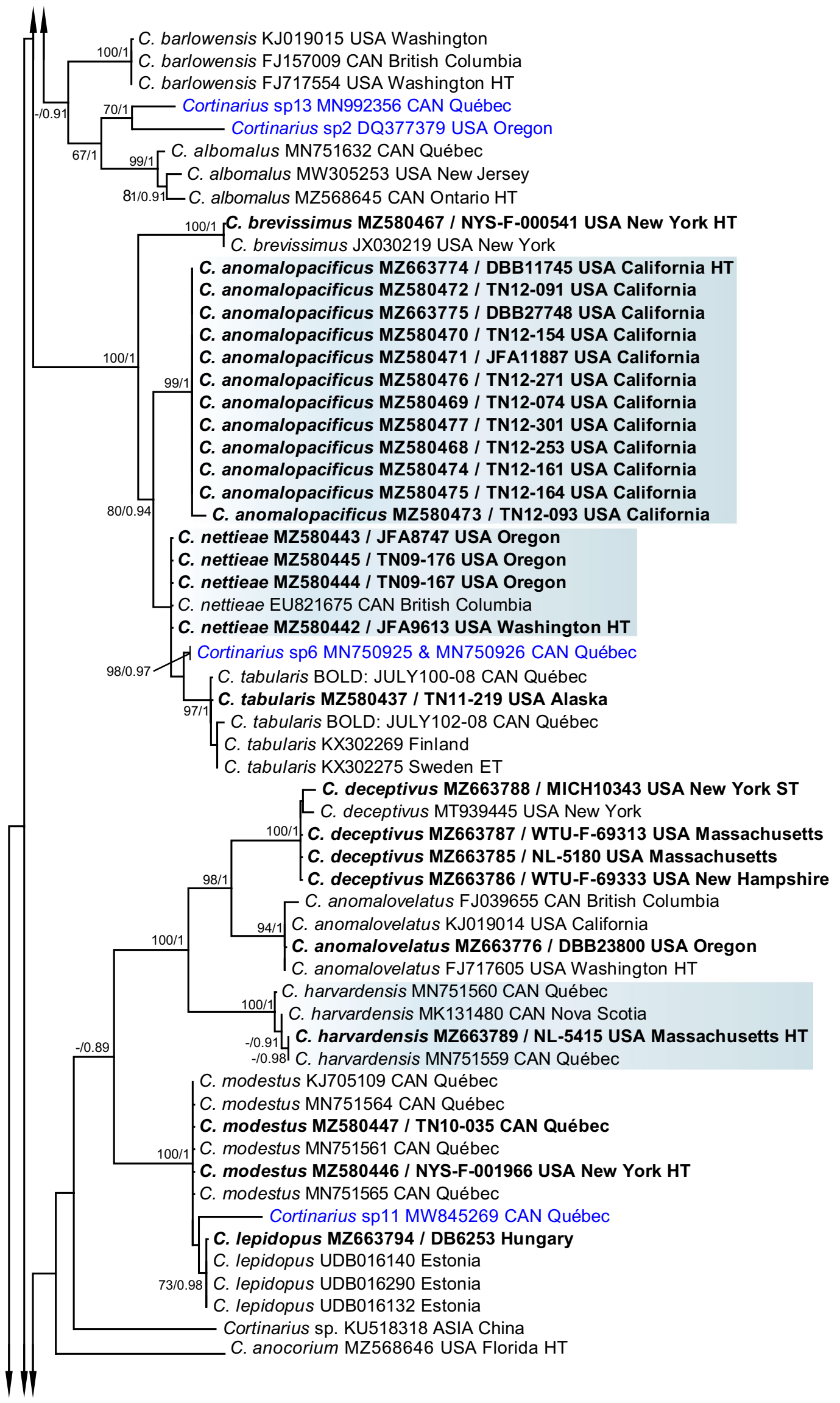


Fig. 2 (continued)

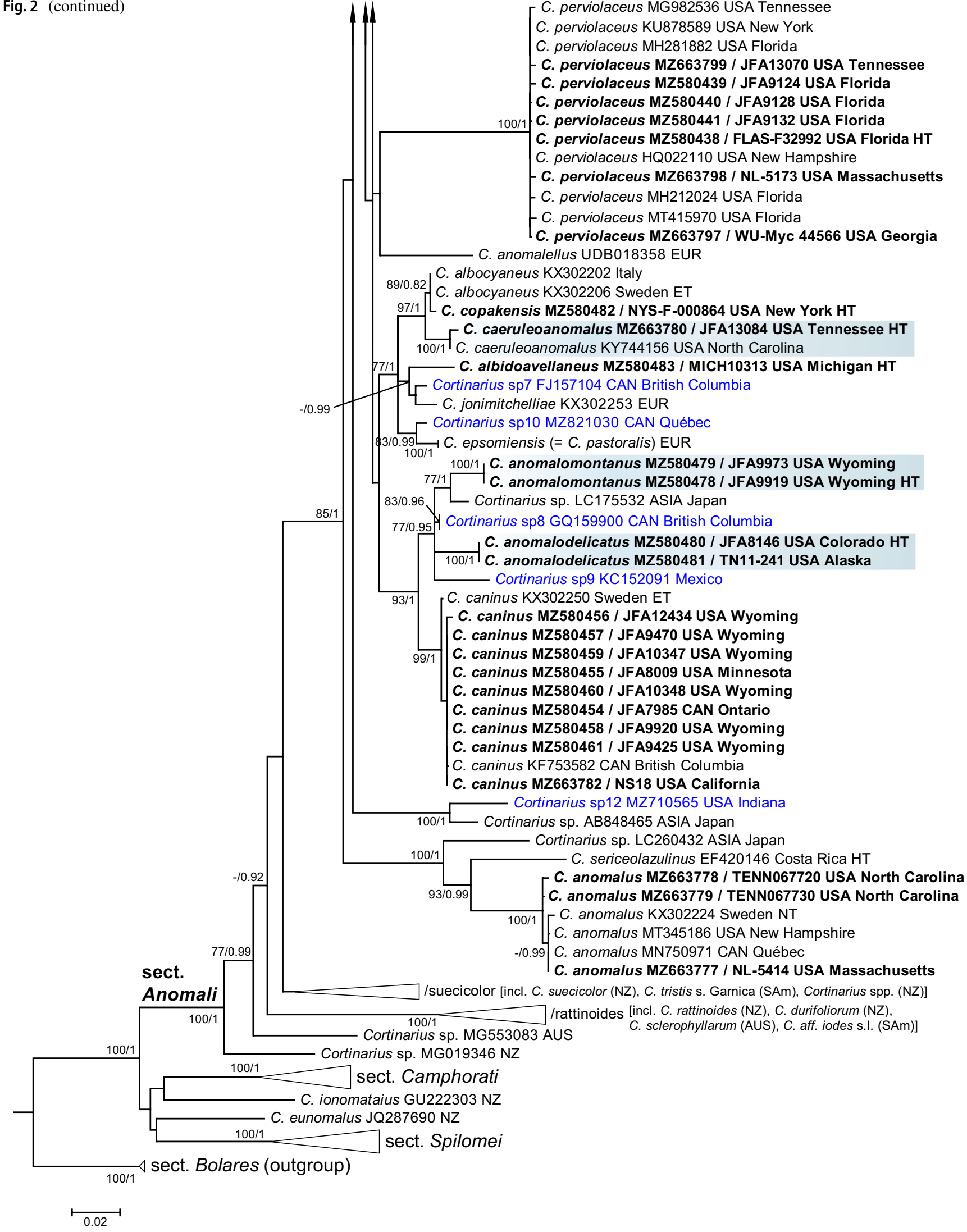


basidiospores on lamella surfaces and those deposited on the stipe apex, pileus surface, and/or veil. Basidiospore measurements, averages, and $Q$ values $(L / W)$ are based on 20-30 basidiospores per collection, and measurements in parentheses (e.g., (10)) are exceptional. The category "Additional specimens examined" are those collections that were examined morphologically and microscopically but do not have any molecular data associated with them. Herbarium designations follow Thiers (continuously updated).

\section{Results}

\section{Phylogeny}

A total of 209 sequences, 191 of which belong to sect. Anomali, were included in the analyses (Table 1). The ITS alignment comprises 774 characters. After gap coding, a binary set of 183 characters was added to the nucleotide alignment, so the data matrix prior to phylogenetic analysis was composed of 957 characters (alignment is deposited as Supplementary information). Cortinarius bolaris (Pers.) Fr. (sect. Bolares) served as outgroup. Phylogenetic trees from ML and BI analyses showed congruent topologies, at least the grouping of the species agreed well in both phylogenetic trees. However, some topological differences in the deeper branches were observed.

Section Anomali received high support in our analyses $(\mathrm{MLBS}=100 / \mathrm{BPP}=1)$ as well as sections Camphorati (100/1), Spilomei (100/1), and Bolares as outgroup (100/1) (Figs. 1 and 2). These results are in concordance with those gained from multigene phylogenetic analyses published recently (Soop et al. 2019).

Altogether, 45 species occurring in North America were revealed (Fig. 2) (see Taxonomy part). In Fig. 1 (as a compressed tree), we show the relationships of the species within sect. Anomali. The following clades can be recognized with weak, moderate, to strong support gained from ML or BI analyses: /albidipes (47/0.99), /sp3-sp4 (100/1), /latiodistributus (45/0.97), /clintonianus (78/1), /barlowensis (33/0.91), /tabularis (100/1), /lepidopus (34/0.83), / albocyaneus (77/1), /caninus (93/1), /sp12 (100/1), /anomalus (100/1). The clades formed by Cortinarius rarus, $C$. caesiifolius, C. anocorium, and C. perviolaceus remained singletons. The clades /suecicolor (49/0.68) and /rattinoides $(100 / 1)$ as well as singleton species-level lineages like $C$. anomalellus from Europe, Cortinarius sp. from Australia, and Cortinarius sp. from New Zealand are present in our phylogenetic tree but have not yet been recorded in North America.

Based on our phylogenetic analyses, most species are monophyletic and strongly supported. There are, however, two cases of species limits not fully resolved. In the first case, the monophyletic European C. lepidopus and the very closely related $C$. modestus are paraphyletic. In the second case, $C$. tabularis, $C$. anomalopacificus, and $C$. sp6 form a clade with $C$. nettieae within the /tabularis clade, but $C$. nettieae itself does not form a monophyletic lineage. In both cases, we recognize these lineages as separate species based on differences in the ITS region, morphology, and/or distribution.

The majority (94\%) of the studied North American species have intraspecific sequence variation between 0 and $0.5 \%$ which means $0-3$ substitution and/or indel differences in the ITS region. Cortinarius anomalovelatus, $C$. rarus, and C. sp1 have $0.6 \%$ and $0.8 \%$ intraspecific variations (4 and 5 substitution and/or indel differences), respectively.

Most of the species (92\%) have 1-5\% interspecific sequence dissimilarity which means $6-30$ substitution and/ or indel differences in the ITS region. The three species that have interspecific difference from their closest relatives less than $1 \%$ (i.e., C. modestus: $0.3 \%, C$. nettieae $0.6 \%$, and Cortinarius sp6: $0.6 \%$ ) have zero intraspecific variability. The average ITS variation within the studied species was $0.15 \%$ in contrast to the significantly larger genetic dissimilarity (1.93\%) between the species.

The ten sequenced North American type materials (see Taxon sampling part above) clustered in eight of the 43 recognized lineages, viz. C. albidipes, $C$. albidoavellaneus, $C$. brevissimus, $C$. caesiifolius, $C$. clintonianus, $C$. deceptivus, C. modestus, and C. perviolaceus, while $C$. caesiellus and $C$. copakensis later become synonyms of $C$. albidipes and $C$. albocyaneus, respectively. Cortinarius albomalus, C. anocorium, C. anomalovelatus, and C. barlowensis, recently described from North America, with available published ITS sequences (Ammirati 2014; Liimatainen and Niskanen 2021), were confirmed as separate species. The four classical European species $C$. albocyaneus, $C$. anomalus, C. caninus, and $C$. tabularis have been shown to occur in North America. Fourteen of the 27 remaining species are described as new to science based on molecular, morphological, and ecological data. Thirteen species were not described formally in this work due to lack of sampling, morphological, and/or ecological information. These were treated as Cortinarius sp1-sp13 in the phylogeny (Fig. 2).

\section{Taxonomy}

Cortinarius sect. Anomali Konrad \& Maubl., Icon. Sel. Fung. VI: 169 (1930)

IndexFungorum: IF 701616

Type species: $C$. anomalus (Fr.) Fr. MycoBank: MB 209878 
= Cortinarius sect. Azurei Kühner \& Romagn. ex Melot. Doc. Mycol. XX (77): 97 (1989)

IndexFungorum: IF 701628

Type species: $C$. azureus Fr.

MycoBank: MB 211057

Description: Basidiomata small to medium or less commonly large in size, often somewhat fragile; young lamellae often bluish to violaceous, less commonly whitish to pallid; universal veil white or buff to yellowish or ochraceous, poorly to strongly developed; stipe often discoloring yellowish, base often enlarged; basidiospores globoid to subgloboid or broadly ellipsoid to ellipsoid, mostly moderately to more coarsely verrucose, often similar in size across species; lamella trama hyphae smooth or slightly encrusted; pileipellis typically with a distinct hypocutis below a \pm well defined epicutis; clamp connections present; associated with broadleaf trees, conifers, shrubs, and subshrubs.

Cortinarius albidipes Peck, Bull. N.Y. St. Mus. 157: 57 (1912) [1911] Figs. 3A, 9A

MycoBank: MB 202134

Type: USA, New York, Lewis County, Constableville, 18 Sept 1911, C. H. Peck, (holotype NYS-F-000129). GenBank ITS: MZ580485.

= Cortinarius caesiellus A.H. Sm., Lloydia 7(3): 187 (1944) MycoBank: MB 285707

Description: Pileus 38-100 mm diam., convex to obtuse then plane to subumbonate, margin inrolled to incurved then
Fig. 3 Basidiomata of A Cortinarius albidipes (YL4408); B C. albidoavellaneus (MICH 10,313, holotype); C C. albocyaneus (DB6557); D C. anomalodelicatus (NS3415); E C. anomalomontanus (JFA9919); F C. anomalopacificus (TN12154). Photos: A: Y. Lamoureux, B: C.H. Kauffman \& A.H. Smith, C: B. Dima, D: N. Siegel, E: J.F. Ammirati, F: K. Liimatainen. Scale bar 3A: $1 \mathrm{~cm}$
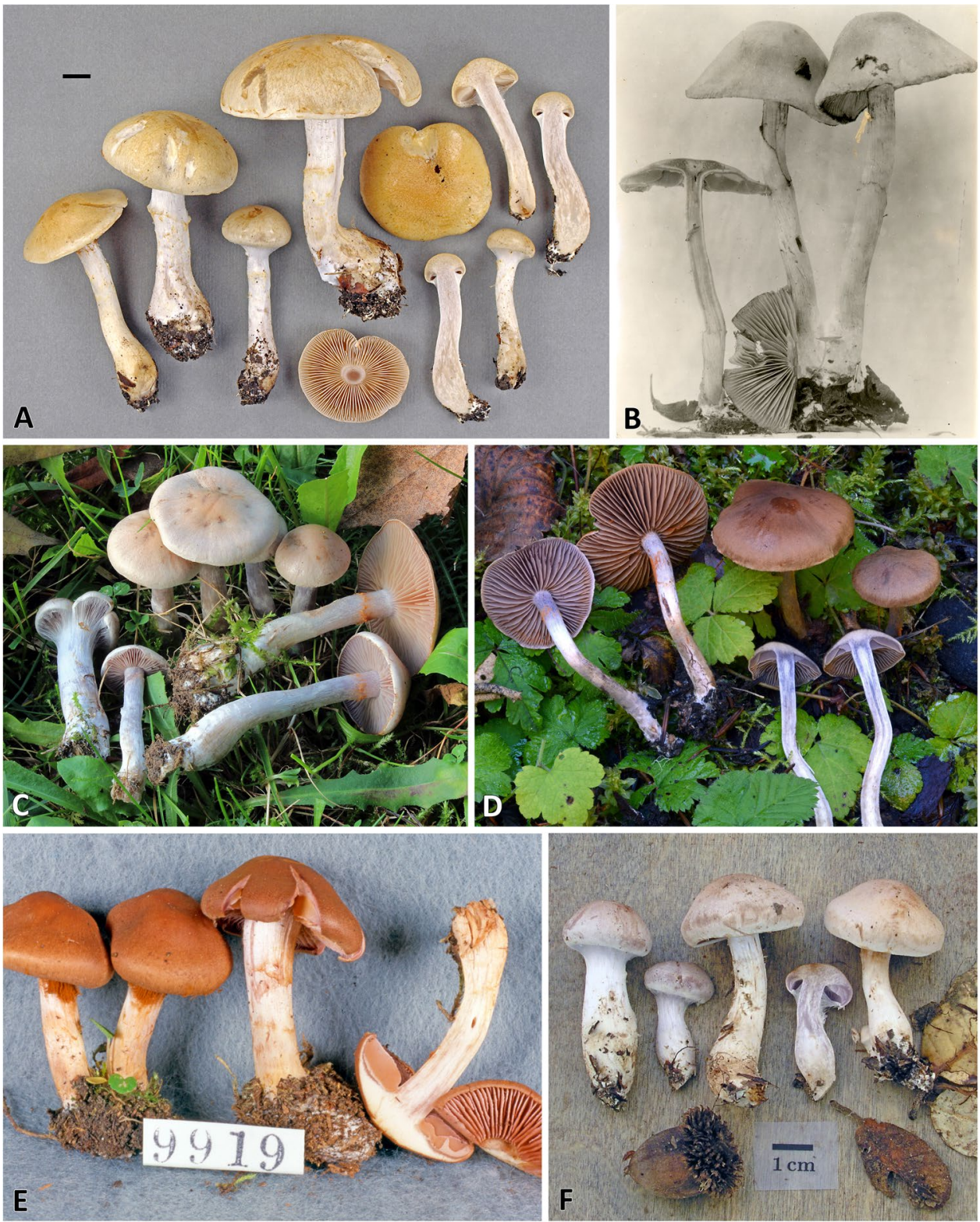
decurved, surface viscid when fresh, glabrous or fringed with silvery white fibrils along the margin, shiny when dry, color evenly pale silvery gray to pale buff or \pm gray vinaceous brown, the disc slightly more brownish, cinnamon buff to brownish cinnamon, then \pm brownish over margin in age. Lamellae adnate with decurrent tooth to slightly adnexed, \pm close, pale violet lilac to pale blue to pale drabgray, finally \pm pale brown to cinnamon. Stipe (40) 60-100 $\mathrm{mm}$ long, $8-15 \mathrm{~mm}$ thick above, equal to somewhat clavate or clavate-bulbous, base $12-15 \mathrm{~mm}$ thick, dry, white to whitish silky fibrillose over a lilac violet or dull gray lilac ground color when fresh, basal mycelium white becoming ochraceous to watery gray, veil forming distinct pale orange buff, pale yellow buff or pale ochraceous zones and patches on lower stipe or these less commonly very pale (whitish) to nearly absent, sometimes disappearing in age. Context of pileus firm, mottled with violet to gray violet becoming white, in stipe solid, above pale bluish drab to pale violet lilac, below some violet at first then whitish or discolored. Odor of lamellae and/or context not distinctive, taste of context mild, not distinctive or fungoid.

Basidiospores 8-9.5 (11) $\times 6.7-7.8 \mu \mathrm{m}$, av. $9 \times 7.5 \mu \mathrm{m}$, $\mathrm{Q}=1.1-1.3$, av. $\mathrm{Q}=1.2$, broadly ellipsoid to subgloboid, moderately to coarsely verrucose, slightly to moderately dextrinoid. Basidia 4-spored, clavate, colorless to yellowish, some with refractive particles. Lamella trama hyphae not encrusted. Pileipellis duplex: epicutis well developed, hyphae \pm cylindrical, moderately to strongly interwoven, 2.5-7.5- $\mu \mathrm{m}$ wide, colorless or yellowish, a few slightly encrusted; hypocutis well developed, hyphae \pm cylindrical to \pm enlarged, (5.5) 7.5-23 $\mu \mathrm{m}$ wide, colorless to yellowish, smooth or slightly encrusted. Clamp connections present.

Ecology and distribution: Cortinarius albidipes is associated with a broad range of broadleaf trees including Carpinus, Carya, Fagus, Quercus, and Ostrya, sometimes in combination with Fraxinus and Vaccinium, or with Pinus and Populus, occurring in temperate, boreal, and subalpine forests indicating a broad ecological range. It has an extensive distribution, occurring in Northeastern USA, Québec, Canada, and the Rocky Mountains. According to our unpublished sequence data, $C$. albidipes also occurs in mixed conifer and broadleaf forests of Northern Europe.

Comments: This is a rather large, stout species with \pm persistent violet to lilac colors in the lamellae and stipe apex and rather large basidiospores (av. $9 \times 7.5 \mu \mathrm{m}$ ) that are commonly broadly ellipsoid. Smith (1944) separated $C$. caesiellus from $C$. albidipes by the presence of the orange buff veil zones on the stipe of the former. Peck in the type description of $C$. albidipes emphasized the white stipe and absence of a colored veil. The additional collections of $C$. albidipes we examined all have some orange buff veil zones on the stipe surface. In our phylogeny, it belongs to the /albidipes clade together with two European species, C. lividomalvaceus and $C$. pelerinii, and 5 additional species from North America (C. tetonensis, C. huddartensis, C. perrotensis, C. kranabetteri, and Cortinarius sp5). Its most closely related species is European C. lividomalvaceus from which it differs by 13 substitutions and indel positions, with a similarity of $97.9 \%$.

Other specimens examined: Canada, Québec, L'Assomption, Chemin de la Presqu'île, Tilia, Fagus, Betula, scattered Tsuga, 20 Sept 2018, coll. Y. Lamoureux, YL4408, CMMF020764. Longueuil (Parc Michel-Chartrand), Quercus rubra, Fagus, Ostrya, Carpinus, 14 Sept 1992, coll. Y. Lamoureux, YL1826 (MQCOR247-18); Île Perrot, Quercus rubra, Carya ovata, 30 Sept 2010, coll. R. Lebeuf, HRL0614 (DAOM). USA, Colorado, Haywood County, Mountain Research Station, Populus tremuloides, Pinus contorta, 17 Aug 1997, coll. C. Schadt, JFA12420 (WTU). Michigan, Washtenaw County, Ann Arbor, Vaccinium, Fraxinus, Quercus, Carya, Ostrya, 27 Sept 1940, coll. A. H. Smith, AHS15476 (MICH); loc. cit., 1 Oct 1942, coll. A. H. Smith, AHS18823, holotype of C. caesiellus (MICH 10,325).

Cortinarius albidoavellaneus Kauffman \& A.H. Sm., Pap. Mich. Acad. Sci. 17: 158 (1933) Figs. 3B, 9B

MycoBank: MB 256211

Type: USA, Michigan, Alger County, Rock River, gregarious in a wet grassy area in cedar swamp, Sept 1929, C. H. Kauffman, A. H. Smith No. 60 (holotype MICH 10313). GenBank ITS: MZ580483.

Description: Pileus 40-65 mm diam., broadly subconic to campanulate, disc obtuse or subtruncate, at length subexpanded, even, hygrophanous, pale tan to brownish cinnamon with a broad pinkish buff zone on the margin after losing moisture, dry, subviscid to dry, glabrous, flexible at first or subfragile, with scanty remains of a universal veil along the margin. Lamellae ascending at first, adnate, crowded, at first white or pallid, then pinkish cinnamon, edges entire. Stipe 80-120 mm long, 5-9 mm thick below, slightly tapering, whitish then pallid-white, silky shining, nearly glabrous, with a scanty very thin appressed veil terminating in a slight zone above, apex white furfuraceous or mealy. Context of pileus watery whitish, then pallid, thin except on the center, in stipe solid to stuffed, cortex becoming cartilaginous, concolor or watery within. Odor of lamellae and/or context slight or radish, taste of context mild to subnauseous.

Basidiospores (8.5) 8.9-10 (10.7-11.5) ×7.4-8.3 (8.9) $\mu \mathrm{m}$, av. $9.5 \times 8 \mu \mathrm{m}, \mathrm{Q}=1.1-1.2(1.3)$, av. $\mathrm{Q}=1.2$, subgloboid, coarsely verrucose, non-dextrinoid to moderately dextrinoid. Basidia 4(2)-spored, 37-50×8-12 $\mu \mathrm{m}$, clavate, colorless, with refractive to granular contents, some with yellowish pigment. Lamella trama hyphae colorless, smooth to slightly encrusted, some with granular contents. Pileipellis 
duplex: sections difficult to revive, epicutis moderately well developed, hyphae radially arranged, interwoven to slightly entangled, loose or strongly compacted, cylindrical, mostly 4-10- $\mu \mathrm{m}$ wide, colorless, walls refractive, yellow or colorless, smooth to slightly encrusted; hypocutis hyphae yellowish in section, somewhat difficult to revive, compacted, radially arranged, interwoven, cylindrical to enlarged, 9-20 $\mu \mathrm{m}$, somewhat cellular in places, colorless to yellowish, smooth or slightly encrusted. Clamp connections present.

Ecology and distribution: From type description: "gregarious in wet grassy area in cedar swamp." Photo shows leaves of broadleaf trees. Known only from the Great Lakes region (type material). Cedar swamps in Michigan are mainly composed of Thuja occidentalis; however, the type material has leaves of broadleaf trees at the base of the stipe, and likely it was a mixed forest.

Comments: Cortinarius albidoavellaneus has a rather slender habit and long stipe, lacks distinct violaceous coloration and the veil leaves only slight, pale-colored remnants on the stipe surface. The basidiospores are darkly pigmented, coarsely verrucose, relatively large (av. $9.5 \times 8 \mu \mathrm{m}$ ) and subgloboid. Phylogenetically, this species belongs to / albocyaneus clade together with $C$. albocyaneus, the European C. epsomiensis, $C$. jonimitchelliae, the North American C. caeruleoanomalus and Cortinarius sp7. The latter is the most closely related species differing by 10 substitutions and indel positions, with a similarity of $98.4 \%$.

Cortinarius albocyaneus Fr., Monogr. Hymenomyc. Suec. (Upsaliae) 2(1): 62 (1863) Figs. 3C, 9C

MycoBank: MB 199757

= Cortinarius copakensis Peck, Ann. Rep. N.Y. St. Mus. nat. Hist. 31: 35 (1878)

MycoBank: MB 228757

Type: Sweden, Jämtland, Ragunda sn, Böle, in Betula forest, 8 Sept 1993, T.E. Brandrud et al. (epitype CFP1177 (S) designated in Dima et al. 2016). GenBank ITS: KX302206.

Description: Pileus (20) 40-70 (100) mm diam., at first rounded, then convex to plano-convex, rarely with a low umbo, margin persistently incurved, with fine, scattered veil remnants, surface smooth to sometimes finely felty, viscid fresh, somewhat shiny to distinctly glittery when dry, usually light blue when young from covering of the universal veil, later center grayish ochraceous, more pale (bluish) gray to whitish towards margin, rarely entirely light blue even when old, becoming pale yellowish brown when dry, weakly hygrophanous in radially fine striations or blotches, sometimes drying with a zone near the umbo. Lamellae adnexed, moderately crowded, violet blue to grayish brown, edges uneven, often lighter than faces. Stipe 40-120 mm long, 4-15 mm thick above, usually clavate to bulbous or cylindrical, base up to $20 \mathrm{~mm}$ thick, fragile, shiny, white fibrillose, at first entirely light blue, later light blue in the upper part, becoming light ochre downwards, basal mycelium white or pale blue, veil usually sparse, forming floccose-girdles on the stipe, often at first bluish white then becoming pale yellow, sometimes indistinct. Context rather thin, fragile, sometimes hollow in stipe, in pileus and in stipe at first bluish white, then below and in pileus becoming pale ochre yellow, with grayish hygrophanous spots. Odor of lamellae and/or context weak, radish-acidic.

Basidiospores (7.5) 8.1-9.6 ×6-7.5 (7.8) $\mu \mathrm{m}$, av. $9 \times 7 \mu \mathrm{m}$, subgloboid to broadly ellipsoid, $\mathrm{Q}=1.11-1.39$, av . $\mathrm{Q}=1.25$, moderately to coarsely verrucose, non-dextrinoid. Basidia 4-spored. Lamella trama hyphae colorless. Pileipellis duplex: epicutis hyphae cylindrical, (2.5) 4-7 $\mu \mathrm{m}$ wide, upward loosely entangled, smooth or weakly encrusted, later with yellowish intracellular pigment; hypocutis well developed, hyphae enlarged, almost isodiametric, somewhat irregular, 10-25 $\mu \mathrm{m}$ wide, thick-walled, upper layer yellowish pigmented. Clamp connections present.

Ecology and distribution: Associated with Betula and Fagus or other broadleaf deciduous trees, such as Tilia and Populus. Widespread in Europe and known from northeastern North America.

Comments: Cortinarius albocyaneus is characterized by its very pale bluish gray to whitish, weakly hygrophanous pileus and the stipe is often with sparse veil remnants. Bluish tinges are present on the pileus, lamellae, and stipe apex in young specimens. The description of the type collection of C. copakensis is rather rudimentary, so parts of the above descriptive data here are adapted from Dima et al. (2016). Basidiospores of the type of $C$. copakensis are similar to the measurements of those for C. albocyaneus (Dima et al. 2016). The ITS sequence of the type of $C$. copakensis is partial (containing ITS1 and ITS2, but lacking 5.8S), and it differs by only one indel position from the epitype of $C$. albocyaneus (KX302206). Therefore, both species are considered here as conspecific from both morphological and phylogenetic perspectives. The sister species of $C$. albocyaneus is $C$. caeruleoanomalus from which it differs by 7 substitutions and indel positions, with a similarity of $98.9 \%$. The taxonomy of $C$. copakensis requires further research.

Other specimens examined: Italy, South Tyrol, Kaltern, Aura, 14 Oct 2000, CFP1482 (S) (GenBank ITS: KX302202). USA, New York, Columbia County, Copake, ground in woods, October 1878, coll. C. H. Peck, NYS-F000864, holotype of C. copakensis (NYS).

Cortinarius albomalus Liimat. \& Niskanen, Index Fungorum 487: 5 (2021) Figs. 7D and 10K

IndexFungorum: IF 558638

Type: Canada, Ontario, Simcoe, Severn Township, Matchedash District, mixed forest of coniferous and 
deciduous trees, 11 Sept 2007, K. Liimatainen \& T. Niskanen, TN07-154 (holotype H 7000816; isotype $\mathrm{K}(\mathrm{M})$ ). GenBank ITS: MZ568645.

Description: see Liimatainen and Niskanen (2021).

Other specimens examined: Canada, Quebec, St-Narcisse, Parc de la Batiscan, Quercus rubra, Fagus, Populus, small Abies balsamea nearby, 22 Sept 2018, R. Lebeuf, A. Paul, HRL2777 (DAOM984881), GenBank ITS: MN751632. USA, New Jersey, Passaic County, Ringwood, Beech Road, Fagus in mixed broadleaf forest, 13 Sept 2020, coll. S. Jakob, iNat: 59505932, (pers. herb.) GenBank ITS: MW305253.

Cortinarius anocorium Liimat. \& Niskanen, Index Fungorum 487: 5 (2021)

IndexFungorum: IF 558639

Type: USA, Florida, Wakulla Co., Crawfordville, 306 Wakulla Beach Road, mixed deciduous forest with Pinus, Live oak (Quercus virginiana), Magnolia glandiflora, sandy soil, on calcareous bedrock, 30 Dec 2014, K. Liimatainen, A. \& T. Niskanen, TN14-111 (holotype H 7068022; isotype K(M)). GenBank MZ568646.

Description: see Liimatainen and Niskanen (2021).

Cortinarius anomalodelicatus Ammirati, Liimat., Niskanen \& Dima, sp. nov. Figs. 3D, 9D

MycoBank: MB 840663

Typification: USA, Colorado, Pitkin County, Fryingpan River, Savage Lakes, Picea, 20 Aug 1978, A. H. Smith, J. F. Ammirati (holotype JFA8146 (WTU)). GenBank ITS: MZ580480.

Etymology: Named for the slender basidiomata.

Diagnosis: Medium-sized basidiomata; pileus grayish lilac to vinaceous brown; lamellae grayish purple; stipe rather slender, 4-6 $\mathrm{mm}$ thick above, apex lilac tinted at first; veil light buff to yellowish buff; basidiospores av. $8.5 \times 6.7 \mu \mathrm{m}$, broadly ellipsoid, ellipsoid or subgloboid, moderately to coarsely verrucose.

Description: Pileus 20-22 mm diam., convex, margin decurved, surface shiny, moist but not hygrophanous, at first slightly grayish lilac on edge, inward tan mixed with grayish vinaceous brown, disc light brownish tan to grayish vinaceous brown. Lamellae adnexed-emarginate, subclose, purplish to grayish with a purple drab cast, then brownish from basidiospores. Stipe 58-65 mm long, 4-6 mm apex, bulbous to clavate, surface shiny, lilac, sordid brownish in age, basal mycelium white, veil forming slight buff to yellowish buff patches or small zones at first, difficult to observe in age. Context in pileus solid, firm, white to whitish tinted with pileus colors beneath surface, slightly lilac over lamellae, in stipe apex and cortex watery lilac, in base whitish or watery grayish, hollow, becoming yellowish in pith. Odor of lamellae and/or context, \pm raphanoid, taste of context \pm raphanoid.
Basidiospores (7-)7.5-9.0(-10.5) $\times(6-) 6.5-7.5(-8) \mu \mathrm{m}$, av. $8.5 \times 6.7 \mu \mathrm{m}, \mathrm{Q}=(1.1-) 1.2-1.35$, av. $\mathrm{Q}=1.3$; broadly ellipsoid, ellipsoid or subgloboid, moderately to coarsely verrucose, moderately dextrinoid. Basidia 4-spored, clavate, 36-39 $\times 9-10.5 \mu \mathrm{m}$, colorless to yellowish to grayish yellow. Lamella trama hyphae colorless, smooth or slightly encrusted. Pileipellis duplex: epictuis \pm well developed, hyphae \pm radially oriented, interwoven, 4-11 $\mu$ m wide, cylindrical, colorless, yellowish or brownish yellow, walls sometimes distinctly thickened, smooth to encrusted; hypocutis distinct, moderately cellular, hyphae interwoven, 7.5-22 $\mu \mathrm{m}$ wide, cylindrical to broadly cylindrical or enlarged, colorless to yellowish, smooth or slightly encrusted. Clamp connections present.

Ecology and distribution: Gregarious under Picea in boreal and subalpine habitats. Known from interior Alaska and the Rocky Mountains.

Comments: Distinguishing features are the moderately large spores that tend to be broadly ellipsoid and coarsely verrucose, rather slender stature, distinct, yellowish buff veil on the stipe and moderate violaceous coloration. Phylogenetically, it belongs to the /caninus clade with C. caninus, C. anomalomontanus, and three unnamed species, two from North America (Cortinarius sp8 and Cortinarius sp9), and one from Japan. The most closely related species is Cortinarius $\mathrm{sp} 8$ from which it differs by 8 substitutions and indel positions, with a similarity of $98.7 \%$.

Other specimens examined: USA, Alaska, Fairbanks, UAF summer trails, NW of the campus area, Picea-dominated forest, 24 Aug 2011, coll. K. Liimatainen, T. Niskanen, TN11-241 (H). Washington, Pierce County, Buck Creek Campground, mixed conifer forest, 20 Oct 2018, coll. N. Siegel, NS3415.

Cortinarius anomalomontanus Ammirati, Liimat., Niskanen \& Dima, sp. nov. Figs. 3E, 9E

MycoBank: MB 840664

Typification: USA, Wyoming, Teton County, Flagstaff Road, Picea, Pinus contorta, 12 Aug 1989, M. Moser (holotype JFA9919 (WTU)). GenBank ITS: MZ580478.

Etymology: Named for the mountain habitat in which it occurs.

Diagnosis: Moderate-sized basidiomata; pileus grayish brown becoming yellowish to more brownish, minutely scaly; lamellae lilac to grayish lilac; stipe slightly lilac; veil pale ochraceous; basidiospores av. $8.2 \times 6.5 \mu \mathrm{m}$, mostly subgloboid to broadly ellipsoid, moderately to coarsely verrucose.

Description: Pileus 20-24 mm diam., conic to obtusely conic, margin incurved to decurved, moist, subhygrophanous, innately fibrillose along edge, minutely appressed fibrillose scaly on margin, minutely scaly on disc, margin 
grayish brown with a slight grayish layer of fibrils, in age pale grayish brown with more brownish minute scales, disc grayish brown with slight yellowish to light brown cast and small brown scales. Lamellae adnexed, close to \pm distant, light grayish lilac, gradually brownish, pale lilac color \pm persistent, edges slightly undulate, paler than faces. Stipe 50-60 $\mathrm{mm}$ long, 6-7 $\mathrm{mm}$ thick above, base 8-11 $\mathrm{mm}$ thick, clavate, apex whitish or pale with very slight lilac tints, at first with whitish veil fibrils above, below whitish mixed with brown and sometimes faint grayish lilac tones, with slight pale ochraceous veil zones and fibrils, basal mycelium whitish. Context of pileus solid, firm, whitish, gray to watery gray over lamellae, stipe cortex solid, hard, pith soft, in apex light violet with white streaks, below whitish with grayish to brownish tones in cortex, whitish in pith. Odor and taste of context strongly fungoid.

Basidiospores (6.5-)7.5-9(-11) $\times(5.5) 6-7(-9) \mu \mathrm{m}$, av. $8.2 \times 6.5 \mu \mathrm{m}, \mathrm{Q}=(1.1-) 1.2-1.3(-1.4,1.6)$, av. $\mathrm{Q}=1.25$, subgloboid to broadly ellipsoid, rarely more ellipsoid, moderately to coarsely verrucose, slightly to moderately dextrinoid. Basidia 4-spored, clavate, 35-38 $\times 8-10 \mu \mathrm{m}$, colorless to yellowish. Lamella trama hyphae colorless, smooth or slightly encrusted. Pileipellis duplex: epicutis thinly to well developed, hyphae interwoven to entangled, \pm radially arranged, 3-11 $\mu \mathrm{m}$ wide, cylindrical, colorless, yellowish or grayish with thickened walls, smooth to encrusted; hypocutis well developed, \pm cellular or hyphae interwoven, \pm radially oriented, 9-21 $\mu \mathrm{m}$ wide, cylindrical to enlarged, colorless to yellowish, some with yellow contents, smooth to encrusted. Clamp connections present.

Ecology and distribution: Known from the Rocky Mountain forests with Picea engelmannii and Pinus contorta.

Comments: This species features lilac tints in the lamellae and stipe apex, a gray brown pileus, and slight ochraceous veil bands on the stipe surface. The basidiospores are globoid to broadly ellipsoid and rather coarsely verrucose. Phylogenetically, it belongs to the /caninus clade with $C$. caninus, C. anomalodelicatus, and three unnamed species, Cortinarius sp 8 and Cortinarius sp9 from North America and one from Japan. The most closely related species is Cortinarius $\mathrm{sp} 8$ from which it differs by 7 substitutions and indel positions, with a similarity of $98.9 \%$.

Other specimens examined: USA, Wyoming, Teton County, Fourmile Meadow, Picea engelmannii, 18 Aug 1989, coll. J. F. Ammirati, M. Moser, JFA9973 (WTU).

Cortinarius anomalopacificus Bojantchev, Liimat., Niskanen, Dima \& Ammirati, sp. nov. Figs. 3F and 9F

MycoBank: MB 840665

Typification: USA, California, Yuba County, New Bullard's Bar Reservoir, Notholithocarpus densiflorus, Pinus ponderosa, 4 Dec 2008, D. B. Bojantchev (holotype
DBB11745 (pers. herb.), isotype (WTU)). GenBank ITS: MZ663774.

Etymology: From Greek: "anomalo" meaning unusual and "pacificus" refering to the Pacific region of distribution.

Diagnosis: Moderate-sized basidiomata, slightly to moderately pale blue, lilac or lavender; pileus becoming strongly brownish with maturity; universal veil white to yellowish or buff; basidiospores av. $6.7 \times 5.5 \mu \mathrm{m}$, subgloboid, slightly to moderately verrucose.

Description: Pileus 25-70 mm diam., hemispheric to convex then plano-convex, margin involute, frequently upturned in age, undulate, disc \pm even, surface smooth to silky, not hygrophanous, slightly gelatinous when moist, innately fibrillose in age, color pale tan with lilac hues, pale silvery gray along edge, with watery gray drab blotches, central area \pm tinted light gray vinaceous to dark gray vinaceous, becoming darker tan with ochraceous discolorations, velar remnants often on margin. Lamellae sinuate to adnexed, close to crowded, light bluish or grayish lavender at first then pale tan to pale yellow, turning rusty brown mature, edges slightly crenate. Stipe $40-120 \mathrm{~mm}$ long, 9-20 mm thick, cylindrical to subclavate, fibrillose to silky at the apex, with a distinct annular zone, pale tan with bluish apex, discoloring to yellow tan or whitish, veil white, rarely pale yellow, partially covering the lower stipe, occasionally leaving buff to light buff zones or patches, sometimes indistinct. Context solid, firm, grayish to whitish or bluish, hollow in stipe, whitish to pale blue-lilac or pale lavender above, silvery along surface, below grayish to pale yellow brown to sordid brownish. Odor of context not distinctive or \pm raphanoid, taste of context fungoid.

Basidiospores (6-)6.5-7(-7.5) $\times(5-) 5-6 \mu \mathrm{m}$, av. $6.7 \times 5.5 \mu \mathrm{m}, \mathrm{Q}=1.1-1.25$, av. $\mathrm{Q}=1.2$, subgloboid, slightly to moderately verrucose, non-dextrinoid. Basidia 4-spored, 22-32 $\times 5-9 \mu \mathrm{m}$, clavate to cylindro-clavate, colorless. Lamella trama hyphae smooth. Pileipellis duplex: epicutis well developed, hyphae interwoven to entangled, radially oriented, 4-11 $\mu \mathrm{m}$ wide, cylindrical, colorless to yellow, smooth to slightly encrusted; hypocutis distinct, moderately cellular, hyphae interwoven, 7.5-17 $\mu \mathrm{m}$ wide, cylindrical to enlarged, colorless to yellowish, smooth. Clamp connections present.

Ecology and distribution. Frequently associated with Notholithocarpus, sometimes also with Quercus, often in combination with Pseudotsuga, Pinus, Picea, and/or Tsuga. Moderately common at autumn in the northern California coastal forests and Sierra Nevada foothills.

Comments: Cortinarius anomalopacificus is a fairly typical representative of section Anomali. However, it lacks the strong violaceous coloration of some species. It has only a slightly colored veil and it has relatively small basidiospores. Phylogenetically, it is in the /tabularis clade with C. tabularis, 
C. brevissimus, C. nettieae, and Cortinarius sp6. The most closely related species is $C$. tabularis, from which it differs by 8 substitutions and indel positions, with a similarity of $98.7 \%$.

Other specimens examined: USA, California, Mendocino County, Caspar, by the road 409, Picea, Pseudotsuga, Notholithocarpus, 7 Dec 2012, coll. K. Liimatainen, TN12253 (H); Mendocino, Jackson Demonstration State Forest, mixed conifer dominated forest (Tsuga, Quercus), $17 \mathrm{Nov}$ 2012, coll. K. Liimatainen, T. Niskanen, TN12-074 (H), 26 Nov 2012, coll. K. Liimatainen, T. Niskanen, TN12154 (H); Mendocino Little Lake Road, Notholithocarpus, Pseudotsuga, 7 Dec 1995, coll. J. F. Ammirati, JFA11887 (WTU); Mendocino Woodlands State Park, Notholithocarpus, Pseudotsuga, 21 Nov 2009, DBB27748 (WTU) (UC); Van Damme State Park, Pygmy forest trail, Pseudotsuga, Tsuga, Quercus, 21 Nov 2012, coll. K. Liimatainen, T.
Niskanen, TN12-091 (H), TN12-093 (H), 27 Nov 2012, TN12-161 (H), TN12-164 (H); Mendocino, near shooting range, Notholithocarpus, Pseudotsuga, 8 Dec 2012, coll. K. Liimatainen, T. Niskanen, TN12-271 (H). Scotts Valley, Big Basin, redwoods, 3 Dec 2012, coll. M. Beug, TN12-301 (H).

Cortinarius anomalovelatus Ammirati, Berbee, Harrower, Liimat. \& Niskanen, Index Fungorum 93: 1 (2014) Figs. 4A, 9G

MycoBank: MB 550402

Type: USA, Washington, Snohomish County, Barclay Lake Trail, Abies, Tsuga, 28 Aug 2007, J. F. Ammirati (holotype JFA13109 (WTU)). GenBank ITS: FJ717605.

Description: Pileus 11-45 mm diam., rounded conic to hemispheric then obtuse to plane, umbonate to subumbonate, margin incurved to decurved then plane to uplifted, rather
Fig. 4 Basidiomata of $\mathbf{A}$ Cortinarius anomalovelatus (NS1032); B C. anomalus (TENN067720); C C. anomalus (NL-5414); D C. barlowensis (SAT-07-276-04 / TN07366); E C. caeruleoanomalus (PBM3902); F C. caesiifolius (TN07-489). Photos: A: N. Siegel, B: E. Harrower, C: L.G. Nagy, D: S. Trudell, E: P.B. Matheny, F: K. Liimatainen. Scale bar 4E: $1 \mathrm{~cm}$

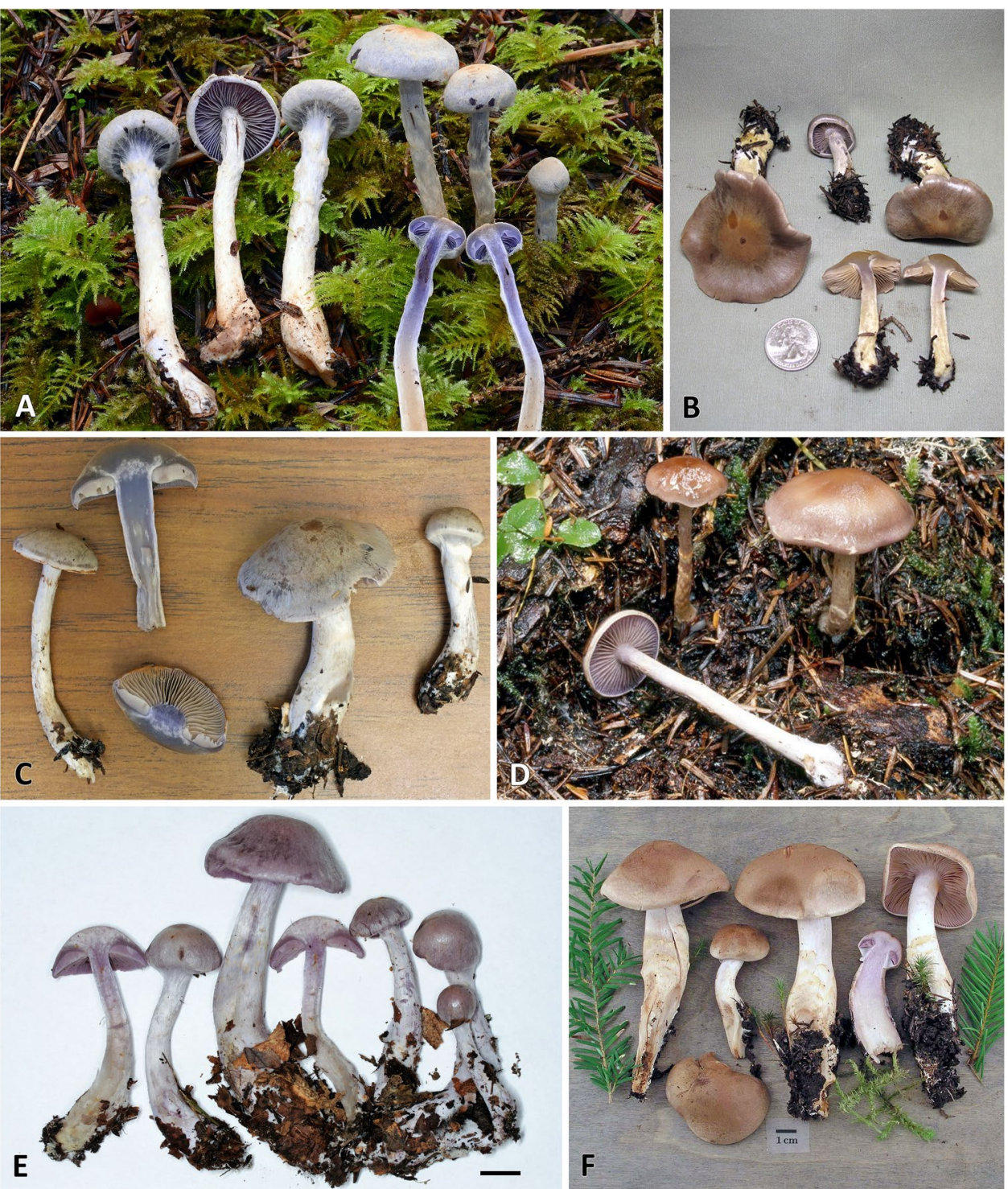


fragile, surface appressed fibrillose, fibrillose tomentose or fibrillose scaly from a silvery to whitish or ochraceous buff veil, margin and disc grayish lavender to grayish blue beneath veil, in age becoming more strongly ochraceous overall, not hygrophanous. Lamellae adnexed, \pm subdistant, grayish violet blue to light blue violet gray, gradually more grayish to brownish, eventually pale brownish cinnamon buff then medium brown, edges whitish at first then more conclorous with faces. Stipe 35-54 mm long, 3-6 mm above, 4.5-9 mm at base, clavate, \pm tapered below, upper portions silky, shiny, lilac violet to violaceous at first, gradually becoming whitish to brownish, veil leaving heavy white to buff or creamy buff floccose zones on the surface. Context solid, whitish to grayish in disc, watery gray over lamellae, beneath pileus cuticle tinted cinnamon buff, stipe stuffed then hollow, above bright blue violet with some whitish streaks and at times a grayish cast, in lower stipe whitish to grayish, with age the blue violet color fades, eventually whitish to grayish or brownish, in a few places with orange brown cinnamon discolorations. Odor of context and/or lamellae fungoid, taste of context fungoid, mild or slightly astringent.

Basidiospores 7.4-9 (9.6-11.1) ×(6) 6.3-7 (7.4) $\mu \mathrm{m}$, av. $8.5 \times 6.7 \mu \mathrm{m}, \mathrm{Q}=1.2-1.4$, av. $\mathrm{Q}=1.3$, subgloboid to broadly ellipsoid, moderately to coarsely verrucose, non-dextrinoid to slightly dextrinoid. Basidia 4-spored, $37-45 \times 7.4-11.8 \mu \mathrm{m}$, clavate to broadly clavate, colorless or with yellowish granules or yellowish pigment. Lamella trama hyphae smooth to slightly encrusted, with scattered colorless to yellowish refractive particles. Pileipellis duplex; epicutis well developed, hyphae strongly interwoven, \pm radially arranged, cylindrical to broadly cylindrical, 4.5-18 $\mu \mathrm{m}$ wide, walls refractive, colorless to slightly yellowish, smooth or faintly encrusted; hypocutis \pm well developed, hyphae cylindrical to enlarged, 7.4-22 $\mu \mathrm{m}$ wide, walls refractive, present.

Ecology and distribution: Cortinarius anomalovelatus occurs in low- to mid-elevation forests on the western mountain slopes and coastal areas from southwestern Canada into northern California. It tends to prefer more mesic forests and occurs from late summer into the fall season. In conifer forests with Tsuga, Abies, Picea, and/or Pinus.

Comments: Cortinarius anomalovelatus is a very distinctive Pacific Northwest species due to the heavy universal veil and grayish blue to violet colors of young specimens. In older specimens, the veil zones may be less conspicuous and the pileus more ochraceous. It often occurs in the same forest, as $C$. barlowensis, but usually appears earlier in the season. Phylogenetically, it forms a strongly supported clade with $C$. deceptivus and $C$. harvardensis, sister to /lepidopus clade based on our analyses (Figs. 1 and 2). Its most closely related species $C$. deceptivus differs by 13 substitutions and indel positions, with a similarity of $97.9 \%$.
Other specimens examined: Canada, British Columbia, Gwaii Haanas National Park, Burnaby Island, Swan Bay, Picea, Tsuga, 6 Sept 2006, coll. P. Kroeger, PK4741 (F16434) (UBC). USA, California, Humboldt County. Conifer forest, coll. J. Olson, K. Liimatainen, TN12-236 (H). Oregon, Florence, Jessie Honeyman Memorial State Park, Pinus, Picea, 9 Nov 2009, coll. D. B. Bojantchev, DBB23800 (Pers. Herb.). Washington, Snohomish County, Barclay Lake Trail, Abies, Tsuga, 28 Aug 2007, coll. J. F. Ammirati, JFA13109, holotype (WTU).

Cortinarius anomalus (Fr.) Fr., Epicr. syst. mycol. (Upsaliae): 286 (1838) [1836-1838] Figs. 4B, c, 9H

MycoBank: MB 209878

Type: Sweden, Ångermanland: Högsjö sn, Möckelsjöberget, in mixed deciduous forest, 20 Sept 1992, T.E. Brandrud et al. (neotype CFP1154 (S) designated in Dima et al. 2016). GenBank ITS: KX302224.

Description: Pileus 18-68 mm diam., convex, margin incurved, becoming broadly umbonate, margin incurved to decurved, not viscid, somewhat hygrophanous, violaceous to grayish buff with slight violaceus tones when moist, when dry buff with a sheen, becoming more brownish with maturity especially on disc. Lamellae adnexed, \pm crowded, pale violet, violaceus gray, then clay brown with age. Stipe 45-75 $\mathrm{mm}$ long, 4-15 mm thick above, equal to clavate, apex violaceus, otherwise pale violaceus to bluish gray or white to buff, soon becoming grayish to grayish brown, veil ochraceous to grayish brown, leaving a zone above, basal mycelium white. Context in pileus off-white to pale buff or pale violaceous, in stipe apex pale violaceus, below violaceus to bluish or pale yellow, with hygrophanous streaks. Odor of lamellae raphanoid or indistinct.

Basidiospores 6.9-8.9 (9.3-10.4) ×5.8-7 (8) $\mu \mathrm{m}$, $8 \times 6.5 \mu \mathrm{m}, \mathrm{Q}=1.1-1.4$, av. $\mathrm{Q}=1.25$, subgloboid to broadly ellipsoid, moderately to coarsely verrucose, slightly or moderately dextrinoid. Basidia 4-spored, rarely 2 or 3 spored, 30-40 $\times 8-9 \mu \mathrm{m}$, clavate, colorless or with yellow contents, some with refractive granules. Lamella trama hyphae colorless, smooth to slightly encrusted, scattered yellow pigmented hyphae. Pileipellis duplex: epicutis well developed, hyphae interwoven to entangled, radially arranged on margin, cylindrical, 5.2-9 $\mu \mathrm{m}$ wide, colorless or with yellow contents, smooth or slightly to coarsely encrusted; hypocutis well developed, some areas strongly cellular, otherwise hyphae more interwoven and radially arranged, cylindrical to very enlarged, 7.5-33.5 $\mu \mathrm{m}$ wide, colorless to yellowish, walls refractive, yellow to colorless, smooth or encrusted. Clamp connections present.

Ecology and distribution: Associated with broadleaf and broadleaf-conifer forests in northern and southeastern North America. Known from Québec south to North Carolina and 
Tennessee. It is a widespread and frequent species in Europe in deciduous broadleaf and conifer forests as well.

Comments: Cortinarius anomalus features a violaceous to bluish pileus surface, lamellae and stipe apex when young, an ochraceous-tinted veil, and moderately large $(8 \times 6.5 \mu \mathrm{m})$ subgloboid to broadly ellipsoid, moderately to coarsely verrucose basidiospores. North American collections are similar to those from Europe. Phylogenetically, it belongs to the isolated /anomalus clade along with an unnamed species from Japan and C. sericeolazulinus known from Costa Rica, from which it differs by 18 substitutions and indel positions, with a similarity of $97.1 \%$.

Other specimens examined: Canada, Québec, Base de plein air La Decouverte, broadleaf forests, Sept 2017, coll. H. Lambert, HL1492, MQCOR429-18. USA, Massachusetts, Berkshire County, Savoy State Forest, Fagus, Tsuga, Betula, 4 Oct 2012, coll. L. G. Nagy, NL-5414 (BP). North Carolina, Swain County, Clingman's Dome, 3 Sept 2012, coll. E. Harrower, EH198, TENN067720; loc. cit., 27 Sept 2012, coll. E. Harrower, EH208, TENN067730.

Cortinarius barlowensis Ammirati, Berbee, Harrower, Liimat. \& Niskanen, Index Fungorum 93: 1 (2014) Figs. 4D and 9I

MycoBank: MB 550403

Type: USA, Washington, Snohomish County, Barlow Pass, Tsuga, Abies, 25 Sept 2007 (holotype JFA13140 (WTU)). GenBank ITS: FJ717554.

Description: Pileus 19-30 mm diam., convex with slight umbo, margin slightly incurved to decurved, surface moist, \pm hygrophanous, developing a pale sheen when drying out, edge sometimes with slight white veil remnants, color gray vinaceous to purple gray, sometimes with slight blue lilac tones, developing brownish tones, disc becoming dark vinaceous brown. Lamellae adnexed, close to \pm crowded, dull light bluish lavender near edge of pileus, otherwise dull light brown with pale, uneven edges. Stipe 65-95 mm long, above 3.5-5 mm thick, base enlarged, clavate-bulbous, 7-12 mm thick, surface shiny, bluish to blue lavender above, below white to pale bluish developing gray tones, veil bands white to slightly ochraceous or light buff, thinly to slightly formed, sometimes with one major zone above, lower stipe sometimes slightly ochraceous, base with white rhizomorphs, becoming watery gray. Context in pileus solid, firm, watery and concolorous with fresh pileus surface, in stipe solid becoming hollow, blue lavender above, downward pale blue lavender, then watery bluish gray to gray below and in base, whitish where faded, sometimes becoming brownish in age, often with a white line at surface above. Odor of lamellae and/or context pleasant fungoid, taste of context mild, fungoid.
Basidiospores 8.5-12.4 (13) $\times 5.8-7.0 \mu \mathrm{m}$, av. $10.8 \times 6.5 \mu \mathrm{m}, \mathrm{Q}=1.45-1.9$, av. $\mathrm{Q}=1.7$, ellipsoid to broadly ellipsoid, occasionally subgloboid, moderately to \pm coarsely verrucose, non-dextrinoid to slightly dextrinoid. Basidia 4-spored, 31-40×8.9-9.6 (10.5) $\mu \mathrm{m}$, clavate, colorless with refractive granules or with pale yellow contents. Lamella trama hyphae colorless, smooth or slightly encrusted. Pileipellis duplex: epicutis hyphae radially arranged, interwoven, cylindrical to broadly cylindrical, 6-9 (13) $\mu \mathrm{m}$ wide, smooth or encrusted, walls colorless to yellowish; hypocutis well developed, hyphae \pm enlarged, 9.6-18.5 (20) $\mu \mathrm{m}$ wide, smooth or encrusted, walls colorless to yellowish, refractive. Clamp connections present.

Ecology and distribution: Cortinarius barlowensis is characteristic of mature and old growth submesic to mesic conifer forests composed of Tsuga, Abies, Picea, and/or Pseudotsuga. Known from the Pacific Northwest coastal to low elevation forests, Oregon, Washington, and British Columbia.

Comments: Cortinarius barlowensis has a rather long, narrow stipe in relation to the size of the pileus. The pileus surface is vinaceous gray to purple gray but soon develops brown coloration. The lamellae and stipe are blue to violaceous, and the universal veil leaves faint to thin yellowish buff bands on the stipe below a distinct single zone. The basidiospores are large (av. $10.8 \times 6.6 \mu \mathrm{m}$ ) and ellipsoid. Based on available data, it has a quite isolated position in the phylogenetic tree (Fig. 2). The most closely related species is $C$. rarus from which it differs by 18 substitutions and indel positions, with a similarity of $97.1 \%$.

Other specimens examined: Canada, British Columbia, North Vancouver, Capilano Canyon Regional Park, Tsuga, 10 Oct 2001, coll. M. Newcombe, (no voucher) (GenBank ITS: FJ157009); Smithers, mixed conifers, Sept 2007, coll. M. Kranabetter, SMIA46, F16437 (UBC). USA, Washington, Snohomish County, Barlow Pass, Tsuga, Abies, 25 Sept 2007, JFA13140, holotype (WTU). Tsuga, Pseudotsuga, Abies, 3 Oct 2007, coll. S. Trudell, SAT-07-276-04 (WTU) / TN07-366 (H).

Cortinarius brevissimus Peck, Rep. (Annual) Trustees State Mus. Nat. Hist., New York 41: 71 (1888) Fig. 9J

MycoBank: MB 213579.

Type: USA, New York, Catskill Mts., on ground in thin woods, Sept 1887, C. H. Peck (holotype NYS-F-000541). GenBank ITS: MZ580467.

Description: Pileus 15-25 mm diam., fleshy, convex, often irregular, surface at first minutely silky, then glabrous, dingy-white to clay brown. Lamellae adnexed, close, at first pale violaceous, then whitish to cinnamon. Stipe very short, 10-15 mm long, 6-8 mm thick, equal, silky fibrillose, white. 
Context of pileus whitish, in stipe hollow, pale violaceous. Odor and taste not recorded.

Basidiospores 7.4-8.9 (9.3) $\times 5.2-5.9 \mu \mathrm{m}$, av. $8 \times 5.5 \mu \mathrm{m}$, $\mathrm{Q}=1.3-1.7$, av. $\mathrm{Q}=1.5$, mostly broadly ellipsoid to ellipsoid or subgloboid, slightly to moderately verrucose, nondextrinoid. Basidia 4-spored, clavate, 25.2-30×7.4-8.1 $\mu \mathrm{m}$, colorless, often with refractive granules, some with yellowish contents. Lamella trama hyphae colorless to slightly yellowish, smooth or slightly encrusted. Pileipellis duplex: epicutis hyphae interwoven to entangled, somewhat radially arranged, cylindrical, 4-9 $\mu \mathrm{m}$ wide, colorless to yellowish, smooth or encrusted; hypocutis hyphae poorly revived, interwoven, radially arranged, cylindrical to enlarged, $8-14.8 \mu \mathrm{m}$ wide, yellowish or colorless, smooth. Clamp connections present.

Ecology and distribution: Known only from New York, on ground in woods, and a GenBank sequence (JX030219) which shows an association with Castanea dentata; otherwise, we know very little about its host trees.

Comments: The description of the type collection is rarther short and cryptic and there is no illustration. No additional collections are known to date. Therefore, this species is poorly known. The whitish to gray brown pileus, violaceous lamellae and stipe, and its medium-sized basidiospores (av. $8 \times 5.5 \mu \mathrm{m}$ ) are not particularly diagnostic in this clade. This is assuming that the short stature of the type collection is not a diagnostic feature. Phylogenetically, it is in a distinct position within the /tabularis clade. Cortinarius nettieae is the most closely related species from which it differs by 23 substitution and indel positions, with a similarity of $96.3 \%$.

Other specimen examined: USA, New York, Cortland County, Heiberg Memorial Forest, Tourtellot, SG et al.,1 SGT-2012 isolate, Cort_H2QY2 (GenBank ITS: JX030219).

Cortinarius caeruleoanomalus Dima, Matheny, K. Hughes \& Ammirati, sp. nov. Figs. 4E and 9K

MycoBank: MB 840666

Typification: USA, Tennessee, Blount County, Middle Prong Trail, Betula, Tsuga, 12 Sept 2004, J. F. Ammirati (holotype JFA13084 (TENN)). GenBank ITS: MZ663780.

Etymology: The epithet refers to the bluish basidiomata of the species.

Diagnosis: Basidiomata medium size; pileus, lamellae, and stipe distinctly blue to purplish when young; veil white; basidiospores mostly subgloboid, av. $7 \times 6 \mu \mathrm{m}$.

Description: Pileus 17-32 mm diam., obtuse and broadly umbonate, then obtuse to flattened on disc, edge inrolled to incurved, surface moist to dry or somewhat sticky, shiny, with some white silky veil fibrils on margin, ground color pale to light blue or purple mixed with gray, margin gradually losing blue color, central part becomes pale ochraceous buff and whitish, eventually the entire surface very buff to whitish. Lamellae adnexed or adnate to subdecurrent, close to crowded, color blue violet with pale edges (blue mixed with lavender or violet), then more bluish to grayish with admixture of brown, eventually light dull brown to grayish brown. Stipe $40-80 \mathrm{~mm}$ long, apex 3-6.5 $\mathrm{mm}$ thick, nearly equal or clavate, base to $9 \mathrm{~mm}$ thick, tapered below, veil white, surface at first covered with white silky longitudinal fibrils over a lavender blue ground color, in age blue-lavender above and whitish below, eventually whitish overall then sordid ochraceous to brownish or dingy below, basal area whitish. Context of pileus solid, watery blue to watery gray, faded whitish or slightly sordid in umbo, in stipe hollow, above light violet-blue (blue lavender color) with some paler/whitish streaks, below watery white and watery gray, in age blue-lavender colors fade to whitish and becoming watery translucent. Odor of context pungent, fairly strong, taste of context fungoid.

Basidiospores $6.5-8 \times(5-) 5.5-6.5 \mu \mathrm{m}$, av. $7 \times 6 \mu \mathrm{m}$, $\mathrm{Q}=(1.1-) 1.2-1.3(-1.4)$, av. $\mathrm{Q}=1.2, \pm$ subgloboid, occasionally broadly ellipsoid, distinctly, \pm moderately verrucose, non-dextrinoid to slightly dextrinoid. Basidia 4-spored, 26-30 $\times 7.5-9 \mu \mathrm{m}$, colorless or filled with dense yellow pigment. Lamella trama hyphae smooth or slightly encrusted. Pileipellis duplex: epicutis thinly to moderately developed, hyphae \pm interwoven, or more loosely arranged, \pm radially oriented, \pm cylindrical, 4-13 mm wide, colorless to rarely yellowish, smooth; hypocutis distinct, hyphae \pm enlarged, 12-22 $\mu \mathrm{m}$ wide, colorless, walls somewhat refractive, smooth. Clamp connections present.

Ecology and distribution: In broadleaf and broadleafconifer forests, oak and birch or birch and hemlock. Known only from southeastern North America.

Comments: A striking blue to violaceous species with a white veil and rather small (av. $7 \times 6 \mu \mathrm{m}$ ), mostly subgloboid basidiospores. Phylogenetically, it belongs to the /albocyaneus clade which contains $C$. albocyaneus, C. albidoavellaneus, C. $\mathrm{sp} 7, C$. epsomiensis, and $C$. jonimichelliae. It is a close sister species to $C$. albocyaneus from which it differs by 7 substitution and indel positions, with a similarity of $98.9 \%$.

Specimens examined: USA, North Carolina, McDowell County, Rose's Creek, Little Switzerland, hardwoods, Quercus, Betula, 22 Sept 2012, coll. P. B. Matheny, PBM3902 (TENN068383), GenBank ITS: KY7444156.

Cortinarius caesiifolius A.H. Sm., Contr. Univ. Mich. Herb. 2: 26 (1939) Figs. 4F and 9L

MycoBank: MB 251174

Type: USA, Washington, Olympic National Park, Olympic Hot Springs, 19 Oct 1935, A. H. Smith, AHS3227 (holotype MICH 10326). GenBank ITS: MZ580462. 
Description: Pileus 50-90 mm diam., obtusely rounded to convex, expanding to nearly plane, sometimes broadly umbonate, edge inrolled, margin incurved, not hygrophanous, surface dry, innately fibrillose at first, nearly glabrous in age, margin usually fringed with yellowish fibrils, at first near clay color to cinnamon buff or more yellowish, becoming darker in age, tawny olive, medium brown, vinaceous brown, dark brown or rich reddish brown, outer margin usually paler, at times edge with faint violaceous cast. Lamellae adnate or slightly adnexed, close to crowded, at first pale lilac, pale violaceous, gray lilac, pale gray blue or grayish blue, becoming dull brownish, edges even. Stipe 62-130 mm long, 9-20 mm thick, clavate, ventricose with tapered base or \pm bulbous, base 18-25 mm thick, silky fibrillose, pale violaceus or white with pale lilac tones, veil distinct, forming yellow ocher to rich ochraceous zones and patches, basal mycelium white, sometimes with white rhizomorphs in substrate. Context of pileus solid, slightly violaceous or whitish to pallid brownish drab, in stipe solid, violaceus to grayish lilac, white towards base. Odor of context and/or lamellae indistinct, fetid but soon vanishing or raphanoid. Taste of context mild.

Basidospores (6.3) 6.7-7.7 (8.5) $\times 5-6$ (6.3), av. $7 \times 5.5 \mu \mathrm{m}, \mathrm{Q}=(1.1) 1.2-1.4$, av. $\mathrm{Q}=1.3$, subgloboid to broadly ellipsoid, finely to moderately verrucose, non-dextrinoid to faintly dextrinoid. Basidia 4-spored, 33-38 $\times 6.7-7.4 \mu \mathrm{m}$, narrow clavate to clavate, colorless, some with granular contents. Lamella trama hyphae smooth or slightly encrusted. Pileipellis duplex: epicutis \pm poorly developed, hyphae interwoven, radially arranged, in places compacted, 3-9 $\mu \mathrm{m}$ wide, cylindrical to broadly cylindrical, colorless to yellowish or distinctly yellow pigmented, smooth or slightly encrusted; hypocutis distinct, hyphae interwoven, 8.1-24 $\mu \mathrm{m}$ wide, broadly cylindrical to enlarged, colorless to yellowish, smooth or slightly encrusted. Clamp connections present.

Ecology and distribution: In conifer forest, Pseudotsuga, Tsuga, Abies, Pinus, and/or Larix, with broadleaf trees and shrubs, Quercus, Populus, Alnus, and Salix sometimes present. Rather common species, known from British Columbia to California and east to Idaho and Montana.

Comments: The distinctive yellow ochre veil, persistent lilac lamellae, and rather small basidiospores (av. $7.2 \times 5.6 \mu \mathrm{m}$ ) are helpful in distinguishing $C$. caesiifolius from other Western species in section Anomali. Based on available knowledge, this is a singleton species with an isolated position in the phylogenetic tree (Fig. 2). The most closely related species are $C$. rarus and $C$. huddartensis from which it differs by 20 substitution and indel positions, with a similarity of $96.8 \%$.

Other specimens examined: Canada, British Columbia, Campbell River, STEMS1 Research Forest, Pseudotsuga,
Tsuga, 21 Oct 2009, coll. M. Kranabetter, J. Friesen, F28442 (UBC). Victoria, Sooke Watershed, Pseudotsuga, Tsuga, 25 Oct 2013, coll. M. Kranabetter, S. Berch, A. MacKinnon, O. Ceska, F31305 (UBC). USA, California, Mendocino, Jackson Demonstration State Forest, mixed conifer dominated forest Tsuga, Quercus, 17 Nov 2012, coll. K. Liimatainen, T. Niskanen, TN12-066 (H), 24 Nov 2012, TN12-118 (H), TN12-136 (H). Montana, Cabinet Mountains, south of Libby, Picea, Pseudotsuga, Tsuga, Pinus, Larix, Populus, 2 Oct 2010, coll. D.B. Bojantchev, DBB37600 (pers. herb.). Oregon, Breitenbush, mesic coniferous forest Tsuga, Pseudotsuga, 18 Oct 2007, coll. K. Liimatainen, T. Niskanen, TN07-489 (H). Washington, Mason County, Twanoh State Park, Pseudotsuga, Tsuga, 20 Oct 2007, coll. J. M. Birkebak, JMB10-20-2007-15 (WTU), GenBank ITS: FJ717517.

Cortinarius caninus Fr., Syst. Mycol. (Lundae) 1: 285 (1838) Figs. 5A and 9M

MycoBank: MB 200810

Type: Sweden, Ångermanland, Säbrå sn, Hällenyland, in young Picea forest on a cultivated field, 11 Sept 1987, T.E. Brandrud et al. (epitype CFP627 (S) designated in Dima et al. 2016). GenBank ITS: KX302250.

Description: Pileus 15-55 mm diam., obtuse to broadly convex, umbonate to even, margin incurved to decurved, edge narrowly inrolled, surface moist, not hygrophanous, innately streaked on margin, sometimes minutely fibrillose, when young and fresh whitish or grayish lilac along edge, otherwise grayish brown, vinaceous gray, brown or vinaceous brown to cinnamon brown. Lamellae deeply emarginated, crowded close or subdistant, pale grayish violaceous or gray mixed with pale vinaceous lavender, becoming light dull medium brown, some lilac remains at pileus edge, edges distinctly uneven, whitish. Stipe 30-63 mm long, (2.5) 4.5-9 (15) $\mathrm{mm}$ thick above, base 5-33 mm thick, clavate to subbulbous, sometimes the base \pm tapered downward, surface silky fibrillose, above violaceous (light lavender), below white with some brownish to cinnamon discolorations, in age entire stipe white to pale brownish, basal mycelium whitish to sordid brownish, veil forming distinct cream buff veil patches and zones (sometimes poorly developed). Context of pileus solid, firm, white to grayish white with some violet streaks and mottling above stipe apex, becoming somewhat brownish in age, in stipe becoming hollow, above violet with white streaks, below white and pale watery brown to discolored, sometimes context entirely white or slightly discolored. Odor of lamellae and/or context agaricoid to slightly raphanoid or pungent, taste of context somewhat raphanoid to pungent.

Basidiospores (7.5) 8-9 (9.6) $\times(6.3) 6.7-7(7.5) \mu \mathrm{m}$, av. $8.5 \times 7 \mu \mathrm{m}, \mathrm{Q}=1.2-1.3$, av. $\mathrm{Q}=1.2, \pm$ subgloboid to broadly ellipsoid, moderately to \pm coarsely verrucose, non-dextrinoid to slightly dextrinoid. Basidia 4- (rarely 2-) spored, 
Fig. 5 Basidiomata of A Cortinarius caninus (HRL2322); B

C. clackamasensis (TN11-451); C C. clintonianus (MCBS-

263b); D C. clintonianus (CMMF002618, YL2618); E C. deceptivus (NL-5180); F C. harvardensis (NL-5415, holotype). Photos: A: R. Lebeuf, B K. Liimatainen, C: S. Adams,

D: Y. Lamoureux, $\mathbf{E}$ and $\mathbf{F}$ :

L.G. Nagy
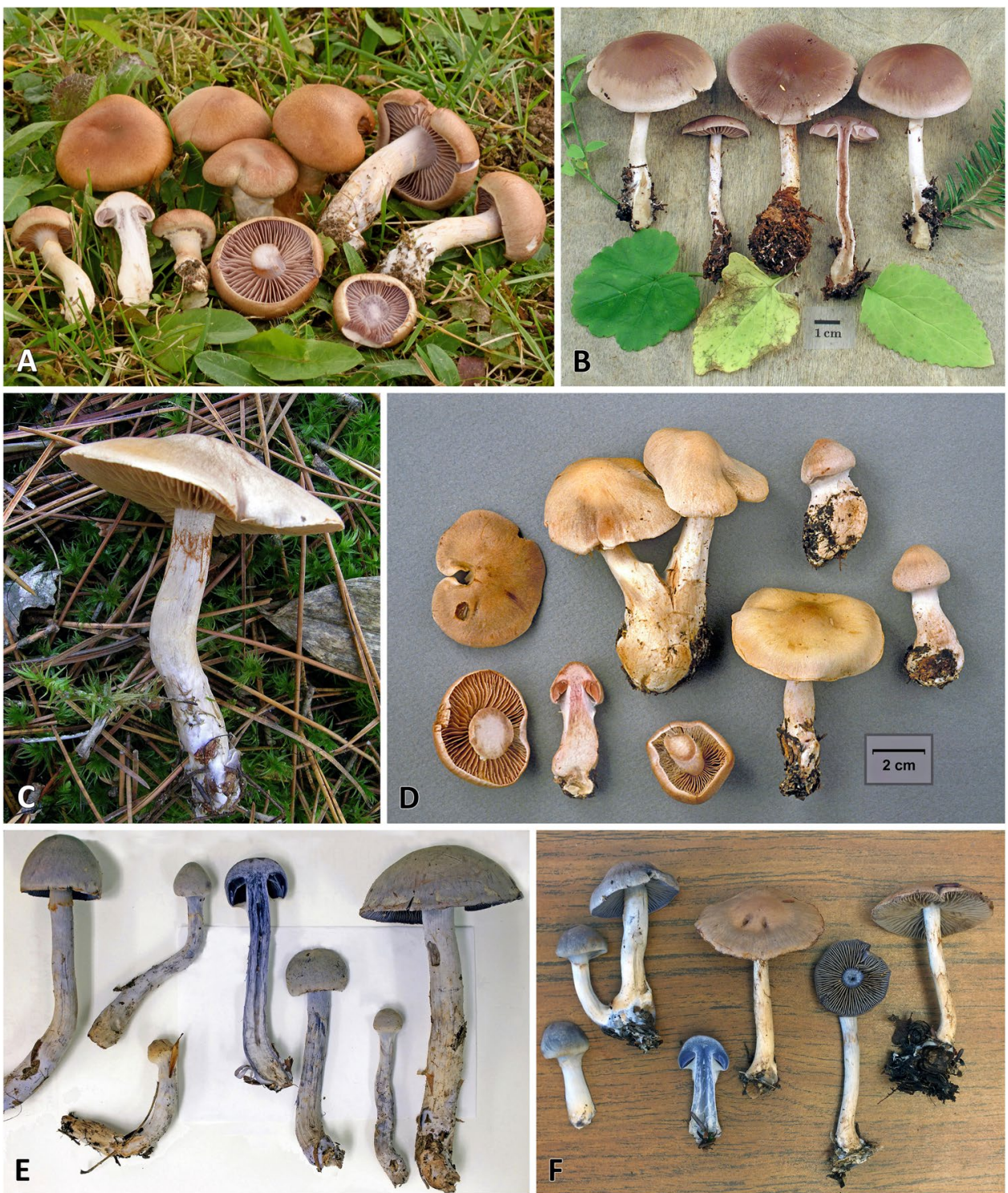

$32-39 \times 8-10.5 \mu \mathrm{m}$, clavate, colorless or containing yellowish pigment, with refractive particles, thick walled and grayish in age. Lamella trama hyphae smooth or faintly encrusted. Pileipellis duplex: epicutis thinly to moderately developed, hyphae interwoven, radially oriented, 4-11 $\mu \mathrm{m}$ wide, cylindrical to broadly cylindrical, colorless to yellow, smooth to slightly encrusted, walls refractive, sometimes dark, thickened; hypocutis distinct, hyphae interwoven, \pm radially oriented, cylindrical to broadly cylindrical or more commonly enlarged, 7.5-21 $\mu \mathrm{m}$ wide, colorless to yellowish, wall refractive, smooth or faintly encrusted. Clamp connections present.

Ecology and distribution: Often with Picea, or combinations of Picea, Pinus, Pseudotsuga, Tsuga, and/or Abies, sometimes mixed with Populus in boreal habitats. This transcontinental species is rather common in boreal forests across North America, in western subalpine conifer forests and west coastal mesic forests. Widespread in Europe as well, under Picea.

Comments: Cortinarius caninus is a medium to larger species that sometimes appears in large numbers, especially with Picea. The pileus is usually dominated by brown colors, especially by maturity. However, white or gray to violaceous colors may be present in fresh, young specimens, especially along the pileus edge. The cream buff veil patches and zones on the stipe surface may be poorly formed in some specimens. Basidiospore size is rather consistent between collections with an average of $8.5 \times 7 \mu \mathrm{m}$ in North American material. Phylogenetically, it forms the /caninus clade together with $C$. anomalodelicatus, $C$. amomalomontanus, Cortinarius sp8, and Cortinarius sp. from Japan. The most closely related species is Cortinarius $\mathrm{sp} 8$ from which it differs by 8 substitution and indel positions, with a similarity of $98.7 \%$. 
Other specimens examined: Canada, British Columbia, Picea, ectomycorrhiza, TN Hay, clone TH4Cc (GenBank ITS: KF753582). Ontario, Peel County, Palgrove Conservation Area, Picea, Pinus, 14 Oct 1977, coll. J. F. Ammirati, JFA7985 (WTU). USA. California, Del Norte County, Environmental Camp, Jedediah Smith Redwood State Park, Picea, Tsuga, Pseudotsuga, 12 Nov 2012, coll. N. Siegel, NS18. Minnesota, Clear Water County, Lake Alice Bog, Populus, Abies, Pinus, Picea, 17 Sept 1977, coll. N. SmithWeber, JFA8009 (WTU). Wyoming, Albany County, Libby Flats, Picea, Pinus, Abies, 19 Aug 1997, coll. J. F. Ammirati, JFA12434 (WTU). Teton County, Flagstaff Road, Picea, Pinus, 9 Aug 1987, coll. J. F. Ammirati, JFA9470 (WTU); Flagstaff Road, Picea, Pinus, 12 Aug 1989, coll. J. F. Ammirati, JFA9920 (WTU); Flagstaff Road, Picea, Pinus, Abies, 1 Sept 1991, coll. J. F. Ammirati, JFA10347, JFA10348 (WTU); Grassy Lake, Picea, Pinus, 7 Aug 1987, coll. J. F. Ammirati, JFA9425 (WTU).

Cortinarius clackamasensis Ammirati, Liimat., Niskanen \& Dima, sp. nov. Figs. 5B, 9N

MycoBank: MB 840667

Typification: USA, Oregon, Clackamas County, Mt. Hood, Summit Meadow, Picea, Pinus, Abies, 24 Oct 1995, J. F. Ammirati (holotype JFA11616 (WTU)). GenBank ITS: MZ580452.

Etymology: Named for Clackamas County, Oregon.

Diagnosis: Medium to large basidiomata; pileus gray brown, vinaceous brown or purplish brown; lamellae grayish brown to light brown or purplish tinted; stipe silky white to watery brown; veil buff to brownish; basidiospores av. $9.7 \times 6.5 \mu \mathrm{m}$, ellipsoid to broadly ellipsoid, rarely subgloboid, moderately to coarsely verrucose.

Description: Pileus 20-53 mm diam., convex to obtusely convex, margin decurved, edge narrowly incurved, surface moist, somewhat hygrophanous, pale silky fibrillose, disc minutely punctate and finely rimose, color evenly light purplish brown to gray brown or purplish brown, edge paler, disc more brownish or deeper brown to dark vinaceous brown, margin \pm hygrophanous, often becoming more grayish. Lamellae adnexed, close to \pm subdistant, pale grayish to very pale gray violaceous then light brown, sometimes with slight grayish tones, eventually deeper brown, edges somewhat uneven. Stipe 30-90 mm long, 4-10 mm thick above, base narrowly clavate, $5-11 \mathrm{~mm}$ thick, at times somewhat narrowed downwards, surface shiny, silky whitish, similar below but developing watery brown coloration, basal mycelium whitish, veil fibrils, zones and patches slightly buff to brownish, nearly lost in age. Context in pileus solid, firm to \pm soft fragile, pale purplish brown to grayish purple, watery gray or brown, faded area whitish to pale brownish, in stipe becoming hollow, in apex light gray purple, below very pale brown to whitish, becoming watery brownish in age. Odor of lamellae and/or context fungoid, indistinct or slightly raphanoid, taste mild.

Basidiospores 9-11×(6-)6.5-7.5 $\mu \mathrm{m}$, av. 9.7×6.5 $\mu \mathrm{m}$, $\mathrm{Q}=(1.3-) 1.4-1.5$, av. $\mathrm{Q}=1.45$, ellipsoid to broadly ellipsoid, rarely subgloboid, moderately to coarsely verrucose, non-dextrinoid to slightly dextrinoid. Basidia 4-spored, $29.5-38.5 \times 9.5-10.5 \mu \mathrm{m}$, clavate, colorless, yellowish or gray yellowish. Lamella trama hyphae with refractive walls, smooth or slightly encrusted. Pileipellis duplex: epicutis well developed, hyphae interwoven, radially arranged, 3-7.5 $\mu \mathrm{m}$ wide, cylindrical, colorless to yellowish or dark yellow, smooth to encrusted; hypocutis distinct, hyphae interwoven, radially arranged, $7.5-35 \mu \mathrm{m}$ wide, cylindrical to enlarged, colorless to yellowish, smooth to slightly encrusted. Clamp connections present.

Ecology and distribution: Gregarious in deep humus under mixed conifers, Picea, Pinus, and Abies. In Pacific Northwest conifer forests.

Comments: This is a very elegant species, somewhat resembling $C$. barlowensis. The pileus is somewhat hygrophanous, vinaceous brown to purplish brown, with the margin becoming more grayish when dehydrating. The lamellae and stipe have limited violaceous coloration. The universal veil remnants on the stipe surface are tinted buff to brownish. The large basidiospores (av. $9.7 \times 6.6 \mu \mathrm{m}$ ) are typically ellipsoid to broadly ellipsoid and rather coarsely verrucose. Phylogenetically, it is the sister species to the morphologically similar $C$. latiodistributus from which it differs by 12 substitution and indel positions, with a similarity of $98.1 \%$. The two species form an isolated clade, tentatively named as the /latiodistributus clade.

Other specimens examined: USA, Oregon, Marion County, Detroit Ranger District at Road 46,855, Psudotsuga, Abies, Tsuga, Nov 2001, coll. N. Bacheller, OSC114858 (OSC) (GenBank ITS: EU669315). Lane County, Mapleton Ranger District, Road 5335, Siuslaw National Forest, 9 Nov 2000, coll. R. Durham, OSC109672 (OSC) (GenBank ITS: EU652360). Washington, Kittitas County, Table Mountain, subalpine, mixed conifers, 9 Oct 2011, coll. J. F. Ammirati, K. Liimatainen, T. Niskanen, TN11-451 (H).

Cortinarius clintonianus Peck, Bull. Buffalo Soc. nat. Sci. 1(2): 55 (1873) Figs. 5C-D and 80

MycoBank: MB 225084

Type: USA, New York, New Scotland, ground in woods, Oct 1872, C. H. Peck (lectotype NYS-F-000786, designated here). GenBank ITS: MZ580450.

Description: Pileus $25-50 \mathrm{~mm}$ diam., broadly umbonate or convex to expanded, surface shiny, with appressed silky fibrils, margin fibrillose from veil, color grayish lilac, grayish vinaceous, brownish gray vinaceous, gray reddish brown 
or light brownish cinnamon, developing yellowish, buff or pale colors in age. Lamellae adnexed to adnate, close to crowded, dull violaceous soon becoming brownish cinnamon, edges concolorous or paler, even to \pm irregular. Stipe 50-75 mm long, 4.5-9 mm thick, clavate to bulbous or \pm equal, silky white fibrillose, color violaceous to light gray or white to brownish below, veil white to buff developing buff veil zones, base subtomentose, white discoloring brownish to yellowish, somewhat violaceous at times. Context in pileus firm, whitish to yellowish white, in stipe watery violet in apex and over lamellae, watery brown and white mottled in lower stipe. Odor of lamellae and/or context earthy, taste of context mushroom-like.

Basidiospores 6.7-8.1 $\times(5.2) 5.6-6.3 \mu \mathrm{m}$, av. $7.5 \times 6 \mu \mathrm{m}$, $\mathrm{Q}=1.2-1.4$ (1.5), av. $\mathrm{Q}=1.3$, subgloboid to broadly ellipsoid, \pm coarsely verrucose, non-dextrinoid to slightly dextrinoid. Basidia 4-spored, 31-32 $\times 8-9 \mu \mathrm{m}$, clavate, colorless with refractive particles, some with yellow pigment. Lamella trama hyphae smooth or faintly encrusted. Pileipellis duplex: epicutis moderately to well developed, hyphae strongly to moderately interwoven, radially oriented, 4-11 $\mu \mathrm{m}$ wide, \pm cylindrical, colorless, to yellowish or with yellow contents, wall refractive, smooth or slightly encrusted; hypocutis well developed, hyphae \pm radially arranged, \pm interwoven, 7.5-26 $\mu \mathrm{m}$ wide, cylindrical to enlarged, colorless to yellowish, walls refractive often yellowish. Clamp connections present.

Ecology and distribution: In conifer forests of Pseudotsuga and Tsuga, Pinus and Thuja or Pinus and Abies, sometimes with Populus and Betula. Known from the Pacific Northwest to the Great Lakes region and into the northeast, New York, Ontario, and Québec.

Comments: Cortinarius clintonianus appears to be a rather widespread species associated with mature conifer forests. The violaceous to gray violet colors of the young lamellae, pileus margin, and stipe are soon replaced by pallid to brownish colors or are nearly absent in some collections, giving the impression of a Telamonia s. str. Violaceous tones may persist in the stipe apex. The veil zones on the stipe surface are pale to buff. The basidiospores are coarsely verrucose, rather small (av. $7.5 \times 6 \mu \mathrm{m}$ ) and subgloboid to broadly ellipsoid. There are two collections (syntypes) by C. H. Peck. One collection is from Croghan and the other one is from New Scotland, and the latter collection is selected as the lectotype for this species. Phylogenetically, it forms an isolated clade with a species known only from environmental sequence data from Japan (Fig. 2). The most closely related species are $C$. rarus and $C$. huddartensis from which it differs by 21 substitution and indel positions, with a similarity of $96.6 \%$.

Other specimens examined: Canada, British Columbia, Squamish, Alice Lake Provincial Park, Picea, 20 Oct 2009, coll. D. B. Bojantchev, DBB21645 (WTU). South Lois
Lake Road, Pseudotsuga, isolate136C (GenBank ITS: KM403009); Victoria, Sooke Watershed, Pseudotsuga, Tsuga, Oct 2015, coll. M. Kranabetter, S. Berch, A. MacKinnon, O. Ceska, 266B (F31352) (UBC). Ontario. Algonquin Park, Found Lake, Tsuga, Pinus, Thuja, 30 Sept 1978, coll. J. F. Ammirati, JFA8329 (WTU). Québec, St-Majorique-de-Grantham (Forêt Drummond), Abies, Betula, Picea, Populus, 20 Sept 1995, coll. Y. Lamoureux, YL2618 (MQCOR258-18). USA, Michigan, Ogemaw County, Pinus, clone SDL13, EcM root sample (GenBank ITS: FJ769528). Minnesota, Hubbard County, Paul Bunyan State Forest, $\pm 1 \mathrm{mi} \mathrm{W}$ of Lake George, $\mathrm{N}$ side of Hwy 71, Pinus, Abies, 28 Sept 2007, coll. D. J. McLaughlin, E. G. McLaughlin, MCBS-263b (MIN 896348). New York, Albany County, New Scotland, ground in woods, Oct 1872, coll. C. H. Peck, NYS-F-000786.1 and NYS-F-000786.2 (lectotype, NYS). Washington, Pierce County, Buck Creek Campground, Tsuga, Abies, Pseudotsuga, 20 Oct 2018, coll. S. Adams, SDA 403 (WTU).

Cortinarius deceptivus Kauffman, Bull. Torrey bot. Club 32(6): 325 (1905) Figs. 5E and 10A

MycoBank: MB 224122

Type: USA, New York, Thompson County, Ithaca, Coy Glen, 24 Aug 1904, C. H. Kauffman (syntype MICH 10343). GenBank ITS: MZ663788.

Illustration: Bull. Torrey Club 32:324. f. 7; C. H. Kauffman, Agar. Mich. Pl. 84.

Description. Pileus 10-70 mm diam., suborbicular to hemispherical, becoming convex to convex-campanulate, basic color strongly grayish blue violet to fawn-colored tinged with lavender, the blue to lavender colors fading very quickly, becoming pure fawn or light tan, disc tan buff, initially covered by yellowish universal veil, which leaves distinct fibrillose patches on the margin or minute, brownish fibrillose squamules on the surface, eventually becoming subglabrous, somewhat hygrophanous, rugulose in age. Lamellae \pm thick, crowded to moderately close, adnate, deep blue to lavender when young, becoming grayish then pale tan with age. Stipe 30-108 mm long, 4-10 mm thick, rather stout, clavate at first then elongate and slender to cylindrical and flexuous with a slightly enlarged base, entirely bluish, at first covered by the yellowish fibrillose veil, eventually with brownish scales and partial zones, these terminate at a zone with the partial veil which is pale at first and then covered by spores, basal mycelium violet. Context hygrophanous, blue to pallid with a strong lavender tinge when young, fading quickly, becoming cork color, thick on disc, thin towards margin, texture spongy, in stipe solid, soon becoming hollow, entirely blue with stronger blue colors at apex and cortex. Odor of lamellae and/or context not distinctive or faintly unpleasant, sweetish. 
Basidiospores 7.8-9.3 $\times 6-7.4 \mu \mathrm{m}$, av. $8.5 \times 6.7 \mu \mathrm{m}$, $\mathrm{Q}=1.1-1.4$, av. $\mathrm{Q}=1.25$, subgloboid to broadly ellipsoid, verrucose. Basidia 4-spored, clavate, 26-29×7.4-9 $\mu \mathrm{m}$, colorless, with granular contents, some slightly yellowish. Lamella trama hyphae colorless to slightly yellowish, smooth to slightly encrusted. Pileipellis sections mainly yellowish, also pileus tramal tissues with considerable yellowish pigment, compacted in places: epicutis well developed, hyphae \pm radially arranged, interwoven to entangled, cylindrical to somewhat broadly cylindrical, mostly 4-10 $\mu \mathrm{m}$ wide, colorless to yellowish, wall refractive, \pm thickened, colorless or yellowish, smooth to faintly encrusted; hypocutis difficult to revive, hyphae, cylindrical to enlarged, mostly 11-15 $\mu \mathrm{m}$ wide, walls colorless or yellowish, smooth to slightly encrusted, colorless to yellowish in section. Clamp connections present.

Ecology and distribution: C. H. Kauffman reported that it was common in hemlock woods, on ground and among remains of very rotten logs and brush heaps. It also occurs with Pinus, August to September. Known from northeastern North America.

Comments: Cortinarius deceptivus was apparently collected more than once. The type is from Coy Glen, New York. Kauffman stated: "The colors and shapes of the plant are very variable and deceptive." Based on the photos of collections, Kauffman was certainly correct about the coloration of basidiomata. Fresh, young specimens are strongly bluish throughout but eventually this color fades and becomes more grayish. The well-developed yellowish universal veil covers the pileus surface at first, leaving behind fibrillose patches as the pileus expands, and distinct yellowish to brownish zones on the stipe surface. Phylogenetically, it forms a strongly supported clade with $C$. anomalovelatus and $C$. harvardensis. The most closely related species is $C$. anomalovelatus from which it differs by 13 substitution and indel positions, with a similarity of $97.9 \%$.

Other specimens examined: USA, Massachusetts, Franklin County, Gale Road, Arthur Iversen Conservation Area, Warwick, 13 Aug 2017, coll. S. Adams, SDA065 (WTU-F69313). New Hampshire, Cheshire County, Rhododendron State Park, 12 Aug 2017, coll. S. Adams, SDA056 (WTUF-69333). New York, Essex County, Newcomb, Huntington Wildlife Forest, Long Pond (220), under Pinus, 14 Aug 2012, coll. L. G. Nagy, J. S. Seelan, NL-5180 (BP).Thompson County, Ithaca, Coy Glen, 24 Aug 1904, coll. C. H. Kauffman, syntype (MICH 10343).

Cortinarius harvardensis L. Nagy, Dima \& Ammirati, sp. nov. Fig. 5F and 10B

MycoBank: MB 840668

Typification: USA, Massachusetts, Worcester County, Petersham, Harvard Forest, Tom's Swamp, Pinus, Quercus,
12 Oct 2012, L. G. Nagy (holotype NL-5415 (BP)). GenBank ITS: MZ663789.

Etymology: The epithet refers to the Harvard Forest, the locality where the holotype was collected.

Diagnosis: Basidiomata medium size; pileus, lamellae, and stipe with bluish to violet colors; universal veil white to pale yellow; basidiospores av. $8 \times 6 \mu \mathrm{m}$, subgloboid to broadly ellipsoid, coarsely verrucose.

Description: Pileus 15-50 mm, hemispherical to convex, faintly hygrophanous, violet to bluish when young, surface whitish silky (from the veil), becoming pale grayish brown and somewhat rugulose with age. Lamellae adnexed, crowded, deep blue when young, becoming bluish gray then somewhat brownish with age. Stipe 40-80 mm long, 5-15 $\mathrm{mm}$ wide at the apex, $8-18 \mathrm{~mm}$ at the base, cylindrical, becoming slightly bulbous at the base, pale bluish to whitish, veil whitish to very pale yellowish but leaving hardly any remains, basal mycelium violet. Context of stipe soon becoming hollow, strong bluish violet when young, later becoming paler. Odor and taste not recorded.

Basidiospores $7.5-8.5 \times 5.5-6.5 \mu \mathrm{m}$, av. $8 \times 6 \mu \mathrm{m}$, $\mathrm{Q}=1.3-1.4$, av. $\mathrm{Q}=1.33$, subgloboid to broadly ellipsoid, coarsely verrucose, weakly to moderately dextrinoid. Basidia 4-spored, 32-33.5 $\times 8-10 \mu \mathrm{m}$, clavate, colorless, some with refractive contents. Lamella trama hyphae colorless, smooth or slightly encrusted. Pileipellis duplex: epicutis well developed, hyphae interwoven to entangled, radially oriented, cylindrical, mostly $3-12 \mu \mathrm{m}$ wide, colorless or mostly commonly containing yellow pigment, smooth or encrusted, walls refractive, colorless to yellowish; hypocutis \pm cellular or hyphae more interwoven and radially arranged, cylindrical to enlarged, mostly $8-23 \mu \mathrm{m}$ wide, colorless to yellowish, walls refractive yellow to colorless, smooth to encrusted. Clamp connections present.

Ecology and distribution: In conifer and mixed coniferbroadleaf forests. Known from eastern North America, Quebec south to Massachusetts.

Comments: This medium-sized species has a violaceous pileus and lamellae when young but mature specimens become more grayish to brownish. The veil is sparse and whitish to yellowish, and the basidiospores are similar in size to those of $C$. deceptivus and $C$. anomalovelatus, which form the sister clade to this species within the /lepidopus clade. The most closely related species is $C$. anomalovelatus from which it differs by 21 substitution and indel positions, with a similarity of $96.8 \%$.

Other specimens examined: Canada, Québec, Chibougamau, Populus, Picea, Sept 5 2017, MQ17058 (QFB29566); Anse de roche, Abies, Pinus, coll. H. Lambert, HL1449 (QFB30070).

Cortinarius huddartensis Bojantchev, Liimat., Niskanen, Ammirati \& Dima, sp. nov. Figs. 6A and 10C 
Fig. 6 Basidiomata of $\mathbf{A}$ Cortinarius huddartensis (DBB12118, holotype); B C. kranabetteri (SMIA26); C C latiodistributus (JFA13487); D C. latiodistributus (DB6139, holotype); E C. modestus (TN10-035); F C. nettieae (TN09-167). Photos: A: D. Bojantchev, B: M. Kranabetter, C: J.F. Ammirati, D: B. Dima,

$\mathbf{E}$ and $\mathbf{F}$ : K. Liimatainen
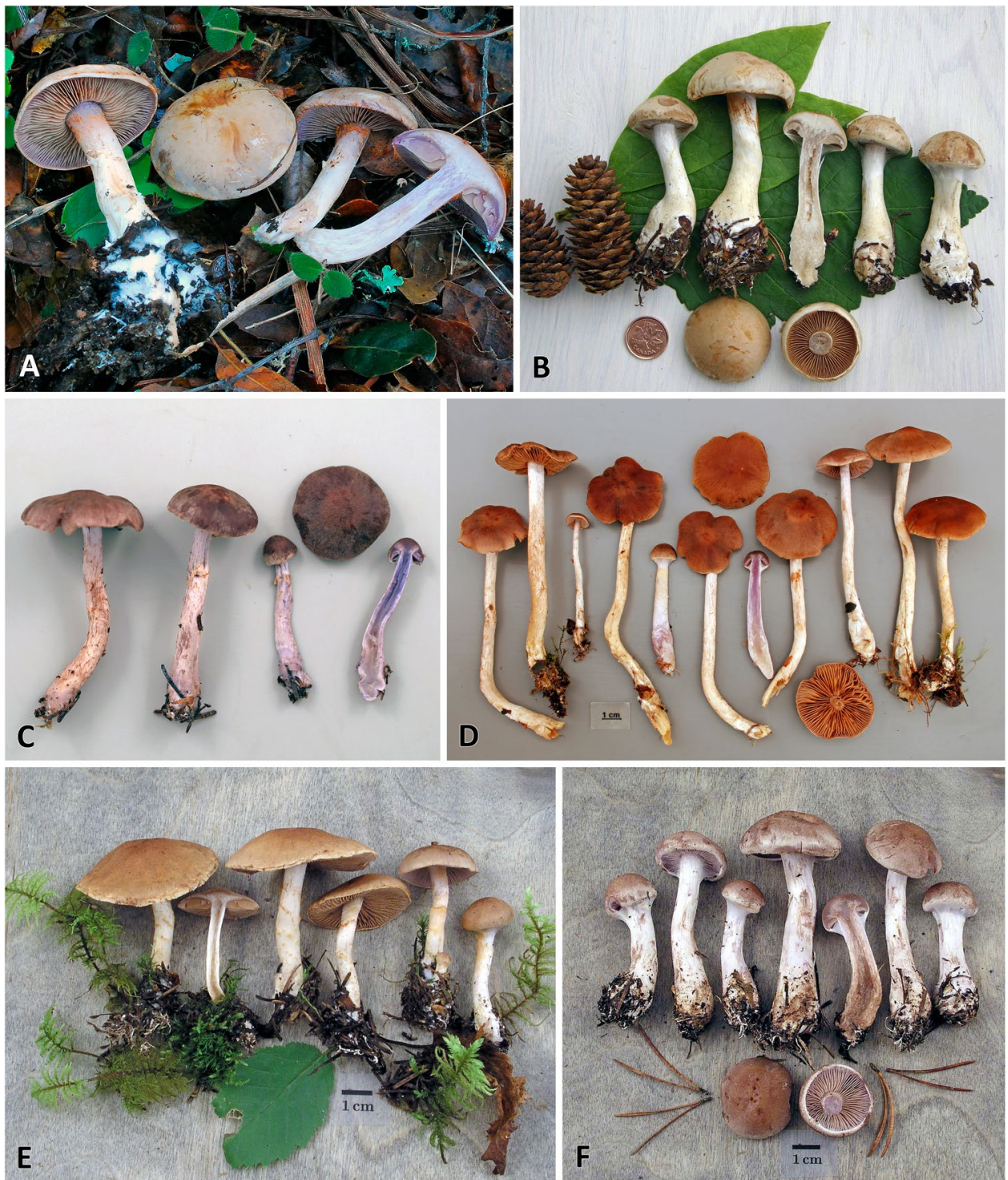

\section{MycoBank: MB 840669}

Typification: USA, California, San Mateo County, Huddart Park, under Quercus agrifolia, 18 Dec 2008, D. B. Bojantchev (holotype DBB12118 (pers. herb.), isotype WTU). Genbank ITS: MZ663790.

Etymology: From Huddart Park where the species was first collected.

Diagnosis: Basidiomata large to medium size; at first with pale lavender colors in the pileus and lamellae and a blue stipe apex; universal veil and cortina white; basidiospores av. $9.0 \times 6.2 \mu \mathrm{m}$, broadly ellipsoid, coarsely verrucose.

Description: Pileus 30-60 mm diam., convex to planoconvex, margin involute, surface smooth, innately fibrillose, not hygrophanous, slightly gelatinous when moist, pale lavender at first then cream to pale pinkish tan, ochraceous where bruised. Lamellae sinuate, moderately crowded, 3-12 $\mathrm{mm}$ broad, pale lavender at first then pale tan, turning rusty brown as spores mature, edges slightly crenate. Stipe 55-110 $\mathrm{mm}$ long, 15-25 mm wide, cylindrical to subclavate, fibrillose to silky at the apex, with a distinct annular zone, whitish with bluish apex, prominent basal mycelium and tomentum, with rhizomorphs, veil white. Context in pileus whitish at the center, pale bluish at the edge and in upper stipe. Odor not distinctive.

Basidiospores (7.5-)8.0-9.5(-10) $\times(5.5-) 6.0-6.5(-$ 7) $\mu \mathrm{m}$, av. $9.0 \times 6.2 \mu \mathrm{m}, \mathrm{Q}=1.3-1.5(-1.6)$, av. $\mathrm{Q}=1.45$, broadly ellipsoid, coarsely verrucose, slightly to moderately dextrinoid. Basidia 4-spored, 24-36×6-12 $\mu \mathrm{m}$, clavate to narrowly clavate, colorless, with refractive granules, some with yellowish pigment. Lamella tramal hyphae colorless or occasionally yellow pigmented, smooth or slightly encrusted. Pileipellis duplex: epicutis thin to more developed, hyphae entangled to interwoven, ascending to more radially arranged, cylindrical, $4-12 \mu \mathrm{m}$ wide, colorless to 
yellowish, walls \pm refractive, smooth or encrusted; hypocutis well developed, often \pm cellular, hyphae \pm radially arranged, cylindrical to enlarged, $8-16 \mu \mathrm{m}$ wide, colorless to yellowish, walls \pm refractive, smooth or encrusted. Clamp connections present.

Ecology and distribution: Thus far only known from California in association with Quercus. Its distribution may be limited to the warmer parts of the Pacific Coast.

Comments: Cortinarius huddartensis occurs under oaks, including Quercus agrifolia, Quercus douglasii, and Quercus wislizenii. The species exhibits pale lavender to pale blue coloration when fresh and has a white universal veil. The basidiospores are large (av. $9.0 \times 6.2 \mu \mathrm{m}$ ), broadly ellipsoid and coarsely verrucose. Phylogenetically, it belongs to the /albidipes clade, with $C$. albidipes, $C$. kranabetteri, $C$. perrotensis, $C$. tetonensis, and $C$. sp5, as well as with two European species, C. lividomalvaceus and $C$. pelerinii. The most closely related species is $C$. kranabetteri from which it differs by 10 substitution and indel positions, with a similarity of $98.4 \%$.

Other specimen examined: USA, California, Yuba County. Koch Natural Area, Quercus douglasii, coll. M. Smith, src174 (GenBank ITS: DQ974719).

Cortinarius kranabetteri Niskanen, Liimat., Harrower, Ammirati \& Dima, sp. nov. Figs. 6B and 10D

MycoBank: MB 840670

Typification: Canada, Alberta, S/SW of Hinton, by the Cold Creek, under Populus in a fairly old mixed forest of Populus, Picea on rich ground, 2 Sept 2011, K. Liimatainen, T. Niskanen (holotype TN11-287 (H)). GenBank ITS: MZ580449.

Etymology: In honor of Marty Kranabetter, fungal ecologist, British Columbia, Canada.

Diagnosis: Medium-sized basidiomata; pileus pale yellowish gray to pale brownish gray; universal veil pale ochraceous; basidiospores relatively small (av. $7 \times 6 \mu \mathrm{m})$ subgloboid to broadly ellipsoid, moderately verrucose.

Description: Pileus 30-50 mm diam., hemispheric to convex then plano-convex, surface smooth, silky, not hygrophanous, color pale yellowish gray to pale brownish gray. Lamellae adnate, close to crowded, light bluish gray at first then pale brown to cinnamon brown. Stipe $50-80 \mathrm{~mm}$ long, 6-9 mm thick above, $8-14 \mathrm{~mm}$ at the base, subclavate to clavate, whitish silky fibrillose with a bluish apex, veil pale ochraceous, forming girdles and patches on the stipe. Context not recorded. Taste and odor not recorded.

Basidiospores 6.5-7.5 $\times(5.5-) 6-6.5 \mu \mathrm{m}$, av. $7 \times 6 \mu \mathrm{m}$, $\mathrm{Q}=1.15-1.21$, av. $\mathrm{Q}=1.18$, subgloboid to broadly ellipsoid, moderately verrucose, non-dextrinoid to slightly dextrinoid. Basidia 4-spored, 24-27 $\times 8-9 \mu \mathrm{m}$, clavate, colorless. Lamella trama hyphae smooth. Pileipellis duplex: epicutis well developed, hyphae interwoven, \pm radially arranged, 3-7 $\mu \mathrm{m}$ wide, cylindrical, colorless, smooth; hypocutis hyphae \pm interwoven, \pm radially arranged, $11-17 \mu \mathrm{m}$ wide, cylindrical to enlarged, colorless, smooth. Clamp connections present.

Ecology and distribution. Known from British Columbia and Alberta in late successional conifer or mixed forests with Populus.

Comments: Cortinarius kranabetteri has relatively small basidiospores (av. $7 \times 6 \mu \mathrm{m}$ ) which it shares with the sister species $C$. perrotensis. Based on descriptions to date, this species does not have strong persistent blue coloration in the lamellae and stipe, and the veil zones on the stipe surface are pale ochraceous. Phylogenetically, it belongs to the /albidipes clade, with $C$. albidipes, $C$. huddartensis, $C$. perrotensis, and $C$. tetonensis, $C$. sp5, as well as with two European species, $C$. lividomalvaceus and $C$. pelerinii. The most closely related species is $C$. perrotensis from which it differs by 6 substitution and indel positions, with a similarity of $99 \%$.

Other specimen examined: Canada, British Columbia, Smithers, McCabe Trail, Picea, Abies, 10 Sept 2007, coll. M. Kranabetter, SMIA26, F16435 (UBC) (GenBank ITS: FJ039656).

Cortinarius latiodistributus Dima, Ammirati, Niskanen, Kytöv., Liimat. \& Brandrud, sp. nov. Figs. 6C-D and 10E

MycoBank: MB 840671

Typification: Sweden, Jämtland, Andersön, Picea, Pinus, 30 Aug 2016, B. Dima (holotype DB6139 (S)). GenBank ITS: MZ663791.

Etymology: The name "latiodistributus" refers to the wide distribution of the species.

Diagnosis: Moderate-sized basidiomata; pileus gray brown to brown with violaceous tones; lamellae violet at first; stipe grayish with some violet coloration in places; veil ochraceous; basidiospores av. $8 \times 6 \mu \mathrm{m}$, broadly ellipsoid or ellipsoid, occasionally more subgloboid, coarsely verrucose.

Description: Pileus 30-45 mm diam., convex, slightly umbonate, margin incurved, slightly inrolled at edge, dull white veil fibrils on edge of margin at first, surface moist, \pm hygrophanous, margin primarily gray brown, at times violaceous, becoming more brownish with age, around disc reddish brown, disc gray brown violaceous, becoming brownish with age, faded areas watery gray to pallid brown. Lamellae adnexed, close, dull violet mixed with gray tones at first, then gray brown, eventually more brownish, edges pale, whitish, \pm even. Stipe 70-73 mm long, above 5-6.5 mm thick, base clavate-bulbous, $10-14 \mathrm{~mm}$ thick, at first light blue to near base, becoming white in age (almost no hint of blue lavender color remains), at base more grayish, basal mycelium white, veil whitish to ochraceous or brownish 
ocharceous, leaving a distinct band mid-stipe, below and fibrils and patches below. Context of pileus solid, firm, watery concolorous, in buttons with violet tones in places, fading to whitish or pale brown, context of stipe hollow mature, light violet above with some whitish streaks, lower portion more grayish to white or watery brown, slight violet tints in places. Odor and taste of context mushroom-like.

Basidiospores 7-9.5(-10) $\times 5-6.5 \mu \mathrm{m}$, av. $8 \times 6 \mu \mathrm{m}$, $\mathrm{Q}=1.2-1.55$, av. $\mathrm{Q}=1.4$, broadly ellipsoid or ellipsoid, occasionally subgloboid, coarsely ornamented, non-dextrinoid or slightly dextrinoid. Basidia 4-spored, 24-33 × 7.5-9.6 $\mu \mathrm{m}$, clavate, colorless to yellow. Lamella trama hyphae smooth to slightly encrusted. Pileipellis duplex; epicutis well developed, hyphae interwoven, \pm radially arranged, cylindrical, 3.3-7.5 $\mu \mathrm{m}$ wide, colorless to yellowish, wall refractive, smooth; hypocutis well developed, hyphae interwoven, radially oriented, cylindrical to enlarged, 9-31(-37) $\mu \mathrm{m}$ wide, colorless, walls refractive, colorless to yellowish, smooth. Clamp connections present.

Ecology and distribution: In mature and old growth mesic conifer forests, with Tsuga and Abies in the Pacific Northwest of North America. Also known from Japan, Finland, Norway, and Sweden with Picea, Pinus, sometimes mixed with Betula.

Comments: This species occurs in similar habitats as $C$. barlowensis in the Pacific Northwest. In the field, these two taxa can appear somewhat similar; however, C. latiodistributus has deeper violaceous colors, a more distinct veil, and significantly smaller basidiospores than C. barlowensis. Phylogenetically, it is distantly related to $C$. barlowensis, but forms an isolated clade with its sister species C. clackamasensis, which is similar in appearance but has significantly larger basidiospores and differs by 12 substitution and indel positions, with a similarity of $98.1 \%$.

Other specimens examined: Canada, British Columbia, Date Creek, Kispiox, mixed conifers, 24 Sept 2002, coll. S. Gamiet, SMI 16, F17514 (UBC); Smithers, mixed conifers, Sept 2007, coll. M. Kranabetter, SMI A46, F16437 (UBC). Finland, Koillismaa, Salla, road 950, Kuusamo to Salla, Kaunishauta viewpoint, dry Pinus sylvestris heath forest on sandy soil and submesic, mixed forest of Pinus, Picea Betula, 2 Sept 2002, K. Liimatainen, T. Niskanen, TN02-490, H6033265 (H). Japan, Yamanashi, Mt Fuji, EcM root sample, YM187 (GenBank ITS: AB848436). Norway, Oppland, Etnedal, Solbjør, Picea, Pinus, 24 Aug 2017, coll. B. Dima, T. E. Brandrud, DB6359. USA, Washington, Greys Harbor County, Quinault Ranger District, road 100, Tsuga, Abies, 8 Nov 2001, coll. J. Garren, OSC115143 (GenBank ITS: EU652359). Snohomish County, Barlow Pass, Tsuga, Abies, 23 Sept 2010, coll. J. F. Ammirati, JFA13487 (WTU). Whatcom County, Mt. Baker Ranger District, Canyon Creek Rd., Tsuga, Abies, 11 Oct 2002, coll. N. L. Browner, OSC114595.
Cortinarius modestus Peck, Ann. Rep. N.Y. St. Mus. nat. Hist. 26: 62 (1874) Figs. 6E and 10F

MycoBank: MB 165504

Type: USA, New York, Lewis County, Croghan, ground in woods, Sept 1872, C. H. Peck (holotype NYS-F-001966). GenBank ITS: MZ580446.

Description: Pileus convex or expanded, $20-70 \mathrm{~mm}$ broad, surface subfibrillose or with minute fibrillose patches on disc and inner margin, not hygrophanous, at first pale to light brown with gray violet tints on the outer margin, becoming light brown to pale brown with darker brown center and pale edge, with veil fibrils on outer margin. Lamellae adnexed, close, pale purplish gray at first then pallid to light brown or cinnamon mature, edges pale. Stipe narrowly clavate, rarely bulbous, $45-75 \mathrm{~mm}$ long, 4-8 $\mathrm{mm}$ thick above, $5-11 \mathrm{~mm}$ thick at base, subfibrillose, white overall or apex with pale violaceous tints at first, veil forming yellowish buff zones and patches on the stipe surface, basal mycelium white, sometimes with white rhizomorphs. Context in pileus solid, white, to pale brownish white, in stipe pale violaceous above, white to brownish white below, hollow or stuffed with white pith. Odor of lamellae somewhat raphanoid. Taste not recorded.

Basidiospores (6.7) 7.4-8.1 (8.5) $\times(5.6) 5.9-6.3 \mu \mathrm{m}$, av. 7.5 $\times 6.5, \mathrm{Q}=1.2-1.4$, av. $\mathrm{Q}=1.2$, mostly subgloboid, some broadly ellipsoid, \pm coarsely verrucose, non-dextrinoid to slightly dextrinoid. Basidia 4-spored, clavate, 36-41 $\times 9-11 \mu \mathrm{m}$, colorless, with refractive granules, some with yellow pigment. Lamella trama hyphae colorless, rarely yellowish, smooth to slightly encrusted. Pileipellis duplex: epicutis \pm well developed, hyphae \pm radially arranged, interwoven to entangled, hyphae cylindrical to broadly cylindrical, mostly 4-10.5 5-19 $\mu \mathrm{m}$ wide, colorless or yellowish with yellow refractive walls, smooth to encrusted; hypocutis well developed, hyphae radially arranged, \pm interwoven, cylindrical to enlarged, mostly 5-19 $\mu \mathrm{m}$ wide, smooth or encrusted, walls refractive, strongly yellowish to colorless. Clamp connections present.

Ecology and distribution: Known from eastern North America from Québec to New York. In mixed forests of broadleaf and conifer, including Abies, Picea, and Pinus, sometimes with Betula, Populus, Alnus, and/or other broadleaf trees.

Comments: This species has a predominately brownish pileus with some gray violet tints on the margin at first. The lamellae and stipe apex are pale violaceous at first but the lamellae soon become brownish and the stipe is often white throughout when mature. The universal veil typically leaves yellowish to buff zone on the stipe surface. The basidiospores are rather small (av. $7.5 \times 6.5$ ), mostly subgloboid and \pm coarsely verrucose. Phylogenetically, it is very closely related to the morphologically similar European $C$. 
lepidopus. They might represent the same species, since they only differ by 2 nucleotides in the ITS region $(=99.7 \%$ similarity); however, it is consistantly different. Intraspecific genetic variability is 0 in both species. We have not yet successfully sequenced the holotype of $C$. lepidopus Cooke from Kew Herbarium. Until the European name is fixed by a type sequence, we treat $C$. modestus as a separate North American taxon.

Other specimens examined: Canada, Québec, Nord-duQuébec, Chibougamau, Betula, Abies, Picea, Populus, 6 Sept 2017, MQ17140 (QFB29648); loc. cit., Betula, Picea mariana, Alnus, Pinus banksiana, 7 Sept 2017, MQ17272 (QFB29780). Amos, Lac Dudemaine, coll. H. Lambert, HL0629 (QFB30005). Portneuf, Rivière-à-Pierre, S entrance of the Réserve faunique de Portneuf, Chutes de la Marmite, conifer dominated forest (Tsuga, Abies, Picea) with some Betula, Populus, 28 Aug 2010, coll. A. Paul, R. Lebeuf, T. Niskanen, TN10-035 (H). Sainte-Famille, Ile d'Orléans, Sugar maple-Basswood ecological domain, 20 Sept 2009, coll. J. Landry, J. Bérubé, Q-2313, (QFB25737).

Cortinarius nettieae Ammirati, C.L. Cripps, Liimat., Niskanen \& Dima, sp. nov. Figs. 6F and 10G

MycoBank: MB 840672

Typification: USA, Washington, Clallam County, La Push, Picea, Tsuga, 10 Oct 1987, N. Laycock (holotype JFA9613 (WTU)). GenBank ITS: MZ580442.

Etymology: Named for the late Nettie Laycock, a wellknown Pacific Northwest citizen scientist and mycologist.
Diagnosis: Basidiomata rather large; pileus brownish with violaceous to vinaceous and grayish colors; lamellae violet at first; stipe violaceous; veil forming inconspicuous buff veil bands on the stipe surface; Basidiospores av. $8 \times 6.3 \mu \mathrm{m}$, broadly ellipsoid to ellipsoid or subglobose, moderately to more coarsely verrucose.

Description: Pileus 40-70 mm diam., obtusely convex to convex, subumbonate with flattened disc, margin incurved, edge slightly inrolled, not hygrophanous, sometimes completely brownish in button stage, normally margin silvery lavender to grayish vinaceous or grayish violet streaked with brown, disc shaded slightly brownish to rusty brown, overall becoming more brownish when mature. Lamellae adnexed, close to crowded, violet when young becoming dull lavender vinaceous, then brownish. Stipe 50-120 mm diam., apex to 5-15 mm thick, somewhat clavate to narrowly clavate, surface white or violet or \pm colored as pileus margin, cortina pale lavender at first, veil forming inconspicuous buff to yellowish bands on the stipe, basal mycelium white to lavender. Context in pileus solid, firm to watery mature, at first pale grayish brown, white mature, in stipe becoming narrowly hollow, with violet areas in cortex especially above, otherwise white with pale grayish brown colors below. Odor of lamellae and/or context rapahnoid or not distinctive, taste of context mild.

Basidiospores 7-9(-9.5) ×6-6.5 $\mu \mathrm{m}$, av. $8 \times 6.3 \mu \mathrm{m}$, $\mathrm{Q}=(1.1-) 1.2-1.4$, av. $\mathrm{Q}=1.3$, broadly ellipsoid to subglobose, moderately to coarsely verrucose, slightly dextrinoid. Basidia 4-spored, 30-37 $\times 7.5-8 \mu \mathrm{m}$, clavate, colorless to
Fig. 7 Basidiomata of $\mathbf{A}$ Cortinarius ochraceodiscus (DJM2195, holotype); B C. perrotensis (HRL2221, holotype); C C. perviolaceus (SDA 061); D C. albomalus (HRL2777). Photos: A: E.G. McLaughlin, B and D: R. Lebeuf, C: S. Adams
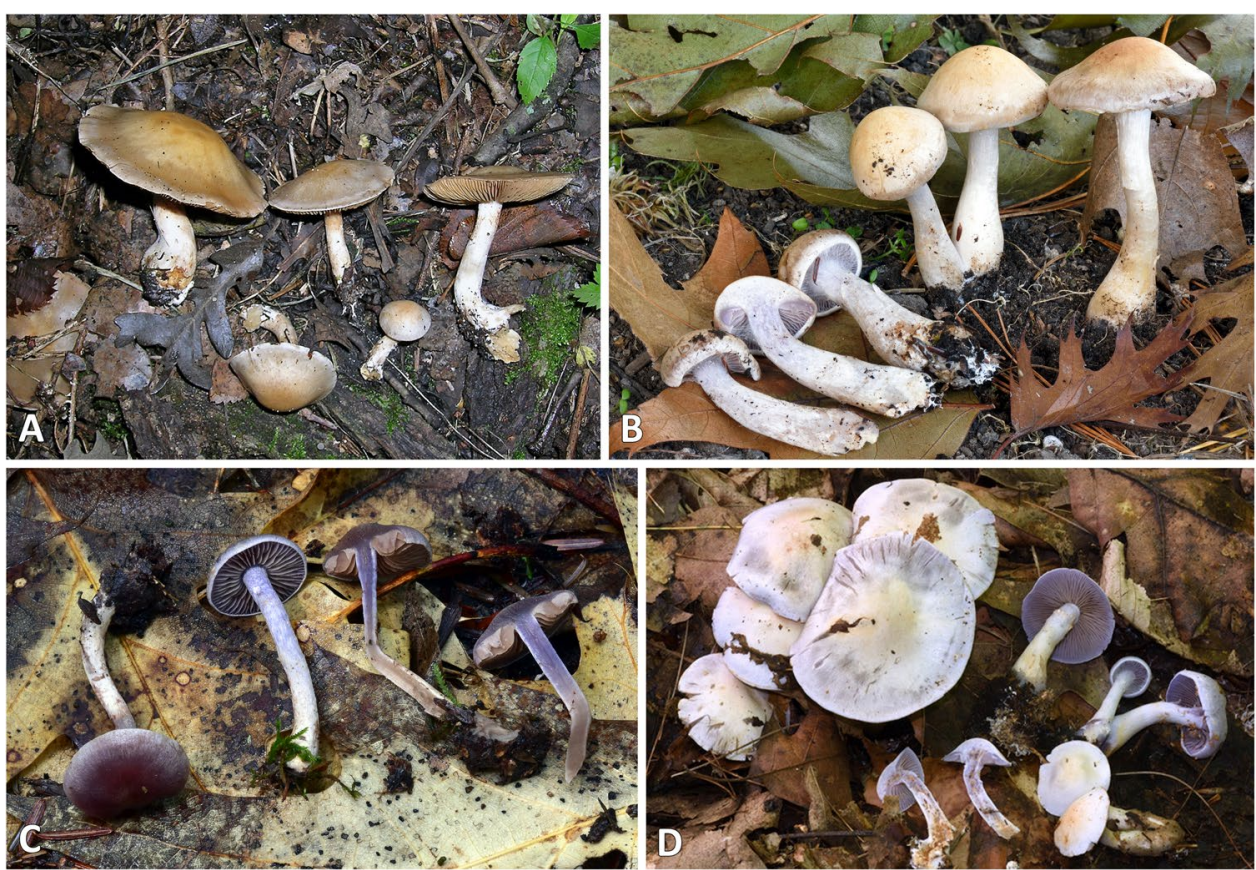
yellowish or grayish. Lamella trama hyphae smooth to slightly encrusted. Pileipellis duplex: epicutis well developed, interwoven to entangled, \pm radially arranged, 4-11 $\mu \mathrm{m}$ wide, cylindrical, colorless or commonly yellow to grayish yellow, walls sometimes thickened, smooth to encrusted; hypocutis well developed, often appearing cellular, interwoven to ascending, or more radially arranged, \pm cylindrical to enlarged, 10-30 $\mu \mathrm{m}$ wide, colorless to yellowish, smooth to slightly encrusted. Clamp connections present.

Ecology and distribution: Known from coastal Oregon and Washington in conifer forests.

of Picea, Pinus, Abies, and Tsuga, from Montana in subalpine forest, with Picea, Pinus, and Abies and from Québec under Betula with Populus, Salix, Abies, and Picea.

Comments: This is a relatively large species compared to other Anomali. The violet to lavender colors of the pileus are not particularly persistent, the pileus soon developing brown to grayish colors. The lamellae and stipe are violaceous at first, and the veil forms only slight buff bands on the stipe surface. The basidiospores average $8 \times 6.3 \mu \mathrm{m}$, and are mostly broadly ellipsoid. It is in the /tabularis clade with C. tabularis, C. anomalopacificus, Cortinarius sp6, and $C$. brevissimus. Even though $C$. nettieae forms a paraphyletic lineage in our phylogenetic tree (Fig. 2), it is distinct from other Anomali species, except for two close sequences from Canada (Cortinarius sp6), which differ by 4 substitution and indel positions with a similarity of $99.4 \%$. The relationship between $C$. nettieae and Cortinarius sp6 needs further study.

Specimens examined: Canada, Québec, Chibougamau, Chemin pres du lac David, Betula, Populus, Salix, Abies, Picea, 11 Sept 2018, coll. A. Paul, R. Lebeuf, MQ19HRL2730-QFB31009, GenBank ITS: MN750924. USA, Montana. Park County. Northeast of Cooke City, Fisher Creek Road, Picea, Abies, Pinus, 20 Aug 2004, coll. C. Cripps, CLC 2039 (MONT). Oregon, Tillamook County, Camp Magruder, near Rockaway Beach, stabilized sand dunes with Picea, Pinus, 31 Oct 2009, coll. S. Trudell, TN09-167 (H); loc. cit., TN09-176 (H). Cascade Head Experimental Forest, Picea, Pinus, Abies, 10 Nov 1982, coll. J. F. Ammirati, JFA8747 (WTU). Canada, British Columbia, Pebble Creek, Riondel, conifer forest, coll. S. Clark, 20 Oct 2003, DAVFP 27503.

Cortinarius ochraceodiscus D.J. McLaughlin \& Ammirati, sp. nov. Figs. 7A and 10H

MycoBank: MB 840673.

Typification: USA, Minnesota, Pope County, Prairie-Woodland Trail, Glacial Lakes State Park, gregarious, among leaf litter, Quercus, Tilia, 13 Sept 2019, D.J. McLaughlin, holotype DJM2195 (MIN), GenBank ITS MZ663795; 13 Sept 2019, D.J. McLaughlin, paratype, DJM2194 (MIN), GenBank ITS MZ663796.
Etymology: Named for the yellowish brown coloration of the pileus.

Diagnosis: Medium-sized basidiomata; pileus light grayish yellow brown to yellowish brown mature; lamellae light yellowish to light yellowish brown; stipe white to very pale orange yellow; veil slightly yellowish, basidiospores av. $9 \times 6 \mu \mathrm{m}$, mostly ellipsoid, less commonly broadly ellipsoid, rarely subgloboid, moderately to coarsely verrucose.

Description: Pileus 32-70 mm diam, convex, becoming broadly subumbonate then plane, subviscid to dry, glabrous, margin floccose, smooth, at first disc light yellowish brown, toward margin light grayish yellow brown to pale grayish then whitish, disc becoming moderate orange yellow, towards margin becoming light grayish yellow brown. Odor faint to slightly fragrant. Taste mild to slightly raphanoid. Lamellae adnexed to uncinate, crowded, light yellowish brown to yellowish brown then brownish orange, edges even, concolorous. Stipe 36-62 mm long, above 5-12 mm thick, base up to 10-12 mm thick, base slightly enlarged or subbulbous to bulbous, surface white overall, becoming very pale orange yellow below, dry, longitudinally fibrillose to longitudinally striate, base subtomentose, apical veil zone becoming strong yellowish brown from spores. Context of pileus firm to soft, light grayish yellowish brown to pale orange yellow, of stipe pale orange yellow in cortex, light yellowish brown within.

Basidiospores $8-10 \times 5.5-6.5(-7) \mu \mathrm{m}$, av. $9 \times 6 \mu \mathrm{m}$, $\mathrm{Q}=1.4-1.8$, av. $\mathrm{Q}=1.6$, mostly ellipsoid to broadly ellipsoid, rarely subgloboid, moderately to coarsely verrucose, nondextrinoid to slightly dextrinoid. Basidia 4-spored, $29-33.5 \times 8-10 \mu \mathrm{m}$, colorless or yellowish. Pileipellis duplex: epicutis moderately developed, hyphae \pm radially arranged, interwoven, cylindrical, $2.5-9(-10) \mu \mathrm{m}$ wide, colorless or yellowish, walls \pm refractive, colorless to yellowish, smooth to faintly encrusted; hypocutis moderately developed, hyphae interwoven, \pm radially arranged, cylindrical, broadly cylindrical or enlarged, 9-18(-21.5) $\mu \mathrm{m}$ wide, colorless to yellowish, walls colorless, smooth. Clamp connections present.

Ecology and distribution: Known from midwestern North America in broadleaf forests with Quercus and Tilia.

Comments: The distinguishing characteristics of $C$. ochraceodiscus are the strong ochraceous coloration of the mature pileus (younger pilei have grayish to whitish colors on the margin), the rather large, mostly ellipsoid, distinctly verrucose basidiospores and its association with broadleaf deciduous trees. Phylogenetically, C. ochraceodiscus belongs to the /albidipes clade in which it constitutes the sister clade of $C$. kranabetteri, but without statistical support. The two species differ from each other in the ITS region by 8 substitution and indel positions with a similarity of $98.7 \%$. 
Other specimen examined: USA, Minnesota, Pope County, Prairie-Woodland Trail, Glacial Lakes State Park, gregarious, leaf litter, Quercus, Tilia, Fraxinus, 13 Sept 2019, coll. D.J. McLaughlin, DJM2194 (paratype) (MIN).

Cortinarius perrotensis A. Paul, Matheny \& Lebeuf, sp. nov.Figs. 7B and 10I

MycoBank: MB 840674

Typification: Canada, Québec, Montérégie County, Île Perrot, Quercus rubra, Pinus strobus, Tsuga canadensis, 6 Oct 2015, R. Lebeuf (holotype HRL2221 (DAOM 984,882), isotype TENN071126). GenBank ITS: KX897405.

Etymology: Named for île Perrot, Québec, Canada.

Diagnosis: Basidiomata medium to large; pileus with pale brown, grey brown and ochraceous coloration; lamellae and stipe apex violaceous at first; veil white to whitish; basidiospores av. $7.5 \times 6 \mu \mathrm{m}$, subgloboid to broadly ellipsoid, moderately to coarsely verrucose.

Description: Pileus 24-40 mm diam., convex then campanulate, margin inrolled at first, surface finely fibrillosesilky, pale brown, pale grayish brown on the margin, pale ochraceous on the disk, slightly viscid, drying rapidly. Lamellae adnate, close, violaceus at first, then pale brown. Context ochraceous white, violaceus in apex of the stipe, but paler with age. Stipe $42-66 \mathrm{~mm}$ long, 6-8 $\mathrm{mm}$ thick above, 10-20 mm thick at base, clavate, surface fibrillose, violaceus at first then whitish, silky, veil white to whitish. Odor of lamellae not distinctive but pleasant.

Basidiospores $6.5-8(-8.5) \times 5.5-6.5(-7) \mu \mathrm{m}$, av. $7.5 \times 6 \mu \mathrm{m}, \mathrm{Q}=1.15-1.4$, av. $\mathrm{Q}=1.25$, subgloboid to broadly ellipsoid, moderately to coarsely verrucose, moderately dextrinoid. Basidia 4-spored, 36-39 $\times 8-10 \mu \mathrm{m}$, clavate, colorless, some with refractive granules or yellowish pigment. Lamella trama hyphae colorless or occasionally with yellow contents, smooth or slightly encrusted. Pileipellis duplex: epicutis moderately developed, hyphae radially arranged, interwoven to entangled, cylindrical, $4.5-11.5 \mu \mathrm{m}$, colorless or yellow pigmented, walls \pm refractive, colorless to yellowish, smooth or slightly encrusted; hypocutis well developed, \pm cellular in places, hyphae otherwise interwoven, \pm radially arranged, cylindrical to enlarged, 7.5-18.5(-22.5) $\mu \mathrm{m}$, colorless to yellowish, wall refractive, colorless to yellowish, smooth or somewhat encrusted. Clamp connections present.

Ecology and distribution: Known only from the type locality in southern Quebec in broadleaf-conifer forests of Pinus, Quercus and Tsuga.

Comments: Cortinarius perrotensis is a rather lightcolored species, with violaceous colors primarily in the young lamellae and stipe apex, a white to pale veil, and small basidiospores (av. $7.5 \times 6 \mu \mathrm{m}$ ), similar in size to those of $C$. kranabetteri. Phylogenetically, it is placed in the /albidipes clade with $C$. albidipes, $C$. kranabetteri, $C$. tetonensis, C. huddartensis, $C$. sp5 and C. lividomalvaceus and $C$. pelerinii from Europe. The most closely related species is C. kranabetteri from which it differs by 6 substitution and indel positions, with a similarity of $99 \%$.

Cortinarius perviolaceus Murrill [as 'Cortinaria perviolacea'], Lloydia 8: 283 (1946) Figs. 7C and 10J

MycoBank: MB 505128

Type: USA, Florida, Alachua County, Gainesville, mixed woods, 24 Sept 1944, W. A. Murrill (holotype F32992 (FLAS)). GenBank ITS: MZ580438.

Description: Pileus 8-22 mm diam., obtuse to hemispheric, shiny, with a silvery violet sheen in places, edge whitish silky fibrillose, minutely fibrillose scaly in places, color dark purple violet to bluish violet mixed with vinaceous brown, disc becoming somewhat ochraceous to brownish in age. Lamellae close to subdistant, violet to gray violet becoming dull light brown (or slightly greyish) mature, dull brown in age. Stipe $21-43 \mathrm{~mm}$ long, apex $1.5-3 \mathrm{~mm}$ diam, base 4-6 mm diam, enlarged, narrowly clavate, surface silvery violet with dark violet streaks or silvery violet on upper half and watery brownish below, veil scant, at first leaving slight ochraceous to yellowish buff zones, in places developing brownish to reddish tints mature, sometimes with white basal mycelium. Context violet to silvery violet when fresh, becoming watery gray brown (dull brownish) in pileus, in upper stipe violet with pale white line at surface, below pale watery brown to watery grey in age. Odor of context raphanoid, pungent or fungoid, taste raphanoid to fungoid.

Basidiospores 6.6-7.5 $\times 6-6.5 \mu \mathrm{m}$, av. $7.2 \times 6.3 \mu \mathrm{m}$, $\mathrm{Q}=1.1-1.3$, av. $\mathrm{Q}=1.25$, subgloboid, less commonly broadly ellipsoid, \pm coarsely verrucose, non-dextrinoid to slightly dextrinoid. Basidia 4-spored, 25-31×7.5-8.9 $\mu \mathrm{m}$, clavate, colorless or yellowish. Lamella trama hyphae smooth to slightly encrusted. Pileipellis duplex: epicutis thinly to \pm well developed, hyphae radially arranged, \pm interwoven, cylindrical, (2.5) 5-11 (13) $\mu \mathrm{m}$ wide, colorless or yellow to ochraceous, smooth or encrusted; hypocutis distinct, hyphae radially oriented, \pm interwoven, cylindrical to enlarged, 9.5-25 $\mu \mathrm{m}$ wide, colorless or yellowish, smooth to slightly encrusted. Clamp connections present.

Ecology and distribution: In broadleaf and broadleafconifer forests. Known from Florida, Georgia, Massachusetts, New Hampshire, New York, and Tennessee.

Comments: Cortinarius perviolaceus is a rather small, \pm entirely purple to bluish species with small mostly subgloboid basidiospores. Our description fits very well with the type description of W. A. Murrill. We gained only ITS1 from the holotype. Genetically, this is the most isolated species in this study with almost 5\% dissimilarity (30 changes) to the closest species, and it occupies a singleton position in 
Fig. 8 Basidiomata of $\mathbf{A} C$. rarus (DBB04712, holotype); B C. rarus (ADP-140531-1); C C. tabularis (DB6069); D C. tabularis (DB6089). Photos A: D. Bojantchev, B: A.D. Parker, C and D: B. Dima
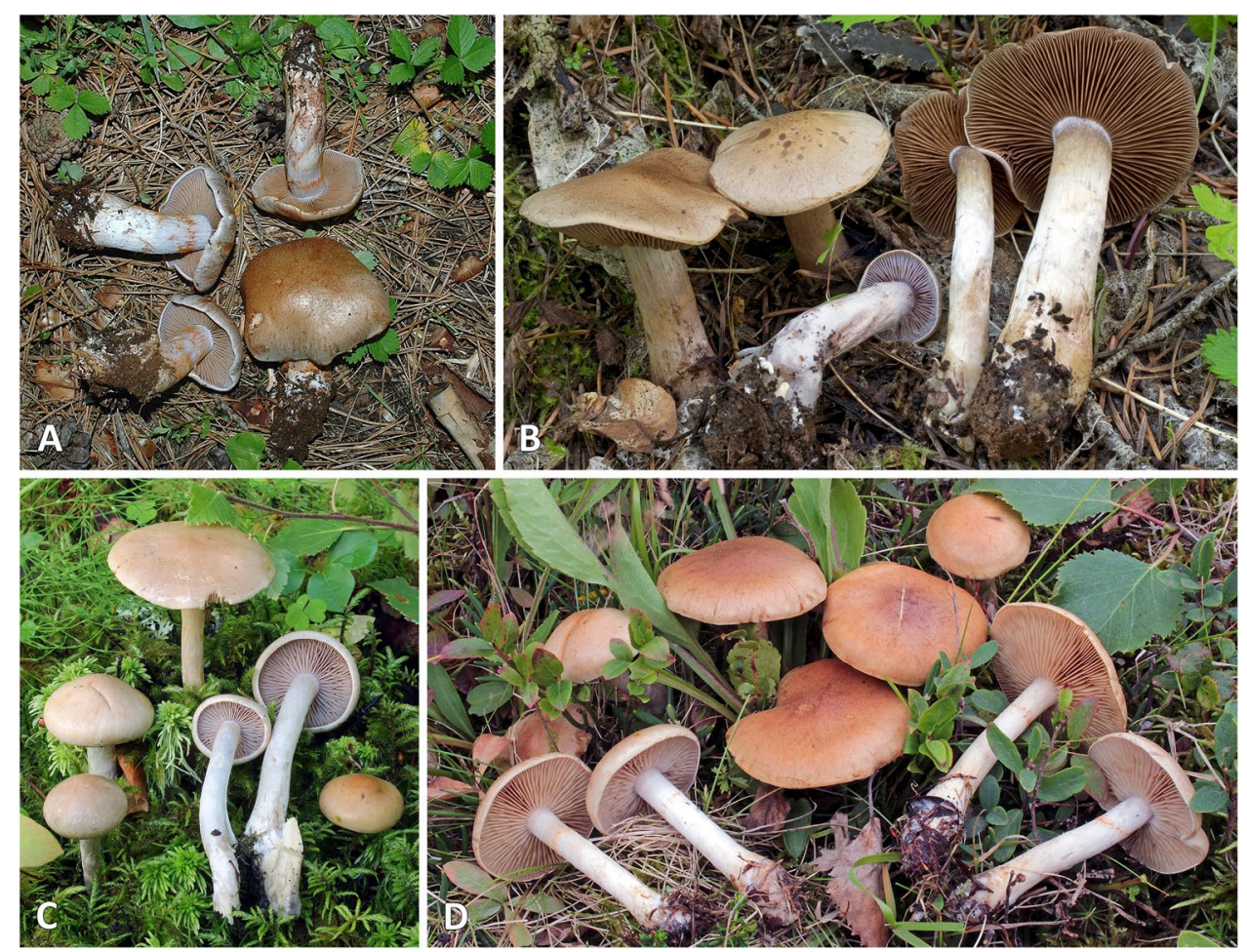

our phylogenetic tree (Fig. 2). The closest species seems to be $C$. huddartensis from which it differs by 30 substitution and indel positions, with a similarity of $95.2 \%$.

Other specimens examined: USA, Florida, Alachua County, Owens-Illinois Park, Newnans Lake, Quercus, 10 Aug 1985, coll. J. Gibson, JFA9124 (WTU); loc. cit., Quercus, Pinus, 11 Aug 1985, coll. M. Castellano, S. Miller, JFA9128 (WTU) \& JFA9132 (WTU). Georgia, Mackon County, Ellicot Rock Trail, Quercus, Tsuga, Pinus, Carpinus, 10 Aug 1996, coll. I. Krisai-Greilhuber, IK7247 (WU-Myc 44566). Massachusetts, Franklin County, Gale Road, Arthur Iversen Conservation Area, Warwick, 13 Aug 2017, coll. S. Adams, 061 (WTU). Newton, Cold Spring Park, Tsuga, Betula, Quercus, L. G. Nagy, 13 Sept 2012, NL-5173 (BP). New Hampshire, Carroll County, Bartlett, isolate 3Bart56R (GenBank ITS: HQ022110). New York, Onondaga County, Syracuse, Castanea dentata, isolate FN05_2 (GenBank ITS: KU878589). Tennessee, Blount County, Cades Cove, Quercus, Tsuga, Pinus, 9 Sept 2004, coll. J. F. Ammirati, JFA13070 (TENN).

Cortinarius rarus Bojantchev, Ammirati, Parker, Liimat., Niskanen \& Dima, sp. nov. Figs. 8A-B and 10L-M

MycoBank: MB 840675.

Typification: USA, California, El Dorado County, Ice House Reservoir Wilderness, Pinus ponderosa, Abies concolor, A. magnifica, Pseudotsuga menziesii, 26 May
2007, D. B. Bojantchev (holotype DBB04712 (pers. herb.), isotype (WTU)). Genbank ITS: MZ663800.

Etymology: From Latin: "rarus" meaning rare, scarce.

Diagnosis: Basidiomata rather large and robust; pileus, lamellae and stipe with strong grayish blue to bluish colors; universal veil and cortina white; basidiospores rather large, av. $8.5 \times 6.5 \mu \mathrm{m}$, subgloboid to broadly ellipsoid or ellipsoid, coarsely to very coarsely verrucose.

Description: Pileus 40-90 mm diam., convex to planoconvex, margin involute, frequently upturned in age, undulating, surface smooth to silky, appressed fibrillose, slightly gelatinous when moist, not hygrophanous, grayish blue at first, darker tan towards the disk, turning darker tan to ochraceous, remaining bluish towards the margin. Lamellae sinuate, close to moderately crowded, $4-12 \mathrm{~mm}$ broad, violaceous gray to grayish blue at first then pale clay, turning rusty brown with maturity edges slightly crenate, concolor. Stipe $60-120 \mathrm{~mm}$ long, 20-30 mm wide, subclavate to bulbous, fibrillose to silky at the apex, grayish blue overall, white with bluish at the apex or white overall, discoloring tan to reddish brown, with a distinct annular zone, universal veil white, partially covering the lower stipe, cortina whitish. Context in pileus whitish to bluish or violaceous gray, with some pale reddish brown discolorations, in stipe pale violaceous gray above and pale reddish brown colors toward the base. Odor of lamellae and/or context not distinctive or pleasant, taste mild. 
Fig. 9 Basidiospores of A Cortinarius albidipes (JFA12420); B C.

albidoavellaneus (holotype);

C C. albocyaneus (holotype of C. copakensis); D C. anomalodelicatus (JFA8146); E C. anomalomontanus (JFA9919); F $C$. anomalopacificus (DBB11745); G C. anomalovelatus (JFA13471); H C. anomalus (EH198); I C. barlowensis (JFA13470); J $C$. brevissimus (holotype); K $C$. caeruleoanomalus (JFA13084); L C. caesiifolius (JFA11520); M C. caninus (JFA12434); N C. clackamasensis (JFA11616); O C. clintonianus (MCBS-263b). Photos: J.F. Ammirati. Scale bars: $10 \mu \mathrm{m}$

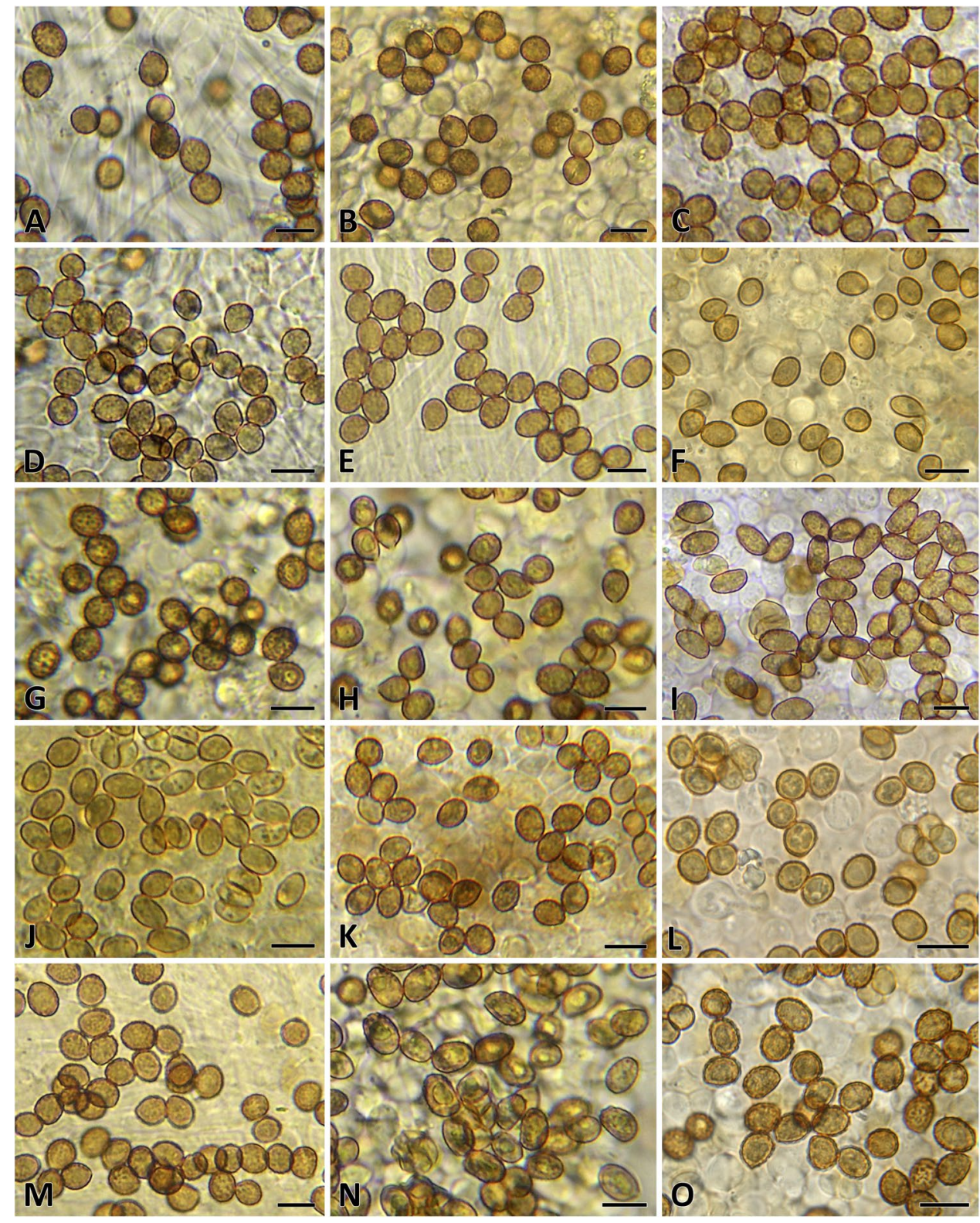

Basidiospores $8-9(-10.5) \times(6-) 6.5-7 \mu \mathrm{m}$, av. $8.5 \times 6.5 \mu \mathrm{m}, \mathrm{Q}=1.2-1.4$ (1.55), av. $\mathrm{Q}=1.3$, subgloboid to broadly ellipsoid or ellipsoid, distinctly, coarsely to very coarsely verrucose, \pm moderately dextrinoid. Basidia 24-40×6-10 $\mu \mathrm{m}, 4$-spored, narrowly clavate to clavate, colorless, with refractive granules, often with yellow to ochraceous contents. Lamella trama hyphae colorless, smooth or slightly encrusted. Pileipellis duplex: epicutis well developed, hyphae interwoven to entangled, \pm radially arranged, cylindrical, 5-9 $\mu \mathrm{m}$ wide, colorless or with considerable yellow pigmented, smooth or encrusted; hypocutis well to moderately developed, hyphae cylindrical to enlarged, 7-15 $\mu \mathrm{m}$ wide, colorless to yellowish, walls \pm refractive, smooth or slight encrusted. Clamp connections present.
Ecology and distribution: Infrequent, vernal species in mountain conifer forests of Abies, Pseudotsuga, Tsuga, and/or Pinus, sometimes mixed with Quercus. Known from California, Oregon, and Washington.

Comments: Cortinarius rarus is rare but widespread, known from numerous collections. It is a rather robust representative of sect. Anomali. Its most distinctive features are the somewhat larger spores, the persistent bluish coloration, the white veil, and its occurrence in the spring season. Phylogenetically, it is a singleton species based on our current knowledge. The most closely related species is the European $C$. pelerinii from which it differs by 16 substitution and indel positions, with a similarity of $97.6 \%$.

Other specimens examined. USA, California, Shasta County, 5 mi. east of McCloud, Pseudotsuga, Abies 
Fig. 10 Basidiospores of A Cortinarius deceptivus (holotype); B C. harvardensis (MQ17058); C C.

huddartensis (holotype); D C. kranabetteri (TN11-287); E C latiodistributus (JFA13487);

F C. modestus (MQ17272); G C. nettieae (JFA8747); H C. ochraceodiscus (DJM2195, holotype); I C. perrotensis (HRL2221, holotype); J C. perviolaceus (JFA13070); K C. albomalus (HRL2777); L-M $C$. rarus (DBB04712, holotype); N C. tabularis (TRTC156541); O C. tetonensis (JFA10350, holotype). Photos: J.F. Ammirati. Scale bars: $10 \mu \mathrm{m}$
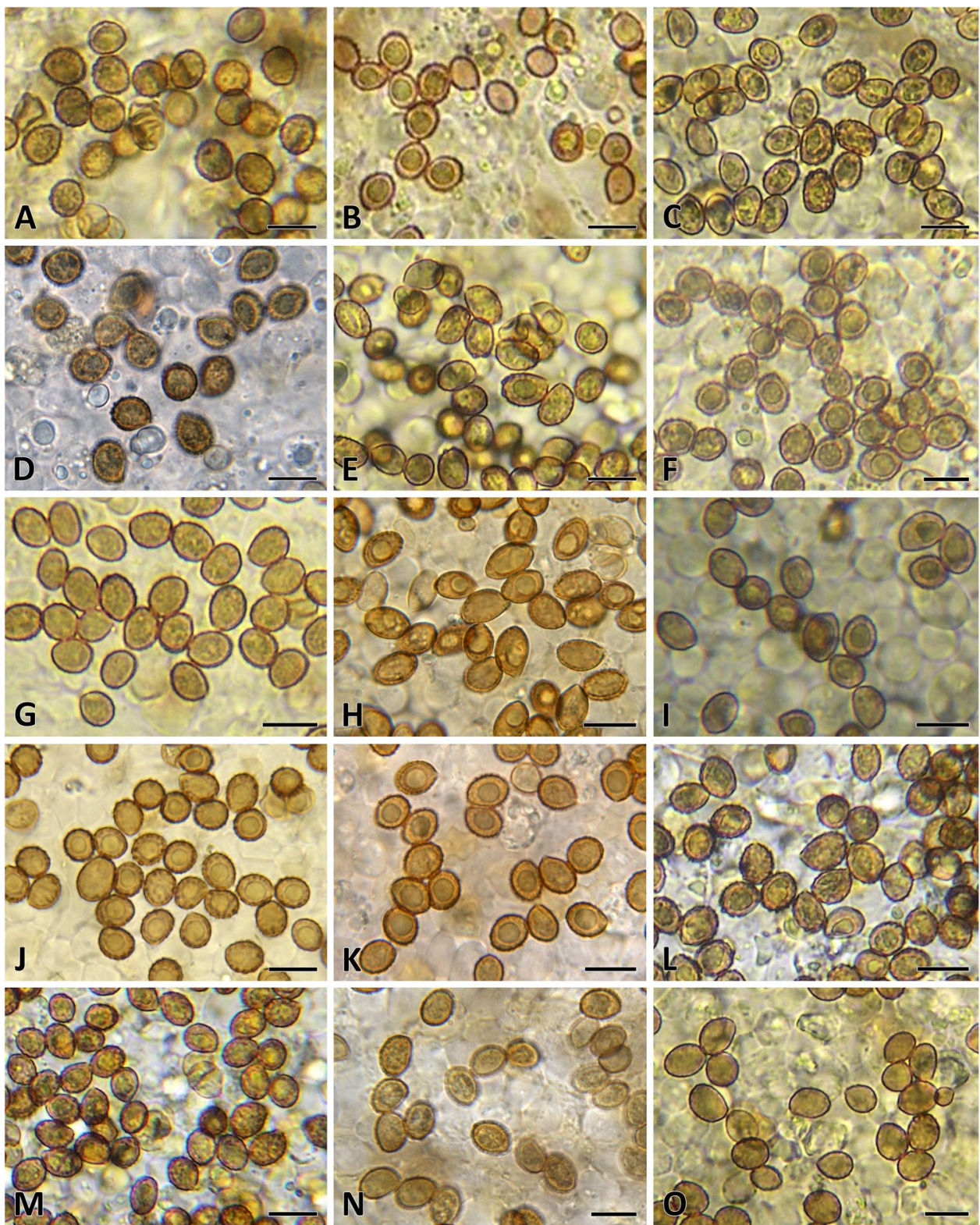

concolor, Tsuga, Pinus, Calocedrus, Quercus kellogii, 3 May 2014, coll. J. L. Frank, JLF3304 (pers. herb.) (GenBank ITS: MF135162, as C. cf. alboviolaceus). Oregon, Jackson County, 5 Jun 2020, coll. J. L. Frank, JFL8707 (pers. herb.) (GenBank ITS: MW341328, as Cortinarius sp.), 19 Jun 2020, coll. J. L. Frank, JLF8771 (pers. herb.) (GenBank ITS: MW341331, as Cortinarius sp.). Washington, Pend Oreille County, Red Bluff Trail North of Sullivan Lake Road, Pseudotsuga, Abies grandis, 31 May 2014, coll. A. D. Parker, ADP-140531-1 (WTU).

Cortinarius tabularis (Fr.) Fr., Epicr. syst. mycol. (Upsaliae): 284 (1838) [1836-1838], Figs. 8C-D and 10N MycoBank: MB151067.
Type: Sweden, Ångermanland, Säbrå sn, Överdal, under Betula, 5 Aug 1990, T. E. Brandrud et al. (epitype CFP949 (S) designated in Dima et al. 2016). GenBank ITS: KX302275.

Description: Pileus $20-110 \mathrm{~mm}$ diam., at first rounded, then convex to plano-convex, sometimes with a broad umbo, later sometimes depressed at center and wrinkled, finely radially hygrophanous striate fresh, margin persistently incurved, surface slightly viscid when young, later somewhat shiny at margin, seldom with fibrous veil remnants, light clay grayish yellow to reddish tawny, sometimes lighter grayish ochraceous at margin. Lamellae moderately crowded to crowded, light grayish blue to beige or grayish brown, sometime darkening on handling, edges even, 
somewhat lighter in color. Stipe 40-120 mm long, 4-15 mm thick above, equal to somewhat clavate at the base, somewhat shiny, white, sometimes bluish at the apex, grayish yellow with age, universal veil usually sparse, thin, somewhat glossy, milk white to light yellow, flocculose or forming a weak girdle on the stipe. Context solid, fragile, white with small hygrophanous spots, bluish in stipe apex, weakly yellowish with age. Odor of lamellae and/or context weak, somewhat raphanoid.

Basidiospores 7.5-8.5 (9) $\times(5)$ 5.5-6.5 (7) $\mu \mathrm{m}$, av. $8 \times 6 \mu \mathrm{m}$, $\mathrm{Q}=1.2-1.4$, av. $\mathrm{Q}=1.3$, broadly ellipsoid to subgloboid, slightly or moderately verrucose, non-dextrinoid. Basidia 4-spored, clavate, colorless to yellowish. Lamella trama hyphae colorless, smooth. Pileipellis duplex; epicutis well developed, hyphae entangled to interwoven, radially arranged, (3) 5-8 $\mu \mathrm{m}$ wide, cylindrical, colorless or pigmented, smooth or somewhat encrusted; hypocutis well developed, hyphae (10) 15-25 (30) $\mu \mathrm{m}$ thick, enlarged, \pm cellular, colorless or pigmented, walls pigmented. Clamp connections present.

Ecology and distribution: Known from boreal, subalpine, and temperate forests and alpine habitats. Found with broadleaf and mixed conifer-broadleaf forests including Picea, Betula, Alnus, Salix, Quercus, and Fagus. Widespread in Europe and in North America from northern Quebec and Alaska.

Comments: The descriptive data presented here is adapted from Dima et al. (2016). Cortinarius tabularis is characterized by its clay grayish pileus that becomes more brownish overall in age, whitish stipe usually with a sparse veil and broadly ellipsoid basidiospores. Phylogenetically, it belongs to the /tabularis clade with C. nettieae, C. anomalopacificus, Cortinarius sp6, and C. brevissimus. The most closely related species is Cortinarius sp6 from which it differs by 6 substitution and indel positions, with a similarity of $99 \%$.

Other specimens examined: Canada, Québec, Jamésie, Radisson, 14 Sept 2007, coll. B. T. M. Dentinger, D. Dewsbury, QC-07-82, TRTC156541, and QC-07-85, TRTC156544. Finland, Pohjois-Karjala, Kitee, Puhos, Suvannonkangas, lake Pyhäjärvi, mesic mixed forest with Betula, Picea abies, Pinus sylvestris, 12 Sept 2006, K. Liimatainen, T. Niskanen, TN06-099, H6029427 (H) (GenBank ITS: KX302269). USA, Alaska, Fairbanks, University of Alaska summer trails, old, mossy Picea dominated forest some Betula, Alnus, and some Populus, 23 Aug 2011, K. Liimatainen, T. Niskanen, TN11-219 (H).

Cortinarius tetonensis Ammirati, Liimat., Niskanen \& Dima, sp. nov. Fig. 100

MycoBank: MB 840676

Typification: USA, Wyoming, Teton County, Flagstaff Road, Picea, Abies, Pinus, 1 Sept 1991, J. F. Ammirati (holotype JFA10350 (WTU)). GenBank ITS: MZ580436.

Etymology: Name is taken from the Teton Mountains.
Diagnosis: Basidiomata rather large; pileus pale grayish vinaceous to light buff developing strong brown colors; lamellae grayish to grayish brown; stipe whitish to pallid then brownish; veil white to brownish cream buff; basidiospores av. $8.4 \times 6.8 \mu \mathrm{m}$, broadly ellipsoid to subgloboid, moderately to more coarsely verrucose.

Description: Pileus 46-90 mm diam. expanded, obtusely convex, broadly obtuse to broadly convex, plane to uplifted, disc broadly rounded to subumbonate, margin incurved, undulate to uplifted in age, edge inrolled, surface dry, edge with pale veil patches, disc tomentose fibrillose, margin innately fibrillose or with minute tomentose patches, radially streaked, margin pale grayish vinaceous, pale buff or light cream buff with some brownish tones, inner margin more brownish - light brownish cinnamon buff, light dull clay color, light medium brown, with some darker brown streaks, disc brownish clay color or brown with gray tones, then darker brown. Lamellae emarginated, close to subdistant, grayish brown to medium gray brown becoming more brownish in age but retaining a grayish cast, eventually rich medium brown, at pileus edge occasionally somewhat lilac, becoming stained and spotted dark reddish brown, edges \pm uneven, paler or concolorous with faces. Stipe 48-80 mm long, apex 10-22 mm thick, base 18-22 mm thick, clavate to bulbous or only slightly enlarged below, sometimes tapered downward or pinched off, above fibrillose, whitish to pallid discoloring brownish, veil sheath-like or in bands, sometimes thinly developed, sometimes ending in a distinct zone above, white, cream buff, brownish cream buff or chamois, basal mycelium white. Context in pileus solid, firm, pallid to whitish, in stipe solid, stuffed, gray avellaneous or pale with watery vinaceous buff streaks in cortex above, becoming watery brown, in lower stipe watery brown, discoloring ochraceous to brownish overall in age, sometimes fading to white throughout. Odor of lamellae and/or context agaricoid to raphanoid, taste of context raphanoid.

Basidiospores (6.5-)8-9.5 $\times(5.5-) 6.5-7.5 \mu \mathrm{m}$, av. $8.4 \times 6.8 \mu \mathrm{m}, \mathrm{Q}=(1.1) 1.2-1.3$, av. $\mathrm{Q}=1.25$, broadly ellipsoid to subgloboid, moderately to more coarsely verrucose, slightly dextrinoid. Basidia 4-spored, 38-42×9-11 $\mu \mathrm{m}$, clavate, colorless to yellowish, often with refractive particles. Lamella trama hyphae smooth. Pileipellis duplex: epicutis well developed, hyphae interwoven to strongly interwoven, radially oriented, $3-10 \mu \mathrm{m}$ wide, \pm cylindrical, colorless or yellow to grayish, wall refractive, \pm thickened, smooth to slightly encrusted; hypocutis \pm well developed, hyphae interwoven, \pm radially arranged, $7.5-24 \mu \mathrm{m}$, cylindrical to enlarged, colorless to yellowish, smooth, walls \pm refractive.

Ecology and distribution: Scattered to gregarious in moist soil and litter, subalpine conifer forest of Picea, Abies, and 
Pinus. It is known from Wyoming, Alaska, and collections associated with Dryas in Svalbard (Norway).

Comments: Cortinarius tetonensis is a widespread species for which we need additional morphological information. There are no color photos of the basidiomata. It is a brownish to grayish species with little violaceous color and whitish to cream buff veil bands on the stipe. Basidiospores are relatively large, av. $8.4 \times 6.8 \mu \mathrm{m}$, often broadly ellipsoid and moderately to more coarsely verrucose. Cortinarius tetonensis is a member of the /albidipes clade with the European C. lividomalvaceus and C. pelerinii, as well as $C$. albidipes, C. huddartensis, C. kranabetteri, C. perrotensis, and $C$. sp5. The most closely related species is the European C. lividomalvaceus from which it differs by 17 substitution and indel positions, with a similarity of $97.3 \%$.

Other specimens examined: Norway, Svalbard, Dryas, M. F. M. Bjorbaekmo et al., 36_N343 (GenBank ITS: HQ445618, as Cortinarius cf. alpinus). USA, Alaska, J. Geml et al., strain ME12-B10 (GenBank ITS: JX436875); loc. cit. J. Geml et al., strain ME12-B4 (GenBank ITS: JX436874); loc. cit., J. Geml et al., strain ME12-D3 (GenBank ITS: JX436876). Wyoming. Teton County. Flagstaff Road, Picea, Abies, Pinus, 1 Sept 1991, coll. J. F. Ammirati, JFA10349 (GenBank ITS: U56024).

\section{Key to the North American species of Anomali}

A large number of species have overlapping morphological and microscopical characteristics, as well as patterns of distribution and ecology, and many will require sequencing the ITS regions to confirm identification. However, the taxonomic key provided below is useful for identifying species using characterisitics of the pileus, stipe and lamellae, the universal veil, the basidiospores, and known distributions and ecology, including host plants. Note that often diagnostic characteristics of species do not only represent phylogenetic clades but often reflect the convergence of similar looking species from different genetic backgrounds. A most important caution relates to the known distributions of species. Our sample size for North America is not sufficient to be certain of the full distributions, and morphological and ecological characteristics of species studied to date. Based on our work, there are several potentially undescribed species in North America.

1 Occurring in conifer forests .......................... 2

$1 *$ Occurring with broadleaf or broadleaf-conifer forests

.................................................. 15

2 Basidiospores av. $9.5 \mu \mathrm{m}$ or more in length ........... 3

$2 *$ Basidiospores av. $8.5 \mu \mathrm{m}$ or less in length .............. 5

3 Basidiomata \pm robust; pileus grayish blue to tan; stipe and lamellae grayish blue; basidiospores av. $9.5 \times 7 \mu \mathrm{m}$, subgloboid, broadly ellipsoid, ellipsoid; spring season; western North America ....................... C. rarus $3^{*}$ Not with the above combination of characteristics ..... 4 4 Pileus gray vinaceous to purple gray then brownish, \pm hygrophanous; lamellae light bluish lavender; stipe blue lavender to blue gray; basidiospores av. $10.8 \times 6.5 \mu \mathrm{m}$, ellipsoid, broadly ellipsoid; western mountains ..........C. barlowensis 4* Pileus gray brown or vinaceous brown to purple brown, \pm hygrophanous; lamellae grayish brown to light brown; stipe white to brownish; basidiospores av. $9.7 \times 6.5 \mu \mathrm{m}$, ellipsoid, broadly ellipsoid, rarely subgloboid; western North America ..................... C. clackamasensis 5 Basidiospores av. 7-7.5 $\mu \mathrm{m}$ long .........................6 $5^{*}$ Basidiospores av. $8-8.5 \mu \mathrm{m}$ long ................. 8 6 Pileus grayish lilac to vinaceous brown or reddish brown; lamellae dull violet; stipe lilac to gray with slight buff veil zones; basidiospores av. $7.5 \times 6 \mu \mathrm{m}$, subgloboid, broadly ellipsoid; northern conifer forests; across North America .................. C. clintonianus $6^{*}$ Not with the above combination of features; basidiospores smaller . .7 7 Pileus cinnamon buff to vinaceous brown or reddish brown; lamellae pale lilac to grayish lilac; stipe pale violet to whitish, with distinct, yellow to ochraceous veil bands; basidiospores av. $7 \times 5.5 \mu \mathrm{m}$, subgloboid, broadly ellipsoid; western North America ................. C. caesiifolius $7^{*}$ Pileus yellowish gray to brownish gray; lamellae light bluish gray; stipe whitish with bluish apex; veil pale ochraceous; basidiospores av. $7 \times 6 \mu \mathrm{m}$, subgloboid, broadly ellipsoid; conifer forests, sometimes mixed with Populus; western North America .......... C. kranabetteri 8 Pileus grayish lavender to grayish blue; lamellae grayish violet blue; stipe lilac violet to vinaceous; veil leaving distinct white to buff floccose veil zones on stipe and patches on pileus margin; basidiospores av. $8.5 \times 6.7 \mu \mathrm{m}$, subgloboid, broadly ellipsoid; western North America ...........C. anomalovelatus 8* Pileus, lamellae, and stipe may be similarly colored, but veil not leaving distinct floccose zones on the stipe or patches on the pileus ................................................ 9 9 Pileus grayish lilac to grayish vinaceous brown; lamellae grayish purple; stipe rather slender, 4-6 mm thick above, apex lilac; stipe with thin, buff to yellowish veil zones and patches; basidiospores av. $8.5 \times 6.7 \mu \mathrm{m}$, broadly ellipsoid, ellipsoid, subgloboid; western North America C. anomalodelicatus

$9^{*}$ Not with the above combination of characteristics ..... 10 10 Pileus grayish blue violet to lavender, \pm hygrophanous; lamellae deep blue to lavender; stipe bluish; veil yellowish; basidiospores av. $8.5 \times 6.7$, subgloboid to broadly ellipsoid; northeastern North America ..................... C. deceptivus $10^{*}$ Not with the above combination of characteristics .......... 11 11 Pileus grayish lilac to brown; lamellae grayish violet to vinaceous lavender; stipe violaceous; veil cream buff, some- 
times indistinct; basidiospores av. $8.5 \times 7 \mu \mathrm{m}$, subgloboid, broadly ellipsoid; across North America ............ C. caninus $11 *$ Not with the above combination of characteristics .........12 12 Pileus pale brown to pale vinaceous brown then darker brown, not hygrophanous; lamellae grayish brown to brown; stipe whitish to pallid; veil white to buff or more ochraceous; basidiospores av. $8.5 \times 7 \mu \mathrm{m}$, broadly ellipsoid to subgloboid; western North America ........C. tetonensis $12^{*}$ Not with the above combination of characteristics ..... 13 13 Pileus grayish brown becoming yellowish to more brownish, somewhat hygrophanous; lamellae light grayish lilac; stipe pale lilac to grayish lilac; veil pale ochraceous; basidiospores av. 8.2 $\times 6.5 \mu \mathrm{m}$, subgloboid, broadly ellipsoid, ellipsoid; western North America .... C. anomalomontanus $13^{*}$ Not with the above combination of characteristics ......14 14 Pileus slightly lavender to grayish soon more brown, not hygrophanous; lamellae violet to lavender vinaceous; stipe white to violet; veil thin, buff; basidiospores av. $8 \times 6.3 \mu \mathrm{m}$, ellipsoid, broadly ellipsoid or subgloboid; western to northeastern North America ......... C. nettieae $14 *$ Pileus gray brown to violaceous brown, \pm hygrophanous; lamellae dull violet to gray violet; stipe light blue lavender; veil ochraceous; basidiospores av. $8 \times 6 \mu \mathrm{m}$, broadly ellipsoid to ellipsoid; western North America C. latiodistributus

15 Species occurring in western North America ........ 16 $15^{*}$ Species occurring in eastern North America ........ 21 16 Pileus lilac tan to gray vinaceous; lamellae light bluish to grayish lavender; stipe pale tan with bluish apex; veil white to pale buff; basidiospores av. $6.7 \times 5.5 \mu \mathrm{m}$, subgloboid, broadly ellipsoid; broadleaf-conifer forests with Notholithocarpus...................... C. anomalopacificus 16* Basidiospores significantly larger; associated with broadleaf trees, shrubs and subshrubs (Salix, Dryas), conifers may be present .......................................... 17 17 Pileus pale brown to pale vinaceous brown then darker brown; lamellae grayish brown to brown; stipe whitish to pallid; veil white to buff or more ochraceous; basidiospores av. $8.5 \times 7 \mu \mathrm{m}$, broadly ellipsoid, subgloboid; with Dryas (also in Svalbard, Norway) ............ C. tetonensis $17^{*}$ Not with the above combination of characteristics .......18 18 Basidiospore length av. $8 \mu \mathrm{m}$..............................19 $18^{*}$ Basidiospore length av. $9 \mu \mathrm{m}$...................... 20 19 Pileus light clay grayish yellow to reddish tawny, \pm hygrophanous; lamellae light grayish blue to grayish brown; stipe bluish to white; veil sparse, white to light yellow; basidiospores av. $8 \times 6 \mu \mathrm{m}$, broadly ellipsoid, subgloboid; broadleaf, broadleaf-conifer forests, across North America C. tabularis 19* Pileus yellowish gray to brownish gray; lamellae light bluish gray; stipe whitish with bluish apex; veil pale ochraceous; basidiospores av. $8 \times 6.4 \mu \mathrm{m}$, subgloboid, broadly ellipsoid; with Populus and conifers C. kranabetteri
20 Pileus pale silvery gray to vinaceous brown; lamellae pale violet to pale gray blue; stipe violet to gray lilac; veil pale buff to pale ochraceous; basidiospores av. $9 \times 7.5 \mu \mathrm{m}$, broadly ellipsoid, subgloboid; broadleaf, broadleaf-conifer forests; northeastern and western North America .............. C. albidipes $20 *$ Pileus pale lavender to pale pinkish tan; lamellae pale lavender; stipe bluish above to white below; veil white; basidiospores av. $9 \times 6 \mu \mathrm{m}$, broadly ellipsoid to ellipsoid; broadleaf forests with Quercus; western North America, coastal to Sierra Foothills ................. C. huddartensis 21 Basidiospores av. $\leq 8 \mu \mathrm{m}$ in length .................. 22 $21 *$ Basidiospores av. $\geq 9$ in length .................... 30 22 Pileus color distinctly violaceous, purplish or bluish ......... 23 $22 *$ Pileus color variable, sometimes with slight violaceous or bluish tones, but mostly dominated by dingy white, yellowish, grayish, grayish brown, brownish, reddish brown, vinaceous brown colors .................... 27 23 Basidiomata rather small; pileus dark purple violet to bluish lavender; lamellae violet to gray violet; stipe purple violet to lilac; veil slight, ochraceous to yellowish; basidiospores av. $7.2 \times 6.3 \mu \mathrm{m}$, subgloboid, broadly ellipsoid; broadleaf and broadleaf-conifer forests ........................... C. perviolaceus $23^{*}$ Not with the above combination of characteristics .........24 24 Pileus violet to bluish, slightly hygrophanous; lamellae blue to gray blue; stipe pale bluish white; veil whitish to pale yellowish; basidiospores av. $8 \times 6 \mu \mathrm{m}$, subgloboid, broadly ellipsoid; broadleaf-conifer forests; northeastern North America ........................ C. harvardensis $24 *$ Not with the above combination of characteristics; basidiospores on av. $\leq 8 \mu \mathrm{m} \ldots \ldots \ldots \ldots \ldots \ldots \ldots \ldots \ldots \ldots \ldots . . .25$ 25 Pileus brown with gray violet tints; lamellae purplish gray; stipe pale violet to white; veil yellowish buff, basidiospores av. $7.5 \times 6.5 \mu \mathrm{m}$, subgloboid, rarely broadly ellipsoid; broadleaf and broadleaf-conifer forests; northeastern North America C. modestus $25^{*}$ Not as above, pileus lacking brownish coloration; basidiospores on av. $<7.5 \mu \mathrm{m}$ long ..................... 26 26 Pileus light blue to purple mixed with gray; lamellae blue violet; stipe blue lavender; veil white; basidiospores av. $7 \times 6 \mu \mathrm{m}$, subgloboid, rarely broadly ellipsoid; broadleaf and broadleaf-conifer forests; southeastern North America C. caeruleoanomalus 26* Pileus lilac to white becoming yellowish, lamellae violaceous, stipe lilac, veil white, basidiospores av. $7.2 \times 5.8 \mu \mathrm{m}$, subgloboid to broadly ellipsoid, broadleaf and broadleaf-conifer forests, northeastern North America ................... C. albomalus 27 Basidiospores av. $<8 \mu \mathrm{m}$ in length ...................... 28 $27 *$ Basidiospores av. $\geq 8 \mu \mathrm{m}$ in length ................... 29 28 Pileus pale brown to pale grayish brown; lamellae violet to pale brown; stipe violaceous to whitish; veil thin, white; basidiospores av. $7.5 \times 5.5 \mu \mathrm{m}$, subgloboid, broadly ellipsoid; broadleaf-conifer forests C. perrotensis 
28* Pileus grayish ochraceous to grayish brown, hygrophanous; lamellae purple to grayish brown; stipe whitish with purple tint at apex; veil forming yellow zones on the stipe; basidiospores av. $7.3 \times 5.8 \mu \mathrm{m}$, subgloboid to broadly ellipsoid; mixed broadleaf pine forest, southeastern North America ............................ C. anocorium 29 Pileus light clay grayish yellow to reddish tawny, \pm hygrophanous; lamellae light grayish blue to grayish brown; stipe bluish to white; veil sparse, white to light yellow; basidiospores av. $8 \times 6 \mu \mathrm{m}$, broadly ellipsoid to subgloboid broadleaf and broadleaf-conifer forests; across North America C. tabularis $29 *$ Pileus grayish buff to slightly violaceous or brownish, \pm hygrophanous; lamellae pale violet to violet gray; stipe violaceous to bluish gray; veil ochraceous to grayish brown; basidiospores av. $8 \times 6.5 \mu \mathrm{m}$, subgloboid to broadly ellipsoid; broadleaf and broadleaf- conifer forests; northeastern North America C. anomalus 30 Pileus light blue to grayish blue, weakly hygrophanous; lamellae violet blue; stipe light blue; veil thin, bluish white to pale yellow; basidiospores av. $9 \times 7 \mu \mathrm{m}$, subgloboid to broadly ellipsoid; broadleaf forests; northeastern North America ....................... C. albocyaneus 30* Not as above, pileus lacking blue to bluish ...31

31 Pileus pale silvery gray to vinaceous brown; lamellae pale violet to pale gray blue; stipe violet to gray lilac; veil pale buff to pale ochraceous; basidiospores av. $9 \times 7.5 \mu \mathrm{m}$, broadly ellipsoid to subgloboid; broadleaf and broadleafconifer forests; northeastern North America and Rocky Mountains. C. albidipes 31 Not as above; basidiomata lacking significant blue or violet coloration .. 32 32 Pileus pale tan, brownish, pinkish buff, hygrophanous; lamellae white to pallid or pinkish cinnamon; stipe white to pallid; veil thin; basidiospores av. $9.5 \times 8 \mu \mathrm{m}$, subgloboid; broadleaf and broadleaf-conifer forests C. albidoavellaneus

$32 *$ Pileus light grayish yellow brown to yellowish brown mature; lamellae light yellowish to light yellowish brown; stipe white to very pale orange yellow; veil slightly yellowish, basidiospores av. $9 \times 6 \mu \mathrm{m}$, mostly ellipsoid; broadleaf forests; north central North America C. ochraceodiscus

\section{Discussion}

\section{Morphological characters}

One of the most interesting characteristics of species in the section Anomali involves the violet to blue coloration of the lamellae, pileus, stipe and context of basidiomata.
There are a handful of species that have almost completely and persistently violet to blue basidiomata, including $C$. anomalovelatus, $C$. deceptivus, and $C$. harvardensis all in the same clade and $C$. caeruleoanomalus and $C$. perviolaceus each in separate phylogenetic groups. By comparison, most of the remaining species, with the possible exception of $C$. tetonensis, have at least some violet to blue coloration in the lamellae, stipe apex, and/ or pileus surface but in some instances, young, fresh specimens are essential to being certain of the coloration. This is especially true in relatively dry habitats where even young appearing basidiomata can lose violet to blue coloration rather quickly. Some species such as $C$. albocyaneus, C. anomalus, C. barlowensis, $C$. huddartensis, C. latiodistributus, and $C$. rarus tend to maintain violet to blue colors in the lamellae and/or stipe or even the pileus margin for some length of time. Typical of many species are gray to brown colors of the pileus surface, sometimes mixed with pale blue to violet colors, blue to violet colored lamellae that become brown as they mature, and violet to blue pigment in the stipe apex which can be lost with age. The various patterns and changes in coloration shared by many species are what make their identification so challenging. In general, these coloration patterns are found across many of the lineages. Several previous studies (e.g., Frøslev et al. 2007; Liimatainen et al. 2017; Clericuzio et al. 2017; Bellanger 2018; Bellanger et al. 2018) have already demonstrated that the presence/absence of blue/violet hues in basidiomata of Cortinarius groups is highly misleading to distinguish phylogenetically supported species.

While a number of species in Anomali have non-hygrophanous or slightly hygrophanous pilei, there are a few taxa that are more distinctly hygrophanous, these include $C$. albidoavellaneus, C. barlowensis, C. clackamasensis, and C. latiodistributus.

The size of the basidiomata appears to be somewhat helpful in separating species from one another. However, a full collection of different stages of development is necessary to determine whether or not this is a significant distinguishing characteristic because of the overlap in pileus diameter and stipe thickness of young to mature basidiomata among and within species. Cortinarius perviolaceus seems to be one species that is consistently smaller and more slender than others.

The universal veil in many species of Anomali occurs as buff to yellowish or ochraceous to light orange buff patches, zones and/or fibrils on the stipe surface, and sometimes the pileus surface as well. The degree of development and coloration of these veil remnants, while rather distinctive in many species, for example $C$. caesiifolius, are variable in others, for example, $C$. albidipes and $C$. caninus, and can lead to erroneous identifications. Only a few species, for example, 
C. rarus and C. huddartensis, appear to have universal veil remains that are white and/or lack significant buff to yellowish coloration. As with other characteristics, universal veil color alone cannot be used for identification.

\section{Microscopic characters}

As for many groups of Cortinarius, section Anomali does not have many characteristics beyond those of the basidiospores that can be used for identification. The structure of the pileipellis is rather consistent across the section, being composed of $\mathrm{a} \pm$ well-developed epicutis over a distinct hypocutis composed of cylindrical to enlarged hyphae that is sometimes cellular in appearance. The basidia and lamella tramal hyphae are \pm consistently the same across the section, with the development of some yellow pigmentation, but no significant encrusting pigment on the tramal hyphae. The basidia are mainly 4-spored, rarely 2 -spored.

Section Anomali, for the most part, produces basidiospores that are subgloboid to broadly ellipsoid in profile view. There are a few species which appear to consistently produce subgloboid basidiospores, but in most instances shape varies from subgloboid to broadly ellipsoid with differing proportions of the two shapes. Several species produce more ellipsoid basidiospores. Basidiospore size is helpful in identifying some species when used in correlation with other characteristics. For example, C. anomalopacificus has rather small basidiospores (av. $6.5 \times 5.5 \mu \mathrm{m}$ ) and $C$. barlowensis has rather large basidiospores (av. $11 \times 6.5 \mu \mathrm{m}$ ), as does $C$. clackamasensis (av. $9.7 \times 6.5 \mu \mathrm{m}$ ). However, most species produce basidiospores that are $7-9 \times 5.5-7 \mu \mathrm{m}$ on average. The most accurate measurements are from mature basidiospores deposited on the stipe surface or veil fibrils. The basidiospore ornamentation is difficult to interpret without considerable observation using a $1000 \times$ oil immersion lens and spores mounted in $3 \% \mathrm{KOH}$. Differences in the size and pattern of ornamentation may differ considerably within and among taxa so it is important to base comparisons on mature basidiospores.

\section{Ecology and distribution}

The patterns of distribution and ecology of most Anomali species in North America cannot be determined for certain because of the small sample size for almost all species treated here. Nonetheless, there are certain patterns of distribution that are noteworthy and to some degree are correlated with ecology and plant hosts. Cortinarius albocyaneus and C. anomalus occur in hardwood and/or mixed hardwood conifer forests in both eastern North America and Europe. By comparison, $C$. caninus and $C$. tabularis are known from Europe and across northern North America in conifer and/ or conifer hardwood forests. Cortinarius latiodistributus has an even more extensive distribution including the Pacific Northwest, Japan, and northern European conifer forests. Cortinarius tetonensis, for which we have relatively few samples, has a broad distribution and interesting ecology, being reported from Svalbard, western North America, and Alaska in subalpine conifer or arctic habitats with Dryas. More widely distributed species that occur across North America, often in conifer forests, include $C$. albidipes and C. clintonianus. Several species have regional patterns of distribution. Cortinarius albidoavellaneus is known only from the type locality in northern Michigan with conifers and one locality in North Europe (data not shown). Several species, including Cortinarius brevissimus, $C$. caeruleoanomalus, $C$. deceptivus, C. harvardensis, $C$. modestus, $C$. perrotensis, and $C$. perviolaceus, occur in hardwood, mixed hardwood conifer, and/or conifer forests in eastern North America. Western North America is the home of $C$. rarus, an unusual vernal species associated with montain conifer forests. Cortinarius anomalodelicatus, C. anomalomontanus, C. anomalovelatus, C. barlowensis, C. caesiifolius, C. clackamasensis, $C$. kranabetteri, and $C$. nettieae have a western distribution with conifers. California has two hardwood-associated species, Cortinarius huddartensis in oak forests and $C$. anomalopacificus in tan oak or oak conifer forests.

Supplementary Information The online version contains supplementary material available at https://doi.org/10.1007/s11557-021-01738-0.

Acknowledgements The following are acknowledged for contributing sequence data, descriptions, specimens, and/or photographs to this manuscript: S. Adams, T.E. Brandrud, S. Jakob, H. Korotkin, I. Krisai-Greilhuber, J. Landry, D. J. McLaughlin, E. G. McLaughlin, A. Parker, N. Siegel.

Author contribution All the authors contributed to the study conception and design. Material preparation, data collection, and molecular work were performed by K. Liimatainen, B. Dima, D. Bojantchev, and E. Harrower. Phylogenetic and microscopic analyses as well as discussions were performed by B. Dima, J. F. Ammirati, V. Papp, and K. Liimatainen. The manuscript was written by J. F. Ammirati and B. Dima and revised by T. Niskanen, D. Bojantchev, E. Harrower, V. Papp, L. G. Nagy, and G. M. Kovács. All the authors commented on the previous versions of the manuscript. All the authors read and approved the final manuscript.

Funding Open access funding provided by Eötvös Loránd University. The D. E. Stuntz Memorial Foundation for long-term support of studies on the genus Cortinarius in North America. The research of B. Dima was supported by the New National Excellence Program (ÚNKP-16-3 and ÚNKP-17-3) of the Hungarian Ministry of Human Capacities. G. M. Kovács and B. Dima were also partly supported by the ELTE Thematic Excellence Programme 2020 supported by the National Research, Development and Innovation Office (TKP2020-IKA-05).

Data availability MycoBank, GenBank.

Code availability Not applicable. 


\section{Declarations}

Conflict of interest The authors declare no competing interests.

Open Access This article is licensed under a Creative Commons Attribution 4.0 International License, which permits use, sharing, adaptation, distribution and reproduction in any medium or format, as long as you give appropriate credit to the original author(s) and the source, provide a link to the Creative Commons licence, and indicate if changes were made. The images or other third party material in this article are included in the article's Creative Commons licence, unless indicated otherwise in a credit line to the material. If material is not included in the article's Creative Commons licence and your intended use is not permitted by statutory regulation or exceeds the permitted use, you will need to obtain permission directly from the copyright holder. To view a copy of this licence, visit http://creativecommons.org/licenses/by/4.0/.

\section{References}

Altschul SF, Madden TL, Schaffer AA, Zhang J, Zhang Z, Miller W, Lipman DJ (1997) Gapped BLAST and PSI-BLAST: a new generation of protein database search programs. Nuc Acid Res 25:3389-3402

Ammirati JF (2014) Nomenclatural novelties. Index Fungorum 93:1

Ammirati JF, Niskanen T, Liimatainen K, Dimitar B, Peintner U, Kuhnert-Finkernagel R, Cripps C (2017) Spring and early summer species of Cortinarius, subgenus Telamonia, section Colymbadini and /Flavobasilis, in the mountains of western North America. Mycologia 109(3):443-458

Bellanger J-M (2018) Cortinarius saturninus l'espèce "caméléon" enfin démasquée? Journ JEC 20:29-49

Bellanger JM, Bidaud A, Moreau P-A (2018) Qu'est-ce que Cortinarius parasuaveolens? Doc Mycol 37:39-51

Borchsenius F (2009) FastGap 1.2. Department of Bio-sciences, Aarhus University, Denmark. Published online at: http://www. aubot.dk/FastGap_home.htm. Accessed 2 June 2021

Clericuzio M, Dovana F, Bellanger J-M, Brandrud TE, Dima B, Frøslev TG, Boccardo F, Jeppesen TS, Vizzini A (2017) Cortinarius parasuaveolens $(=C$. pseudogracilior $)$ : new data on a very poorly known species of section Calochroi. Sydowia 69:215-228

Dima B, Lindström H, Liimatainen K, Olson A, Soop K, Kytövuori I, Dahlberg A, Niskanen T (2016) Typification of Friesian names in Cortinarius sections Anomali, Spilomei, and Bolares, and description of two new species from northern Europe. Mycol Prog 15:903-919

Dima B, Liimatainen K, Lindström H, Soop K, Ammirati JF, Geml J, Niskanen T, Kovács MG (2017) Phylogenetic species diversity of Cortinarius sect. Anomali. Mikol Közlem Clusiana 56(1):34-36

Frøslev TG, Jeppesen TS, Læssøe T, Kjøller R (2007) Molecular phylogenetics and delimitation of species in Cortinarius section Calochroi (Basidiomycota, Agaricales) in Europe. Mol Phyl Evol 44:217-227

Gardes M, Bruns TD (1993) ITS primers with enhanced specifity for basidiomycetes - application to the identification of mycorrhizae and rusts. Mol Ecol 2:113-118

Garnica S, Schön ME, Abarenkov K, Riess K, Liimatainen K, Niskanen T, Dima B, Soop K, Frøslev TG, Jeppesen TS, Peintner U, Brandrud TE, Saar G, Oertel B, Ammirati JF (2016) Determining threshold values for barcoding fungi: Lessons from Cortinarius (Basidiomycota), a highly diverse and widespread ectomycorrhizal genus. FEMS Microbiol Ecol 92(4):fiw045
Gouy M, Guindon S, Gascuel O (2010) SeaView version 4: a multiplatform graphical user interface for sequence alignment and phylogenetic tree building. Mol Biol Evol 27:221-224

Harrower E, Ammirati JF, Cappuccino A, Ceska O, Kranabetter JM, Kroeger P, Lim S, Taylor T, Berbee M (2011) Cortinarius species diversity in British Columbia and molecular phylogenetic comparison with European specimen sequences. Botany 89:799-810

Katoh K, Standley DM (2013) MAFFT multiple sequence alignment software version 7: improvements in performance and usability. Mol Biol Evol 30:772-780

Kauffman CH (1905) The genus Cortinarius: a preliminary study. Bull Torr Bot Club 32:301-325

Kauffman CH (1932) Cortinarius fries. N Am Fl 10:282-348

Kauffman CH, Smith AH (1933) Agarics collected in the vicinity of Rock River, Michigan in 1929. Pap Mich Acad Sci 17:153-200

Kropp BR, Matheny PB, Nanagyulyan SG (2010) Phylogenetic taxonomy of the Inocybe splendens group and evolution of supersection "Marginatae". Mycologia 102(3):560-573

Kumar S, Stecher G, Tamura K (2016) MEGA7: molecular evolutionary genetics analysis version 7.0 for bigger datasets. Mol Biol Evol 33(7):1870-1874

Liimatainen K, Niskanen T (2021) Nomenclatural novelties. Index Fungorum 487:1-7

Liimatainen K, Niskanen T, Dima B, Kytövuori I, Ammirati JF, Frøslev TG (2014) The largest type study of Agaricales species to date: bringing identification and nomenclature of Phlegmacium (Cortinarius, Agaricales) into the DNA era. Persoonia 33:98-140

Liimatainen K, Niskanen T, Ammirati J, Kytövuori I, Dima B (2015) Cortinarius, subgenus Telamonia, section Disjungendi, cryptic species in North America and Europe. Mycol Prog 14:1016

Liimatainen K, Carteret X, Dima B, Kytövuori I, Bidaud A, Reumaux P, Niskanen T, Ammirati JF, Bellanger J-M (2017) Cortinarius section Bicolores and section Saturnini (Basidiomycota, Agaricales), a morphogenetic overview of European and North American species. Persoonia 39:175-200

Liimatainen K, Niskanen T, Dima B, Ammirati JF, Kirk P, Kytövuori I (2020) Mission impossible completed: unlocking the nomenclature of the largest and most complicated subgenus of Cortinarius, Telamonia. Fungal Divers 104:291-331

Murrill WA (1946) More fungi from Florida. Lloydia 8:263-290

Nagy LG, Kocsubé S, Csanádi Z, Kovács GM, Petkovits T, Cs V, Papp T (2012) Re-mind the gap! Insertion-deletion data reveal neglected phylogenetic potential of the nuclear ribosomal internal transcribed spacer (ITS) of fungi. PLoS ONE 7:e49794. https:// doi.org/10.1371/journal.pone.0049794

Niskanen T, Liimatainen K, Kytövuori I (2009) Cortinarius sect. Brunnei (Basidiomycota, Agaricales) in North Europe. Mycol Res 113:182-206

Niskanen T, Kytövuori I, Liimatainen K, Lindström H (2013) The species of Cortinarius, section Bovini, associated with conifers in northern Europe. Mycologia 105(4):977-993

Niskanen T, Liimatainen K, Kytövuori I, Lindström H, Dentinger B, Ammirati JF (2016) Cortinarius subgenus Callistei in North America and Europe-type studies, diversity, and distribution of species. Mycologia 108(5):1018-1027

Peck CH (1873) Descriptions of new species of fungi. Bull Buff Soc Nat Sci 1:41-72

Peck CH (1874) Report of the botanist (1872). Ann Rep New York St Mus Nat Hist 26:35-91

Peck CH (1878) Report of the botanist (1877). Ann Rep New York St Mus Nat Hist 31:19-60

Peck CH (1888) Report of the botanist (1887). Ann Rep New York St Mus Nat Hist 41:51-122 
Peck CH (1912) Report of the state botanist 1911. Bull New York St Mus 157:1-139

Ronquist F, Huelsenbeck JP (2003) MRBAYES 3: Bayesian phylogenetic inference under mixed models. Bioinformatics 19:1572-1574

Schoch CL, Seifert KA, Huhndorf S, Robert V, Spouge JL, Levesque CA, Chen W, and Fungal Barcoding Consortium (2012) Nuclear ribosomal internal transcribed spacer (ITS) region as a universal DNA barcode marker for Fungi. PNAS 109:6241-6246

Silvestro D, Michalak I (2012) RaxmlGUI: a graphical front-end for RAxML. Org Divers Evol 12:335-337

Simmons MP, Ochoterena H, Carr TG (2001) Incorporation, relative homoplasy, and effect of gap characters in sequence-based phylogenetic analysis. Syst Biol 50(3):454-462

Smith AH (1939) Studies in the genus Cortinarius I. Contr Univ Mich Herb 2:4-42

Smith AH (1944) New and interesting Cortinarii from North America. Lloydia 7:163-235

Soop K, Dima B, Cooper JA, Park D, Oertel B (2019) A phylogenetic approach to a global supraspecific taxonomy of Cortinarius (Agaricales) with an emphasis on the southern mycota. Persoonia 42:261-290

Stamatakis A (2014) RAxML Version 8: a tool for phylogenetic analysis and post-analysis of large phylogenies. Bioinformatics 30:1312-1313
Thiers B [continuously updated]. Index Herbariorum: a global directory of public herbaria and associated staff. New York Botanical Garden's Virtual Herbarium. http://sweetgum.nybg.org/science/ ih/. Accessed 1 June 2021

Varga T, Krizsán K, Cs F, Dima B, Sánchez-García M, SánchezRamirez S, Szőllősi G, Szarkándi GJ, Papp V, Albert L, Angelini C, Antonín V, Bougher N, Buchanan P, Buyck B, Bense V, Catcheside P, Cooper J, Dämon W, Desjardin D, Finy P, Geml J, Hughes K, Justo AF, Karasiński D, Kautmanova I, Kerr S, Kiss B, Kocsubé S, Kotiranta H, Lechner BE, Liimatainen K, Lukács Z, Morgado L, Niskanen T, Noordeloos ME, Ortiz-Santana B, Ovrebo C, Rácz N, Savchenko A, Shiryaev A, Soop K, Spirin V, Cs S, Tomsovsky M, Tulloss RE, Uehling J, Cs V, Papp T, Martin FM, Miettinen O, Hibbett DS, Nagy LG (2019) Megaphylogeny resolves global patterns of mushroom diversification. Nature Ecol Evol 3(4):668-678

White TJ, Bruns T, Lee S, Taylor JW (1990) Amplification and direct sequencing of fungal ribosomal RNA genes for phylogenetics. In: Innis MA, Gelfand DH, Sninsky JJ, White TJ (eds) PCR protocols: a guide to the methods and applications. Academic Press, New York, pp 315-322

Publisher's note Springer Nature remains neutral with regard to jurisdictional claims in published maps and institutional affiliations. 